DEPARTMENT OF COMMERCE

BUREAU OF STANDARDS

George K. Burgess, Director

TECHNOLOGIC PAPERS OF THE BUREAU OF STANDARDS, No. 249

[Part of Vol. 18]

\title{
THERMAL-CONDUCTIVITY METHOD FOR THE ANALYSIS OF GASES
}

BY

P. E. PALMER, Chemist

E. R. WEAVER, Chemist

Bureau of Standards

January 7, 1924

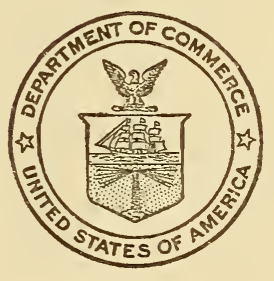

PRICE, 20 CENTS

\$1.25 PER VOLUME ON SUBSCRIPTION

Sold only by the Superintendent of Documents, Government Printing Office Washington, D. C.

WASHINGTON

GOVERNMENT PRINTING OFFICE 



\title{
THERMAL-CONDUCTIVITY METHOD FOR THE ANALY- SIS OF GASES.
}

\author{
By P. E. Palmer and E. R. Weaver.
}

\section{ABSTRACT.}

Methods for the rapid analysis of gas mixtures have come more and more into use during recent years. Of the various physical characteristics of gases which offer possibilities for the development of gas-analysis instruments the thermal conductivity is probably the most useful. By a comparison of the resistance of two electrically heated wires surrounded, respectively, by the gas for analysis and a reference gas, a determination is possible of the concentration of certain constituents in a wide variety of gas mixtures of importance in industry and research. High sensitivity and great accuracy are secured at a relatively small expense and the method is well adapted for either manual or automatic continuous operation. By the use of suitable auxiliary devices various automatic-process controls based on gas composition are easily arranged.

\section{CONTENTS.}

Page.

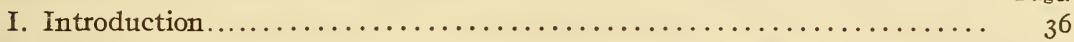

I. Physical principles upon which the method is based .......... ${ }_{36}$

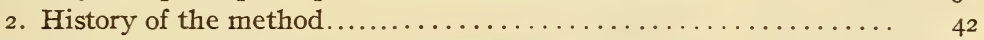

II. General description of the possible applications of the method........ 45

I. Limitations and advantages....................... 45

2. Applications to the analysis of complex mixtures of gases........ 47

3. General applicability of the methods................. 55

4. Process control based on gas analysis ................. 55

III. Results obtained in the actual application of the method.......... 56

I. Determination of hydrogen in hydrogen-air mixtures......... $5^{8}$

2. Determination of hydrogen in electrolytic oxygen .......... 59

3. Hydrogen in hydrogen-nitrogen mixtures................ $6_{2}$

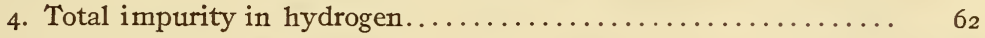

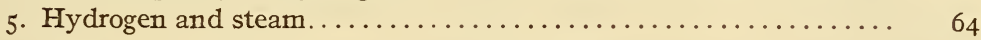

6. Helium in mixtures of helium and nitrogen .............. 64

7. Determination of carbon dioxide in carbon dioxide-air mixtures. . $6_{5}$

8. Sulphur dioxide in mixtures of sulphur dioxide and air....... 67

9. Determination of carbon dioxide in mixtures of hydrogen, nitrogen, and carbon dioxide............................. 69

Io. Determination of ammonia in mixtures of ammonia, nitrogen,

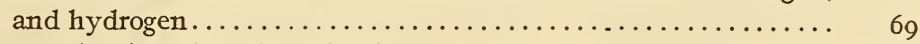

I r. Determination of methane in air...................... 70

I2. Determination of oxygen in mixtures of oxygen and nitrogen..... 7 I

I3. Carbon monoxide in a mixture of nitrogen, hydrogen, and carbon

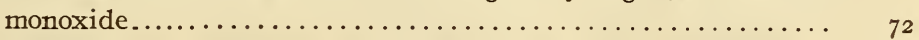

IV. Details of construction, calibration, and care of the apparatus employed. . 73

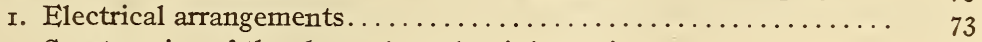

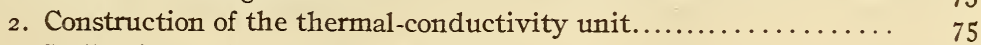

3. Indicating and recording instruments.................... $8 \mathrm{I}$

4. Source and adjustment of current................. $8 \mathrm{I}$ 
IV. Details of construction, etc.-Continued.

5. Maintenance of constant temperature ................... 86

6. Regulation of flow of gas.............................

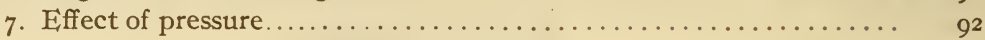

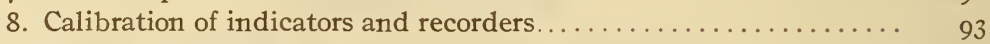

9. Multiple operations ........................... Iо

\section{INTRODUCTION.}

This paper presents the results of a somewhat extended investigation, made at the Bureau of Standards, of the analysis of gas mixtures by a method which is at present little known but which gives promise of the widest usefulness to industry. The investigation has resulted in the development of thoroughly practical instruments and methods for several purposes. It is the purpose of this paper to give the practical results obtained in considerable detail; but no description of the investigation itself, of apparatus which was tried out and discarded, or of experimental results which do not have direct bearing on the practical application of the general method is given. Only such theory is included as is required for an understanding of the practical uses of the method.

The results of applications that have actually been made, which perhaps form the most important part of the paper, are given in Section III. Section IV contains details of the electrical and mechanical arrangements which have been successfully used and directions for the calibration and care of the apparatus.

\section{PHYSICAL PRINCIPLES UPON WHICH THE METHOD IS BASED.}

Although the ability of gases to conduct heat is very much less than that of either solids or liquids, this property is possessed to considerably different extents by the various gases. This fact is quite apparent from an inspection of Table $\mathrm{I}$, in which the thermal conductivities of various gases and vapors are tabulated. Among the gases hydrogen and helium are distinguished by their relatively high conductivities, which are, however, something like I,000 times less than those of the metals. From the wide differences between gases it is apparent that any accurate means of determining this physical property will afford a useful method for estimating the composition of a mixture of gases. It is a difficult matter to determine, in absolute units, the conductivity of a gas; but, fortunately, it is not hard to make an indirect comparison between the conductivity of the mixture to be analyzed and that of a reference gas and such a comparison will serve the analyst quite as well as a determination of conductivity. By 
making use of differences in chemical properties, in addition to the differences in thermal conductivity, it is possible to successfully use this method of analysis for many purposes.

TABLE 1.-Thermal Conductivities of Gases and Vapors.

\begin{tabular}{|c|c|c|c|c|}
\hline Gas. & $t^{\circ} \mathrm{C}$ & $k$ & $\frac{k \text { gas. }}{k \text { air. }}$ & Authority. \\
\hline Air.................... & $\begin{array}{r}0 \\
100 \\
0 \\
0 \\
100\end{array}$ & $\begin{array}{c}0.0000566 \\
.0000719 \\
\ldots .00078 \\
.0000458 \\
.0000709\end{array}$ & $\begin{array}{r}1.00 \\
1.00 \\
1.15 \\
.81 \\
.98\end{array}$ & $\begin{array}{l}\text { Eucken. } \\
\text { Do. } \\
\text { Computed. } \\
\text { Winkelmann. } \\
\text { Do. }\end{array}$ \\
\hline $\begin{array}{l}\text { Argon } . . . \cdots \cdots \\
\text { Benzene......... }\end{array}$ & $\begin{array}{r}0 \\
0 \\
100 \\
0\end{array}$ & $\begin{array}{c}.0000388 \\
.0000509 \\
\cdots\end{array}$ & $\begin{array}{l}.686 \\
.676 \\
.708 \\
.405\end{array}$ & $\begin{array}{l}\text { Eucken. } \\
\text { Computed. } \\
\text { Eucken. } \\
\text { Computed. }\end{array}$ \\
\hline 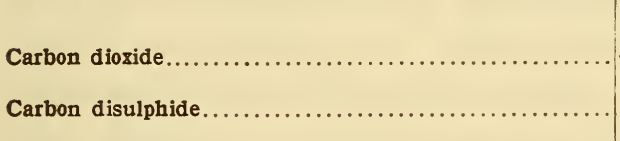 & $\begin{array}{r}0 \\
0 \\
100 \\
100 \\
0\end{array}$ & 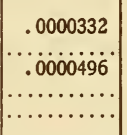 & $\begin{array}{l}.585 \\
.625 \\
.690 \\
.760 \\
.312\end{array}$ & $\begin{array}{l}\text { Eucken. } \\
\text { Computed. } \\
\text { Eucken. } \\
\text { Computed. } \\
\text { Do. }\end{array}$ \\
\hline 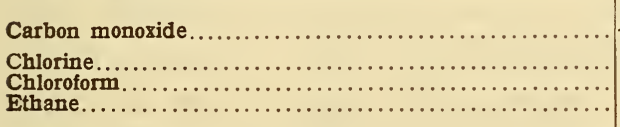 & $\begin{array}{l}0 \\
0 \\
0 \\
0 \\
0\end{array}$ & $\begin{array}{c}.0000542 \\
\cdots \cdots \\
\cdots \\
\cdots \\
.0000496\end{array}$ & $\begin{array}{l}.958 \\
.936 \\
.370 \\
.273 \\
.876\end{array}$ & $\begin{array}{l}\text { Eucken. } \\
\text { Computed. } \\
\text { Do. } \\
\text { Do. } \\
\text { Ziegler. }\end{array}$ \\
\hline 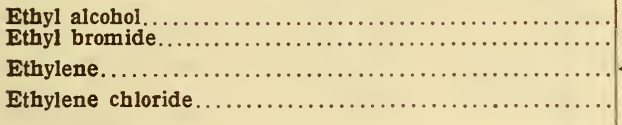 & $\begin{array}{r}0 \\
0 \\
0 \\
100 \\
0\end{array}$ & $\mid \begin{array}{c}\ldots \ldots \ldots \ldots \\
.0000395 \\
.0000636 \\
\ldots \ldots \ldots \ldots\end{array}$ & $\begin{array}{l}.708 \\
.607 \\
.698 \\
.885 \\
.718\end{array}$ & $\begin{array}{l}\text { Computed. } \\
\text { Do. } \\
\text { Winkelmann. } \\
\text { Do. } \\
\text { Computed. }\end{array}$ \\
\hline 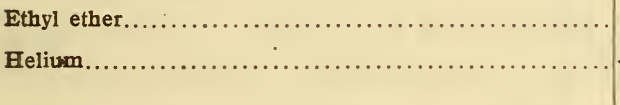 & $\begin{array}{r}0 \\
0 \\
100\end{array}$ & $\begin{array}{c}.000344 \\
.000398\end{array}$ & $\begin{array}{l}.582 \\
6.08 \\
6.34 \\
5.53\end{array}$ & $\begin{array}{l}\text { Do. } \\
\text { Weber. } \\
\text { Computed. } \\
\text { Weber. }\end{array}$ \\
\hline 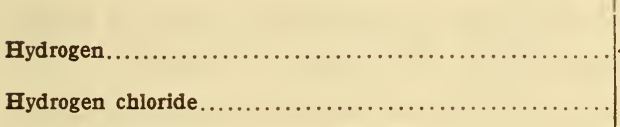 & $\begin{array}{r}0 \\
0 \\
100 \\
100 \\
0\end{array}$ & $\begin{array}{c}.000416 \\
\ldots \ldots \ldots \ldots \\
.000499 \\
\ldots \ldots \ldots \ldots \\
\ldots \ldots \ldots\end{array}$ & $\begin{array}{l}7.35 \\
6.88 \\
6.94 \\
6.68 \\
.635\end{array}$ & $\begin{array}{l}\text { Do. } \\
\text { Computed. } \\
\text { Weber. } \\
\text { Computed. } \\
\text { Do. }\end{array}$ \\
\hline 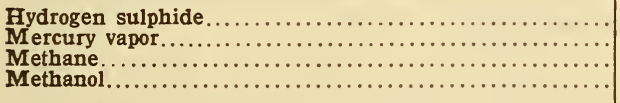 & $\begin{array}{r}0 \\
203 \\
0 \\
0\end{array}$ & $\begin{array}{r}.0000815 \\
.0000720 \\
\cdots\end{array}$ & $\begin{array}{r}.648 \\
1.127 \\
1.314\end{array}$ & $\begin{array}{l}\text { Do. } \\
\text { Schwarze. } \\
\text { Weber. } \\
\text { Computed. }\end{array}$ \\
\hline $\begin{array}{l}\text { Nitric oxide.... } \\
\text { Nitrogen........ } \\
\text { Nitrous oxide... }\end{array}$ & $\begin{array}{r}8 \\
0 \\
100 \\
100 \\
0\end{array}$ & $\begin{array}{c}.000046 \\
.0000568 \\
.0000718 \\
\ldots .000353 \\
.0000353\end{array}$ & $\begin{array}{r}.812 \\
1.004 \\
.999 \\
.955 \\
.624\end{array}$ & $\begin{array}{l}\text { Winkelmann. } \\
\text { Eucken. } \\
\text { Do. } \\
\text { Computed. } \\
\text { Weber. }\end{array}$ \\
\hline Oxygen. & $\begin{array}{r}0 \\
0 \\
100 \\
100\end{array}$ & $\begin{array}{c}.0000570 \\
\ldots .000743 \\
.000 \ldots \ldots\end{array}$ & $\begin{array}{l}1.007 \\
1.002 \\
1.034 \\
1.013\end{array}$ & $\begin{array}{l}\text { Eucken. } \\
\text { Computed. } \\
\text { Eucken. } \\
\text { Computed. }\end{array}$ \\
\hline 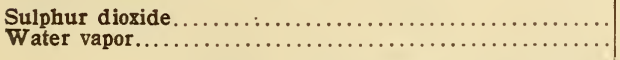 & $\begin{array}{r}0 \\
100\end{array}$ & & .415 & $\begin{array}{l}\text { Do. } \\
\text { Do. }\end{array}$ \\
\hline
\end{tabular}

$k$ is the amount of heat in $g$ calories flowing per sec. through an area of $\mathrm{x} \mathrm{cm}^{2}$ with a temperature gradient of $\mathrm{I}^{\circ} \mathrm{C}$. per $\mathrm{cm}$.

The ratio $\frac{k \text { gas }}{k \text { air }}$ ascribed to an observer is the ratio of the experimental value of the conductivity of the gas found by the observer to Eucken's experimental value for air. The ratios designated as "computed" are derived from miscellaneous experimental data on specific heats and viscosities by employing the formula: $k=1 / 4(9 r-5)$ v $s$ (Jeans, Dynamical Theory of Gases).

$r=$ ratio of specific heat at constant pressure to specific heat at constant volume.

$v=$ coefficient of viscosity.

$s=$ specific heat at constant volume.

Because of the number and uncertain accuracy of the experimental data involved in the "computed" ratios, they are not to be regarded as more than rough approximations.

Theoretically $k$ should be independent of the density and has been found to be so by Kundt and Warburg and others within a wide range of pressure below one atmosphere. It increases with the temperature. 
All successful gas-analysis methods so far developed, which depend upon thermal conductivity, are based on the following principles. Let us assume a wire to be surrounded by a gas which is contained in a chamber, the walls of which are maintained at a constant temperature. When connected to a source of constant electromotive force, the temperature of the wire rises until a state of equilibrium is reached, in which the continuous dissipation of thermal energy is equal to the electrical energy supplied to the wire. The dissipation of energy is accomplished by radiation, by conduction through the connections to the ends of the wire, by currents of gas circulating in the atmosphere surrounding the wire (thermal convection), and by conduction through the gas. Some heat is also carried away by the current of gas, in case there is a flow of gas past the wire. It is difficult to ascribe to each of the above its exact share of the total energy dissipated, however, it is known that when the temperature of the wire does not exceed $400^{\circ} \mathrm{C}$. radiation can account for only a small portion, and that when the distance between the walls of the chamber and the wire does not exceed $5 \mathrm{~mm}$ convection is also a small factor.

It seems obvious, therefore, that by carefully arranging the conditions, all loss of heat, except by conduction through the gas surrounding the wire, can be reduced to a small proportion of the whole. Under such conditions, it is evident that the equilibrium temperature attained by the wire will depend mainiy upon the ability of the gas which surrounds the wire to conduct heat, being lower when the gas has a high conductivity and higher when the gas has a low conductivity. If the wire used has a high temperature coefficient of electrical resistance, this resistance will have a value corresponding to the thermal conductivity, and, therefore, to the composition of the surrounding gas. By a comparison of the resistances of two such wires, surrounded, respectively, by a reference gas and a mixture of two gases of which the qualitative composition is known, the quantitative composition of the mixture can be rapidly and accurately determined after an empirical calibration has been made.

The magnitude of the electrical effects, which correspond to differences of gas composition, are shown by the following experiments on some of the more common gases. A platinum wire having a diameter of $0.05 \mathrm{~mm}$ and a length of $100 \mathrm{~mm}$ was stretched along the axis of a cylindrical copper chamber of $5 \mathrm{~mm}$ radius. The wire was kept under tension by means of a helical spring of copper wire and one end was electrically insulated 
from the metal chamber by means of a glass-platinum seal. The chamber was provided with inlet and outlet tubes for sweeping through any desired mixture of gases, and was mounted vertically in a thermostated oil bath. With the chamber filled, in turn, with various gases, the currents corresponding to various potential differences between the ends of the wire were measured by means of a potentiometer. No exhaustive efforts were made to purify the gases used in these experiments, since the data were not to be used for precise computations. A diagram of the electrical arrangement employed is shown in Figure I. From the current and emf values obtained, the resistances of the wire were computed. The relation between the resistance or temperature of the wire and the nature of the surrounding gas is shown graphic-

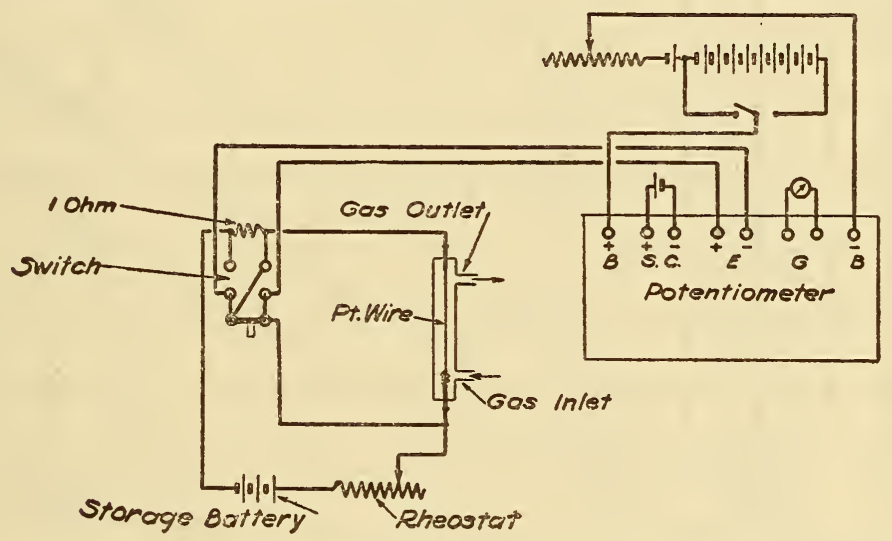

FIG. I.-Diagram of electrical arrangement for determining variations in resistance of a wire surrounded by various gases.

ally in Figure 2. It is to be noted that as the emf increases, the curves become more widely separated, indicating that the sensitivity to changes in gaseous composition is greater at higher than at lower voltages.

Assuming that the loss of heat by radiation, by conduction through the connections to the ends of the wire, and by thermal convection is constant, the relative amounts of power expended in maintaining a given temperature difference between the wire and the walls of the chamber when filled with various gases should afford a measure of the relative thermal conductivities of the gases. That such is the case is indicated by the good agreement (Table 2) between the ratio of the values of the power required to maintain the resistance of the electrically heated wire at a constant value (corresponding approximately to an 
average temperature of $100^{\circ}$ C.) in the various gases to that required in air and the values for the relative thermal conductivities of the gases with respect to air as obtained by the experiments of the different investigators.

The variations in resistance with the composition of the surrounding gas are better shown in the case of mixtures. Measurements made with mixtures of nitrogen and hydrogen, carbon dioxide and air, and sulphur dioxide and air are plotted in Figure 3.

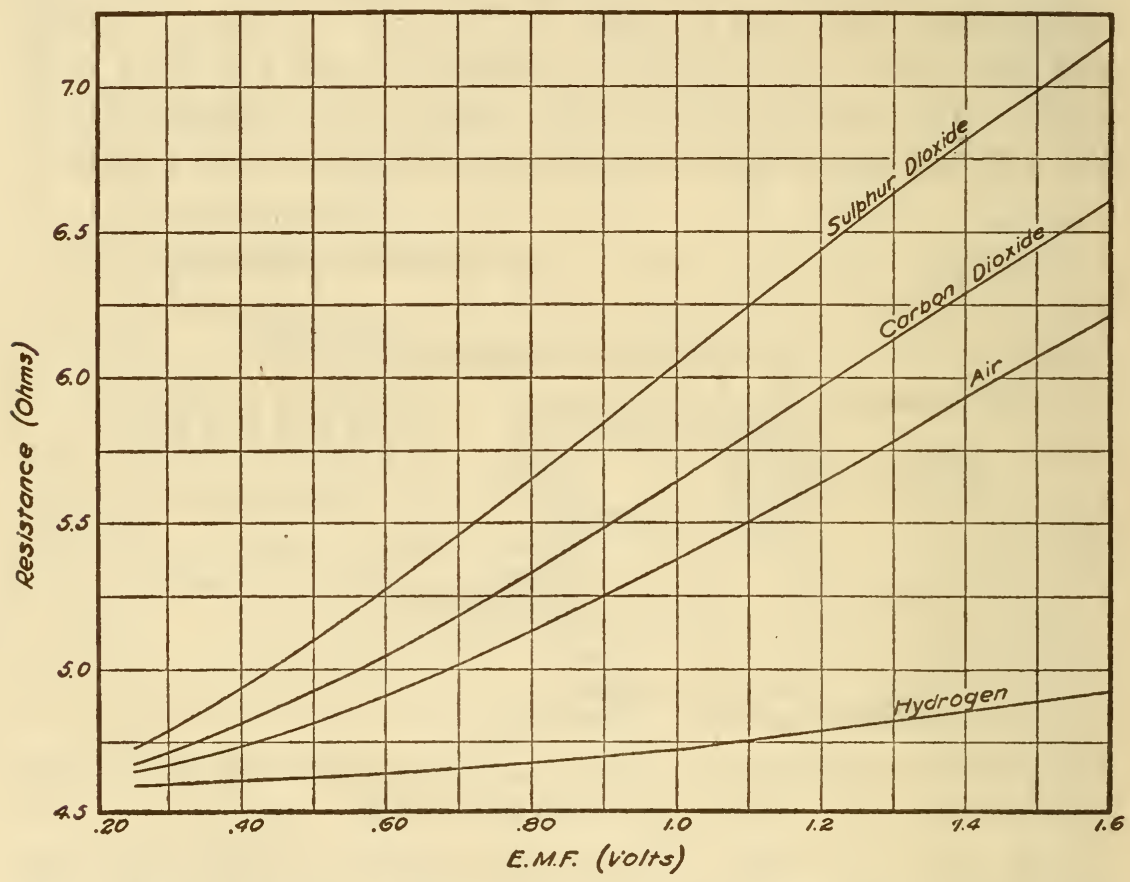

FIG. 2.-Relation between resistance or temperature of an electrically heated wire and the nature of the surrounding gas.

TABLE 2.-Relative Power Losses in Various Gases.

\begin{tabular}{|c|c|c|c|c|}
\hline Gas. & $\mathrm{E}$ & I & $\mathbf{P}$ & $\mathbf{P}_{\mathbf{g}} / \mathbf{P}_{\mathbf{a}}$ \\
\hline 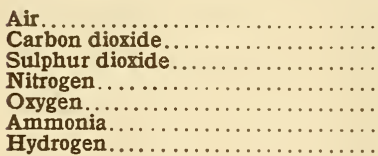 & $\begin{array}{l}1.212 \\
1.012 \\
.8036 \\
1.206 \\
1.228 \\
1.229 \\
3.115\end{array}$ & $\begin{array}{l}0.2141 \\
.1787 \\
.1420 \\
.2131 \\
.2170 \\
.2172 \\
.5508\end{array}$ & $\begin{array}{r}0.2595 \\
.1808 \\
.1141 \\
.2571 \\
.2665 \\
.2669 \\
1.716\end{array}$ & $\begin{array}{r}1.000 \\
.697 \\
.440 \\
.991 \\
1.024 \\
1.029 \\
6.613\end{array}$ \\
\hline
\end{tabular}

$E$ is the difference of potential between the two ends of the wire, $I$ is the current through the wire. $P$ is the product $E I . \quad P_{\mathrm{g}} / P_{\mathrm{a}}$ is the ratio of the value of $P$ for the gas in question to the value of $P$ for air.

For each measurement the current was adjusted until the wire had the resistance 5.66 ohms. The wire then had an average temperature of about $100^{\circ} \mathrm{C}$. The walls of the chamber were maintained at $30^{\circ} \mathrm{C}$. 


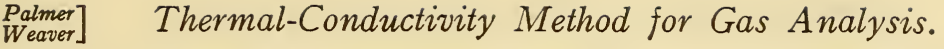

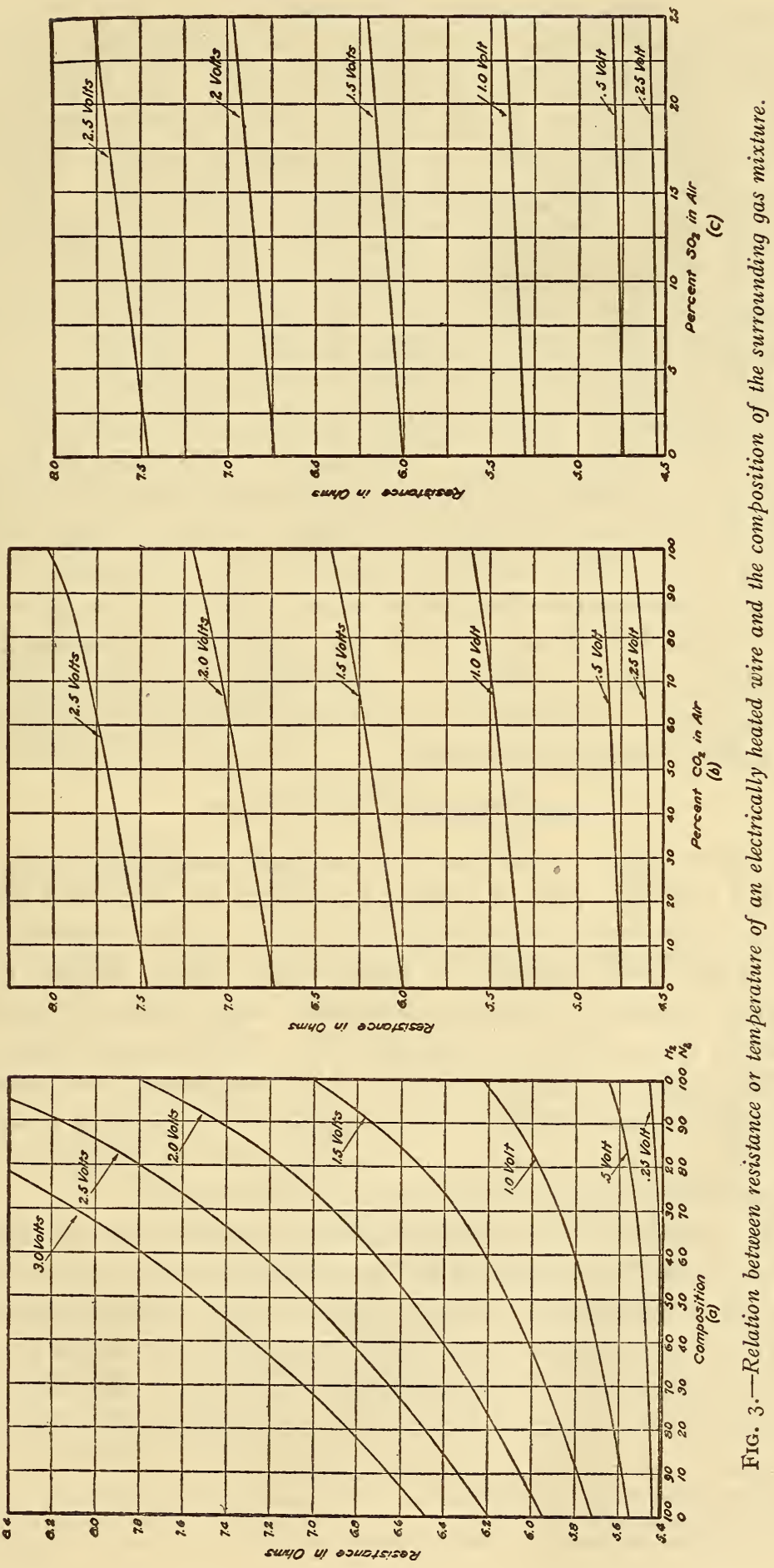


From the data given above it is apparent that in certain cases, at least, the composition of the gas mixture surrounding a wire can be inferred from electrical measurements made upon a single wire. An accurate analysis by this means would, however, require the most careful measurement or adjustment of several conditions, and would be correspondingly tedious and expensive. By comparing in any suitable manner the resistances of two similar wires, one of which is surrounded by the gas to be analyzed and the other by a gas of known composition, it is possible to largely compensate for several of the possible sources of error in the use of a single wire and to simplify the observations and adjustments necessary.

The comparison is most simply made by the use of some form of the Wheatstone bridge. Generally, the two wires to be compared are connected in series as two adjacent arms of the bridge. The other two "ratio" arms of the bridge may then either be fixed resistances, in which case the bridge is usually unbalanced and the potential drop across the bridge is measured; or the ratio arms may be variable resistances, which are adjusted to bring the bridge to balance when making a determination. Either of these arrangements is suitable for use with indicating and recording instruments now on the market.

\section{HISTORY OF THE METHOD.}

Schleiermacher ${ }^{1}$ developed a method for determining the thermal conductivities of gases by utilizing the fact that a platinum or nickel wire stretched along the axis of a glass tube immersed in a water bath assumes a temperature, when heated by an electrical current of constant strength, which depends upon the nature of the gas surrounding the wire. Goldschmidt ${ }^{2}$ improved Schleiermacher's original method by comparing two wires of different lengths inclosed in silver capillaries inserted in a massive brass block. This improved method was used by Eucken ${ }^{3}$ in his experiments on the thermal conductivities of gases.

The use of a thermal-conductivity method for gas analysis was probably first suggested by Leon Somzee about I880. Unfortunately, a description of his method is not available, since the report of the Prussian Fire Damp Commission, in which the only known reference to it occurs, gives no details. The Vereinigte Maschinenfabrik, Augsburg, patented in Germany and in England ${ }^{4}$

${ }^{1}$ Schleiermacher, Wied. Ann., 34, p. 623; 1888; 36, p. 346; 1889.

${ }^{2}$ Goldschmidt, Physik. Zeit., 12, p. 4I7; I9I I.

${ }^{3}$ Eucken, Physik. Zeit., 12, p. I IоI; IgIr.

${ }^{4}$ D. R. P., I65349; 1904; Brit. Pat., I 5706; 1904. 
the use of the thermal conductivity of a gas containing hydrogen to obtain an indication or a record of the variation in composition of a gas mixture. Several devices are specified; in one of them the resistance of an electrically heated wire in a closed tube is measured. This firm appears, however, to have been unsuccessful in applying the method. Koepsel ${ }^{5}$ developed an instrument for the determination and continuous indication of the hydrogen content of producer gas, which he stated was capable of easily detecting the presence of 0.00 I per cent of hydrogen without the use of very refined measuring apparatus. He also proposed the application of his apparatus to the determination of carbon dioxide in flue gases and of methane in mine gases, but he did not demonstrate experimentally the feasibility of his proposals. In its most improved form, Koepsel's instrument consisted of four electrically heated wires exposed in pairs to the two gases to be compared,

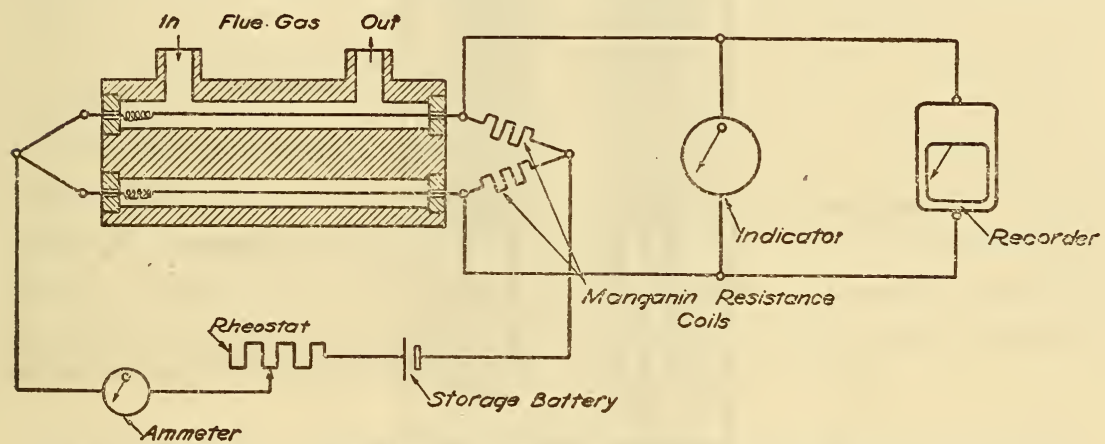

FIG. 4.-Diagram of Siemens and Halske arrangement for carbon dioxide recorder.

the two wires of each pair being connected to form opposite arms of a Wheatstone bridge. Koepsel's instrument was especially intended for use in a rather rapid stream of gas, and somewhat elaborate housings were arranged for the wires to shield them from the effects of convection.

The Siemens \& Halske Co. ${ }^{6}$ improved Koepsel's instrument by passing the gases going to the two sides of the bridge through tubes in the same metal block to bring them to the same temperature, and eliminated Koepsel's special housing for the wires. This firm ${ }^{7}$ has recently described its application of the method for indicating or recording the percentage of carbon dioxide in boiler-flue gases. Figure 4 is a diagram of the arrangement of the instrument.

\footnotetext{
${ }^{5}$ Koepsel, Ber. Physik. Ges., 10, p. 814; 1908; 11, p. 237; 1909; Z. Chem. Apparat., 3, p. 377 and $401 ;$ r908.

${ }^{6}$ D. R. P., 283677 ; I9I3.

${ }^{7}$ Moeller, Siemens Zeit., 1, p. 460; I921; Chem.-Zeit., 46, p. 595; 1922; Wiss. Veröffent1. Siemens Konzern, 1, p. $147 ;$ I920.
} 
In January, I9I6, an application for a British patent was made covering an instrument developed in the Physics Department of the University of Birmingham, by G. A. Shakespear, which has been named the "katharometer." This device utilizes a thermalconductivity unit, in which two small helices of thin platinum wire are inclosed each in one of two cells in a copper block to serve as two arms of a Wheatstone bridge. The remaining arms of the bridge are of manganin wire. Figure 5 shows the construction of the unit. Successful applications of this type of instrument have been made to the determination of the amount of air in

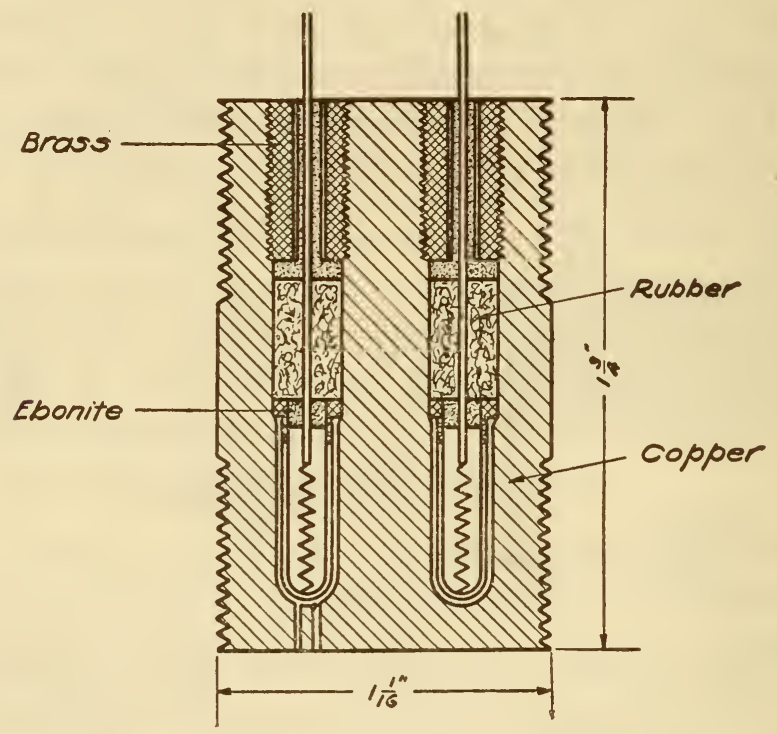

FIG. 5.-Shakespear thermal conductivity unit.

balloon gas, ${ }^{8}$ to the testing of the permeability of balloon fabrics, and to the indicating and recording of the percentage of carbon dioxide in flue gases.

In America, the Sperry Gyroscope Co., in 1915 or I9I6 developed an instrument similar to that of the Siemens \& Halske Co. for detecting hydrogen in air. About the same time, but before learning of the work of this company, some similar investigations were begun at the Bureau of Standards, but were abandoned because the delicacy of the indicating instrument required made it unsuitable for the immediate purpose in view. In the first months of 1917 a gas-analysis apparatus utilizing the thermal-

${ }^{8}$ Shakespear, Proc. Phys. Soc., London, 33, p. I63; I92I. Daynes, Proc. Phys. Soc., London, 33, p. I64; I92I. U.S. Patent I304208; I9I9. 
conductivity principle was developed by a group of men at the University of California, was submitted to the Navy Department, and was tried successfully for a number of purposes.

About the ist of January, I9I8, work was begun at the Bureau of Standards to utilize thermal-conductivity methods in connection with a number of problems. In addition to the schemes used by other investigators, a number of other combinations were tried and what is believed to be the most generally useful form of apparatus was arrived at by a process of elimination.

As opportunity has permitted, experiments have been made to ascertain the applicability of the method to various industrial processes. The uniform success which has been obtained indicates that its field of usefulness extends to a large number of operations and processes where a knowledge of changes in the composition of mixtures of gases is desired. The truly remarkable thing in connection with this history is that a method capable of such great accuracy and such a wide variety of important applications should remain practically unknown to the technical world for at least Io years after its simplicity, accuracy, and some of its important applications were pointed out by Koepsel. This is especially strange in view of the fact that an instrument having useful properties is not at all hard to construct, as shown by the five or six independent investigators who have obtained good results with apparatus of very different forms.

\section{GENERAL DESCRIPTION OF THE POSSIBLE APPLICA- TIONS OF THE METHOD.}

\section{LIMITATIONS AND ADVANTAGES.}

Before proceeding to a detailed description of applications it will be well to point out some of the characteristics of the method which favor or limit its usefulness.

Probably the principal limitation upon the usefulness of the method is the fact that one can not calculate the significance of the indications obtained, but must, in every case, depend upon empirical calibration under conditions closely approximating those of actual service. This limitation makes the method of little or no use for the occasional examination of isolated samples of gas, especially samples of which the qualitative composition is not known. 
However, the qualitative compositions of most gas mixtures of industrial importance are known; their variations in composition are more or less regular, and the probable limits of variations are also known approximately. For the purpose of observing or recording changes in the composition of such mixtures, the thermal-conductivity method possesses a combination of advantageous features not possessed by other methods of analysis. Inasmuch as the thermal conductivity of a gas is practically independent of its pressure over considerable ranges of variation, it is not necessary to provide for the maintenance of the gas at a constant pressure. ${ }^{9}$

It has been found that in many applications the indications of the apparatus developed at the Bureau of Standards are practically unaffected by small variations in the rate of flow of the gas. These two facts make it possible to obtain a continuous rather than an intermittent record of gas composition and to employ several expedients, to be described further on, which are of the utmost importance in dealing with complex mixtures. High sensitivity is secured with apparatus of small dimensions, consequently the time lag between changes in composition and the corresponding indications of the apparatus is small, even when the flow of gas is very slow. By the use of refined apparatus far greater sensitivity to variations in the composition of many mixtures can be secured and at less expense than by any other well-known method.

For the sake of conveying a more definite idea of the relative advantages of this method and several of the more familiar methods of analysis, under the conditions outlined above to which the thermal-conductivity method is suited, a tabular comparison is made in Table 3 . This table represents the judgment of the authors, who have had some experience with all the types of apparatus listed, and relates to methods of observing, rather than of recording, analyses. Since the thermal-conductivity method loses little of its accuracy or dependability when used with a recorder, and is, in other respects, ideally suited to continuous operation, while the contrary is true of recording apparatus depending upon density or volumetric measurements, it is at once apparent that this method makes possible a considerable advance over the older methods of recording gas analyses.

${ }^{9}$ It will be shown further on that the resistance of a wire mounted in a thermal conductivity cell will vary somewhat with the pressure. The variations in pressure occurring in most processes, however, are not sufficiently great to materially affect the accuracy of the method. 
TABLE 3.-Estimated Relative Advantages of Various Methods of Observing Gas Composition. ${ }^{1}$

\begin{tabular}{|c|c|c|c|c|c|}
\hline \multirow[b]{2}{*}{ Desirable characteristics. } & \multicolumn{5}{|c|}{ Method. } \\
\hline & $\begin{array}{l}\text { Thermal } \\
\text { conduc- } \\
\text { tivity. }\end{array}$ & $\begin{array}{l}\text { Inter- } \\
\text { ferom- } \\
\text { eter. }\end{array}$ & $\begin{array}{l}\text { Density } \\
\text { balance. }\end{array}$ & $\begin{array}{l}\text { Direct } \\
\text { weigh- } \\
\text { ing. }\end{array}$ & $\begin{array}{l}\text { Chemical } \\
\text { separa- } \\
\text { tion and } \\
\text { volu- } \\
\text { metric } \\
\text { determi- } \\
\text { nation. }\end{array}$ \\
\hline 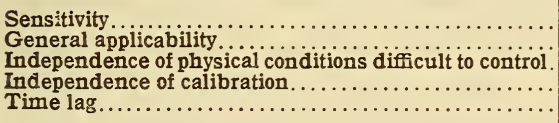 & $\begin{array}{l}1 \\
3 \\
2 \\
5 \\
1\end{array}$ & $\begin{array}{l}2 \\
2 \\
4 \\
4 \\
2\end{array}$ & $\begin{array}{l}5 \\
5 \\
3 \\
3 \\
3\end{array}$ & $\begin{array}{l}4 \\
4 \\
5 \\
2 \\
5\end{array}$ & $\begin{array}{l}3 \\
1 \\
1 \\
1 \\
4\end{array}$ \\
\hline 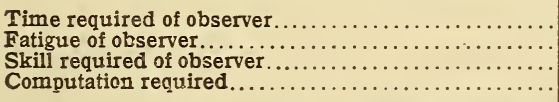 & $\begin{array}{l}1 \\
1 \\
1 \\
1\end{array}$ & $\begin{array}{l}2 \\
5 \\
4 \\
4\end{array}$ & $\begin{array}{l}3 \\
2 \\
3 \\
3\end{array}$ & $\begin{array}{l}5 \\
3 \\
5 \\
5\end{array}$ & $\begin{array}{l}4 \\
4 \\
2 \\
2\end{array}$ \\
\hline 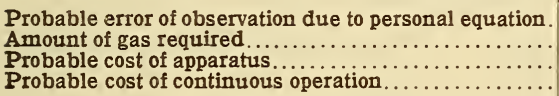 & $\begin{array}{l}1 \\
1 \\
3 \\
1\end{array}$ & $\begin{array}{l}4 \\
4 \\
4 \\
4\end{array}$ & $\begin{array}{l}3 \\
2 \\
2 \\
2\end{array}$ & $\begin{array}{l}5 \\
5 \\
5 \\
5\end{array}$ & $\begin{array}{l}2 \\
3 \\
1 \\
3\end{array}$ \\
\hline
\end{tabular}

1 The method possessing the greater advantage is given the smaller number.

\section{APPLICATIONS TO THE ANALYSIS OF COMPLEX MIXTURES OF GASES.}

The thermal-conductivity method is always essentially a comparison of the thermal conductivities of two gases. Details of the methods for making such a comparison will be discussed in a later section.

Method I.-Comparison With a Standard Gas.-Probably the simplest method of application of the thermal-conductivity apparatus is the comparison of the mixture to be analyzed with a gas of known composition, called a "standard gas." This method is applicable to the following classes of gas mixtures:

(a) Mixtures containing only two components.-While the composition of any binary mixture may conceivably be determined by this method, high sensitivity is to be expected only when the two components differ materially in thermal conductivity. Among the binary mixtures of interest may be mentioned the determination of hydrogen in electrolytic oxygen, oxygen in electrolytic hydrogen, hydrogen in electrolytic chlorine, helium in mixtures of helium and nitrogen occurring in the later stages of the separation of helium from natural gas, and the relative proportion of hydrogen and nitrogen in the purified gases used in the synthetic ammonia process.

(b) Mixtures of two gas mixtures in each of which the proportion of the various constituents is known to be constant.-This class in- 
cludes mixtures of pure gas with mixtures of constant composition. The determination of hydrogen in air is an example of this class of determinations which is extremely easy and accurate.

(c) Mixtures in which it is known that the constituent of interest has a conductivity widely different from the conductivities of the other constituents, all of which latter conductivities are known to be of nearly the same magnitude.-This class includes the determination of hydrogen in water gas and in the mixture of nitrogen, hydrogen, and carbon monoxide existing at one stage in one of the synthetic ammonia processes. The conductivities of nitrogen and of carbon monoxide lie very close together, while that of hydrogen is relatively very great. The relative proportions of nitrogen and carbon monoxide, therefore, make little difference in the determination of hydrogen. The same relation is practically true in the case of carbon dioxide in boiler-flue gases. These gases are composed chiefly of nitrogen, carbon dioxide, oxygen, water vapor, and sometimes small amounts of carbon monoxide. The thermal conductivities of nitrogen, oxygen, and carbon monoxide are all nearly the same, while that of carbon dioxide is considerably lower. The effect of variations in water-vapor content may be well compensated for by keeping both the gas for analysis and the comparison gas saturated at the same temperature. The determination of sulphur dioxide in burner gases is a similar case.

Another example of this method is the determination of the lifting power of balloon gas. The impurities likely to occur in hydrogen produced for balloon purposes, and also the gases of the atmosphere, including water vapor and carbon monoxide, all have relative effects upon the lifting power of the balloon gas which approximate their relative effects upon its thermal conductivity. This relation holds whether helium or hydrogen is used in the balloon.

Air and hydrogen have been found to be the gases most generally useful as the standard comparison gas; air is used when the mixture for analysis has a low conductivity, and hydrogen is compared with mixtures which have a high conductivity. In those instances where a high degree of accuracy is required it is sometimes advantageous to use as a comparison gas a mixture which has a conductivity closely approximating the mean conductivity of the mixture for analysis; in this way good compensation is secured for the effects of possible changes in temperature or current. 
Method 2.-Comparison OF the Gas Before and AFter a ChEMICAL REACTION.- (a) The determination of a constituent of a mixture of gases by the comparison of the mixture before and after the removal of the constituent by absorption in a suitable reagent is probably even more important than the comparison with a standard gas. Determinations of ammonia in the mixtures of hydrogen and nitrogen existing in a synthetic ammonia plant, carbon dioxide in air, and chlorine, hydrogen chloride, sulphur dioxide, hydrogen sulphide, acetylene, oxygen, water vapor, and many other gases in mixtures of certain kinds are feasible by this method.

(b) Instead of removing a constituent of the mixture by absorption, it may be subjected to any other process which will cause its removal or change its form of combination. The most important process of this kind is that of exposing the gas, preferably in the presence of a catalyst, to a sufficiently high temperature to cause reaction between different constituents of the mixture. For example, the total amount of atmospheric gases in a hydrogenfilled balloon may be determined by comparing the gas with pure hydrogen as a standard, as described above. The oxygen can be determined very accurately, independently of other impurities, by comparing the conductivities of the gas before and after passing it through a combustion furnace in which the oxygen is removed by its reaction with hydrogen.

An interesting application of this method is the determination of methane in air by the simple process of comparing the conductivities of the mixture before and after passing over hot copper oxide or hopcalite. The methane is burned to carbon dioxide and water vapor. The gas is then either dried or saturated with water vapor at the same temperature, both before and after the combustion. The net result of the combustion is, therefore, the replacement of I molecule of methane and 2 of oxygen by I molecule of carbon dioxide. Since carbon dioxide has only about half of the conductivity of methane, while oxygen and air are intermediate, this results in a very considerable lowering of the conductivity of the mixture.

Method 3.-Addition of a Gas to the Mixture to be AnaLYZED, FOLLOWED BY METHOD 2.-While the methods already described are probably applicable to a majority of the gas analyses of industrial importance, there are certain important instances where they do not apply, and still others where a modification is $57033^{\circ}-24-2$ 
desirable. Let us consider, for example, the determination of oxygen in flue gases. After the removal of carbon dioxide an approximate determination of oxygen could, perhaps, be made by absorbing the oxygen in an appropriate reagent and comparing the conductivity of the gas before and after the absorption. The result would be affected, however, by the presence of methane, water vapor, sulphur dioxide, oxides of nitrogen, ammonia, hydrogen, any trace of unabsorbed carbon dioxide, and even carbon monoxide. The effect of these gases is serious only because the difference between the conductivities of oxygen and of nitrogen, which is the principal remaining constituent, is small. If, however, hydrogen were first mixed with the gas, say in equal volumes, the conductivity of the residual mixture of nitrogen and hydrogen

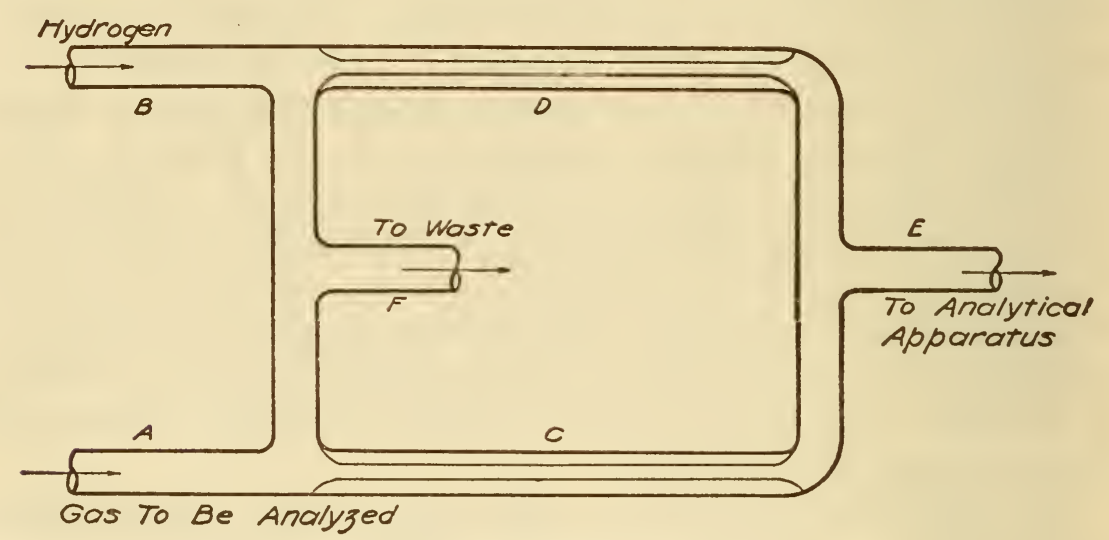

FIG. 6.-Capillary mixing device.

would be several times that of the oxygen removed, and the determination of oxygen would be accurate in spite of small variations in the composition of the residue.

The essential feature of this method is the addition of gas in constant proportions to the mixture to be analyzed and the subsequent removal of the desired constituent. The device shown diagrammatically in Figure 6 readily accomplishes the addition of a constant proportion of a gas. An excess of the mixture to be analyzed is passed through $A$ and an excess of the gas to be added, usually hydrogen, through $B$. Part of each gas stream flows to waste through $F$ and part flows through the connecting capillary tube $C$ or $D$ to $E$ and thence to the gas-analysis apparatus. Since both ends of the capillaries are connected, the pressure drop through one is always the same as that through the other, and 
since the viscosity of a gas is practically independent of pressure and all gases have within narrow limits the same thermal coefficient of viscosity, it is only necessary to maintain the two capillaries at a constant temperature in order to insure uniform mixing of the gases by this method. The relative proportions of the two gases can be readily varied by changing the relative lengths and diameters of the capillaries. Of course, the relative proportions of the two gases will vary slightly with the composition of the mixture to be analyzed. The total measured effect of a change of composition is, therefore, to a certain small extent, a function of viscosity as well as of thermal conductivity; but since viscosity and thermal conductivity are closely related functions of molecular motion, and since the relations depended upon in making a determination are entirely empirical, this fact makes no difference in the convenience or accuracy of the method.

The adjustments of the electrical instruments to give a direct reading on a linear scale, described later, are exactly the same as in the other cases. Resistances are determined by trials which make the instrument reading correspond to the percentage of the constituent sought in the mixture before the addition of a gas.

It is of interest to determine the amount of enriching gas which will produce a maximum reading by this method when the gas to be determined is removed and no other change takes place. For this purpose we may assume that the simple law of mixtures, as expressed by the following relation, holds: If $A, B, C, \ldots N$ represent the relative volumes of each constituent of a mixture, and $a, b, c, \ldots \ldots$ the thermal conductivities of the respective gases when pure, the thermal conductivity of the mixture will be represented by the expression

$$
\frac{a A+b B+c C+\ldots \ldots n N}{A+B+C+\ldots \ldots} \text {. . . . . . . }
$$

It is known that this simple law does not hold exactly, but it is, in most cases, a sufficiently close approximation to permit one to determine, in advance, the feasibility of using thermal-conductivity methods for a definite purpose and to choose between the several procedures usually possible.

Let $A$ represent the number of parts by volume of the gas to be removed by absorption, $B$ the number of parts of the residual gas in the original mixture, and $C$ the number of parts of enriching gas to be added. Let $a, b$, and $c$ represent the thermal conduc- 
tivities of the three gases, respectively. It can be shown ${ }^{10}$ by the usual method of differential calculus that the ratio of the conductivity of the mixture after the removal of the desired constituent to the conductivity before the removal is a maximum when the amount of gas used for enrichment is in accordance with the following formula:

$C=\frac{c(a-b) B \pm \sqrt{c^{2}(a-b)^{2} B^{2}+\left(c^{2}-a c\right)\left(a c A B+a c B^{2}-a b A B-b^{2} B^{2}\right)}}{c^{2}-a c}$

The sign before the radical is positive when $c$ is greater than $a$, and negative when $c$ is less than $a$.

By substituting the appropriate values in this equation we find, for example, that the maximum reading for small variations of carbon dioxide in air is obtained when hydrogen is added in the ratio of 0.16 to $\mathrm{I}$. The maximum reading for small amounts of oxygen in nitrogen prepared from the air is obtained when hydrogen is mixed with the gas in the ratio of 0.44 to $I$. The most favorable condition for determining variations in the percentage of oxygen in nearly normal air is obtained by adding hydrogen in the ratio of 0.39 to $\mathrm{I}$. Hydrogen could be determined in mixtures with helium by adding carbon dioxide and passing the mixture over hot copper oxide. The most favorable condition would be obtained by adding three parts of carbon dioxide to one of the original mixture.

In the determination of methane in mixtures of nitrogen, methane, and helium, oxygen is added in constant proportions, not for the purpose of altering the thermal conductivity of the mixture but to permit the combustion of the methane. After the addition of oxygen, the determination of methane is made in the manner described above for the determination of methane in air.

\footnotetext{
${ }^{10}$ Letting $R$ denote the ratio of the conductivity of the mixture before to the conductivity of the mixture after the removal of the constituent of which the volume is represented by $A$, it is evident that the greatest sensitivity will be secured when $d R / d A$ is a maximum. This condition is secured when

$$
\begin{gathered}
\frac{d^{2} R}{d A \cdot d C}=0 . \\
\text { Assuming that } R=\frac{\frac{b B+c C}{B+C}}{\frac{a A+b B+c C}{A+B+C}}
\end{gathered}
$$

the solution of ( $\mathrm{I}$ ) involves the solution of an equation of the fifth power of $C$. It is evident, however, that for small values of $A$, the conditions which make $d R / d A$ a maximum also make $R$ a maximum. It has been found by experiment that $R$ is not far from a linear function of $A$. Hence, for practical purposes it may always be assumed that the most favorable condition is found when $R$ is a maximum.

Differentiating (2) with respect to $C$, equating to zero, and solving for $C$ leads to the equation given in the text.
} 
MeThod 4.-Successive Combustion with Oxygen and HYDROGEN.-A difficult class of mixtures to deal with by comparisons of thermal conductivity is that of mixtures of various combustible gases containing hydrogen and, in some cases, oxygen. For the purpose of analyzing such mixtures, the following method has been applied successfully in the laboratory to the determination of carbon monoxide in the presence of large amounts of hydrogen.

Into a slow stream of the gas to be analyzed is run a stream of oxygen from an electrolytic generator having platinum electrodes and containing potassium hydroxide solution as the electrolyte. The mixture is passed into a small electrically heated combustion tube, containing, preferably, copper oxide, and through a carbon dioxide absorber. It is then mixed with the hydrogen from the electrolytic generator supplying the oxygen and passed through a second combustion tube similar to the first. The electrolysis of an alkali (freed from carbonates by precipitation with barium hydroxide) between platinum electrodes produces hydrogen and oxygen in exactly equivalent proportions. Let us suppose that nitrogen or other inert gas were alone in the original sample. Then the hydrogen and oxygen introduced will combine in the second furnace to form water which may be eliminated, leaving the original gas unchanged. If, however, the original mixture contains carbon monoxide, methane, or other combustible constituents, an amount of oxygen sufficient to burn the combustible gas completely will be removed in the first combustion tube, and a corresponding amount of hydrogen will be in excess in the second. The gas leaving the second combustion tube will, therefore, contain hydrogen in place of all the combustible gases originally present. If, as is usually the case, the inert gas is of constant composition (atmospheric nitrogen), the oxygen equivalent of the total amount of combustible can be found directly and accurately by a comparison of the gas resulting from this so-called double combustion with a standard gas (hydrogen or air). Since the hydrogen in the original gas was replaced by hydrogen, a comparison of the gas before and after the double combustion process gives directly the sum of the combustible gases, other than hydrogen, present.

When the above data are desired, oxygen, if originally present, must first be removed by bubbling through a solution of potassium pyrogallate or other suitable reagent. However, if it be desired to learn the excess of reducing gases over the oxygen present, 
these data can be recorded directly by performing the double combustion as indicated and comparing the conductivity of the resulting mixture with that of a standard gas. The excess of combustible gas other than hydrogen over the oxygen present can be equally well recorded directly, in case anyone is interested in such data. A comparison of the conductivities of the mixtures resulting from the double combustion of two samples of the gas to be analyzed, from one of which the oxygen is first removed, will obviously give the oxygen content of the gas directly.

Combinations of THE BASIC MeiThods.- So many combinations of the basic methods already described are possible that it is not worth while trying to enumerate all of them. Probably the most important is the combination of methods in which a combustible gas containing carbon is burned, and the resulting carbon dioxide is determined by absorption. This should prove a useful method, for example, in processes for the recovery of organic solvents. Oxygen may be added by means of one of the mixing devices, if necessary, in order to secure complete combustion.

Only one other example will be given, that of the complete analysis of the rather complex mixture existing in the gases which have passed through the reaction chamber in the synthetic ammonia process. We are dealing here with a mixture containing approximately one part of nitrogen to three of hydrogen, some ammonia, argon, and considerable amounts of hydrocarbons, principally methane. It is important to know the amounts of both the hydrocarbons and the argon, since they become an increasingly large portion of the mixture as the gas is passed again and again through the ammonia converter, until they slow down the reaction to such an extent that it is no longer profitable to employ the mixture.

The mixture, as a whole, has a high conductivity, somewhat more than three-quarters that of hydrogen. The moderate amount of ammonia present can, therefore, be determined easily and accurately by Method 2, somewhat diluted sulphuric acid being used as the absorbent. As compared with hydrogen, the conductivities of all the remaining gases lie close together, those of methane and argon being on opposite sides of nitrogen. Hydrogen can, therefore, be quite accurately determined by a comparison with pure hydrogen, according to Method I. Methane could now be most accurately determined by Method 4, but the apparatus would be quite complicated, and, for the purpose in view, a simpler method will give sufficiently accurate results. Oxygen 
is mixed with the gas in slight excess (Method 3), the mixture is passed through a combustion tube (Method $2 b$ ) and the resulting carbon dioxide determined by absorption (Method $2 a$ ). The excess oxygen is absorbed, and the residual gas, containing only nitrogen and argon, is compared with air as a standard (Method I). We thus have a direct determination of ammonia, hydrogen, and total carbon, and the determination of the ratio of argon to nitrogen in the residue after the removal of the other constituents.

\section{GENERAL APPLICABIITY OF THE METHODS.}

It is quite evident that the thermal-conductivity method gives no information regarding the qualitative composition of an unknown mixture of gases, and that it can be applied quantitatively only when much is known about the probable identity of the constituents and the amounts likely to occur in the gas mixture to be analyzed. The greatest usefulness of the method is certain to be in the continuous or frequent analysis of gas mixtures in industrial control work and, fortunately, most mixtures of which it is industrially important to know the composition, vary in a somewhat regular manner. Each class of gas mixtures must be studied individually with regard to the probable limits of variation of every constituent; but unless the mixtures are extremely complex, a method can generally be found for indicating the composition of the mixture, although the data may not be expressed in the familiar units of percentage of the original mixture. Thus, when several constituents are determined in a single mixture, the amounts of some of them must generally be expressed in percentage of the residue remaining after the removal of other constituents. The data obtainable should not be less useful to a plant operator on that account after he has learned to interpret them.

\section{PROCESS CONTROL BASED ON GAS ANALYSIS.}

The possibilities of increased efficiency in large numbers of industrial processes by the automatic control of temperatures have become very widely recognized. The tremendous loss in fuel and spoilage of product which occur because of the difficulty of obtaining uniformly constant temperatures by improperly guided hand control have led to the introduction of automatic equipment in which the human element is largely eliminated. In many industrial operations or processes it is necessary or desirable to maintain a gas composition between certain limits. Just as in 
the case of temperature control, a workman, with perhaps little idea as to what he is trying to do, usually attempts to control the composition by hand with the assistance of periodic analyses made in the plant or laboratory as a guide. By the use of methods such as have been outlined above, routine analyses can, in a wide variety of instances, be automatically made and continuously recorded more quickly and at less expense than by men. Frequently, also, automatic control, signal, or alarm devices actuated and guided by the gas-analysis equipment offer possibilities for a reduction of labor costs and the more effective control of processes.

By far the most insistent demand for automatic gas-analysis recorders has arisen from a desire to control the carbon-dioxide content of flue gases as an aid to fuel economy in the operation of combustion processes. In answer to this demand, a considerable number of carbon-dioxide recorders have appeared on the market in the United States. With few exceptions these instruments are essentially automatic Orsat apparatus. The volumes of a sample of flue gas are periodically measured before and after the absorption of the carbon dioxide and the differences are recorded directly in terms of the volume percentages of carbon dioxide. While this type of instrument is probably reasonably accurate when given proper attention, it is at best intermittent in its action, its indications are frequently untrustworthy, and it is inherently unsuited for the control of signals, valves, dampers, or switches. On the other hand, the thermal-conductivity method can be successfully adapted not only to flue gas determinations but also when suitably modified to the numerous other important applications already mentioned.

The various lamp signal and alarm devices, relay switches, and valve and damper controls which have been developed by manufacturers for temperature regulation can be readily adapted for the control of gas composition in connection with the gas-analysis recorders.

\section{RESULTS OBTAINED IN THE ACTUAL APPLICATION OF THE METHOD.}

In order to indicate the wide applicability of the thermal-conductivity method and to show the accuracy that has been obtained by its use, a list is given below of some of the results secured in specific applications. Many of the numerical results were obtained under laboratory conditions with all accessory apparatus of excellent quality and in accurate adjustment. It does not follow, 
of course, that as good results would be obtained under plant conditions, particularly with a recorder. However, the reproductions of typical charts taken from recorders actually installed in plants show what has been accomplished in certain instances.

The factors which govern the accuracy of the determinations may be pointed out in connection with a consideration of the analysis of hydrogen in mixtures with nitrogen. The relation between the composition of the gas and the unbalanced potential measured across a thermal-conductivity bridge is shown by the curves plotted in Figure 7. Each of the fixed arms had, approximately, Io ohms resistance and the unit was maintained at a tem-
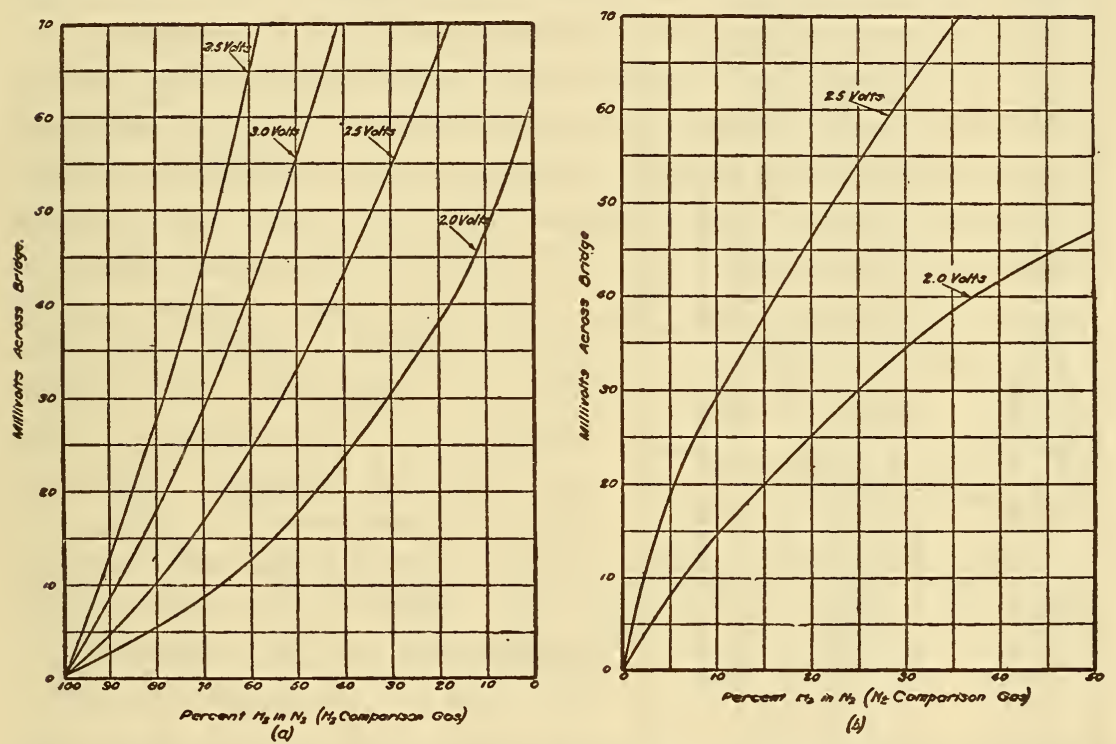

FIG. 7.-Relation between composition of the gas and the unbalanced potential measured across thermal conductivity bridge.

perature of $30^{\circ} \mathrm{C}$. It will be observed that in no case is the relation exactly linear, though the departure from a straight line is not great over small ranges of variation in gas composition. The accuracy of the determination will depend on the regulation of the temperature, rate of flow, and applied emf, the precision of the measuring instrument, and whether the instrument readings are corrected for the deviation from a linear relation. The inaccuracies resulting from variations in the temperature or the emf are least when the comparison gas is most nearly equal in thermal conductivity to the gas for analysis. Similarly, variations in the rate of flow introduce the smallest errors when the wires in the two cells are surrounded by gases flowing at about the same rates. 
It is obvious that the auxiliary equipment required and the precautions that must be taken in the various adjustments depend not only on the accuracy desired but also on the nature of the gases compared.

It will be shown in Section IV that by means of electrical adjustments it is easy to make two points of the scale of the electrical-

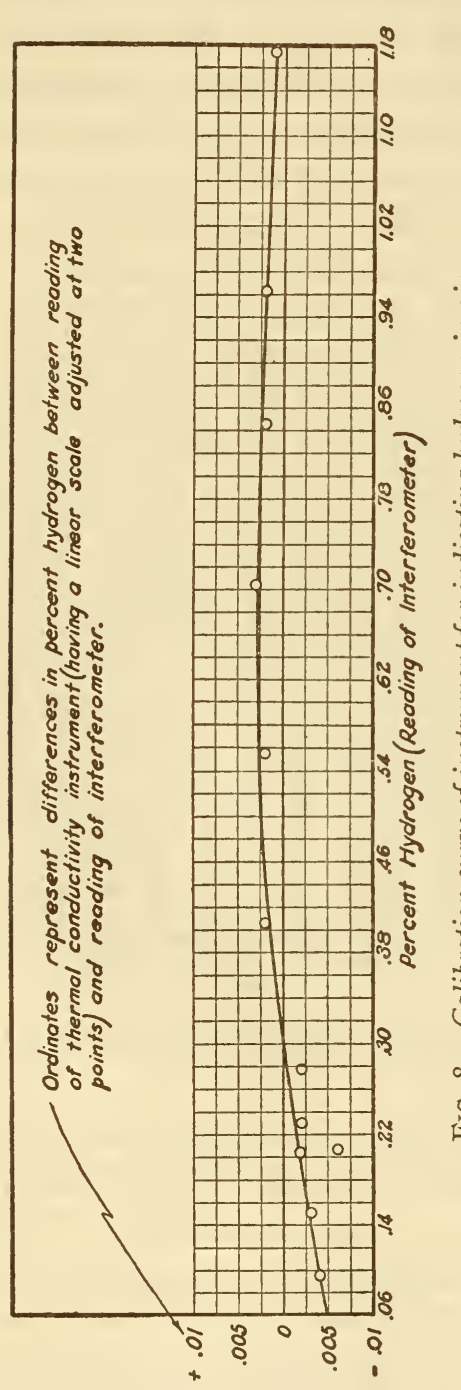
measuring instrument have any desired values in terms of gas composition. It is then possible, by determining a sufficient number of other corresponding values, to subdivide the scale into intervals which will represent accurately convenient differences of composition of the gas mixture. Frequently this subdivision of the scale into correct, but unequal intervals, is unnecessary because a scale of equal divisions, which will be called a linear scale because it represents the relation between the composition of the gas and the electrical quantity which is measured as linear, is accurate enough for the purpose of the analyses. In most of the applications to be described in this part of the paper the existing linear scale of the measuring instrument was not changed, but the analyses, numerically expressed in convenient units, were made to coincide with the scale at two points, and, if necessary, a calibration curve was then constructed to correct the readings of the instrument to more accurate values.

\section{DETERMINATION OF HYDROGEN IN HYDROGEN-AIR MIXTURES.}

The readings obtained with a thermal-conductivity instrument, being calibrated for use in determining the permeability of balloon fabrics to hydrogen, are compared in Figure 8 with the analyses of mixtures of hydrogen and air determined with a gas 
interferometer. The gas mixture for analysis surrounded one wire of the thermal-conductivity unit, and pure dry air the other. A balanced bridge arrangement was employed with a manually operated slide-wire. Before taking the readings represented in the figure, the constants of the circuit had been adjusted, not altogether successfully, to make the readings correct at 0.25 and I.oo per cent. It is worth noting that only I of I 3 analyses lies more than about 0.001 per cent from a smooth calibration curve.

\section{DETERMINATIOIN OF HYDROGEN IN ELECTROLYTIC OXYGEN.}

Two instruments for recording the purity of oxygen delivered by electrolytic generators have been constructed in the bureau laboratories and tested for several months under plant conditions. A portion of a day's chart from one of these recorders is reproduced in Figure 9. This chart was selected because it shows the rapidity with which the instrument followed changes in gas purity arising from faulty separators in the electrolytic cells. The accuracy of the instument is indicated in Table 4 by the comparison of read-

TABLE 4.-Comparison of Records and Volumetric Analyses November 8, 1921.

\begin{tabular}{|c|c|c|c|c|c|c|c|}
\hline \multirow{2}{*}{ Time. } & \multicolumn{2}{|c|}{ Ozygen. } & \multirow{2}{*}{$\begin{array}{l}\text { Room } \\
\text { temper- } \\
\text { ature. }\end{array}$} & \multirow{2}{*}{ Time. } & \multicolumn{2}{|c|}{ Oxygen. } & \multirow{2}{*}{$\begin{array}{l}\text { Room } \\
\text { temper- } \\
\text { ature. }\end{array}$} \\
\hline & $\begin{array}{c}\text { Recorder } \\
\text { chart. }\end{array}$ & $\begin{array}{c}\text { Orsat } \\
\text { analysis. }\end{array}$ & & & $\begin{array}{c}\text { Recorder } \\
\text { chart. }\end{array}$ & $\begin{array}{c}\text { Orsat } \\
\text { analysis. }\end{array}$ & \\
\hline $\begin{array}{c}\text { a.m. } \\
9.50 \ldots \ldots \ldots \ldots \ldots \\
10.10 \ldots \ldots \ldots \ldots \ldots \\
10.50 \ldots \ldots \ldots \ldots \ldots \\
11.20 \ldots \ldots \ldots \ldots \ldots \\
11.45 \ldots \ldots \ldots \ldots \ldots\end{array}$ & $\begin{array}{c}\text { Per cent. } \\
99.3 \\
99.5 \\
99.3 \\
99.3 \\
99.4\end{array}$ & $\begin{array}{c}\text { Per cent. } \\
99.4 \\
99.5 \\
99.3 \\
99.3 \\
99.5\end{array}$ & $\begin{array}{l}{ }^{\circ} \mathrm{C} . \\
18.0 \\
18.5 \\
19.8 \\
20.7 \\
21.3\end{array}$ & $\begin{array}{c}\text { p. m. } \\
1.20 \ldots \ldots \ldots \ldots \ldots \ldots \\
1.55 \ldots \ldots \ldots \ldots \ldots \ldots \\
2.30 \ldots \ldots \ldots \ldots \ldots \ldots \\
3.05 \ldots \ldots \ldots \ldots \ldots \ldots\end{array}$ & \begin{tabular}{|c|} 
Per cent. \\
99.1 \\
99.0 \\
98.9 \\
98.8
\end{tabular} & \begin{tabular}{|c|} 
Per cent. \\
99.1 \\
99.0 \\
99.0 \\
98.9
\end{tabular} & $\begin{array}{l}{ }^{\circ} \mathrm{C} . \\
22.4 \\
22.9 \\
22.9 \\
22.7\end{array}$ \\
\hline
\end{tabular}

ings taken from the recorder chart and the corresponding periodic volumetric analyses. The indications of this recorder were found to be independent of the rate of flow of gas from o to $20 \mathrm{cc}$ per minute, but very rapid flow caused the recorder to show an apparent decrease in gas purity. A decrease of 0.05 volt from the calibration potential of 2.50 volts caused an increase of about 0.07 per cent in the recorded percentage of oxygen. The temperature coefficient was negligible over the probable range of electrolyzer room temperatures.

To show the applicability of a purity recorder to the actual control of an electrolytic gas plant, a demonstration apparatus is set up in the bureau's laboratories. An electrolytic generator supplies a stream of oxygen, the purity of which is automatically indicated and recorded by the thermal-conductivity method. A 
second electrolytic generator introduces a small quantity of hydrogen into the stream of oxygen. As the purity of the oxygen decreases to 99 per cent, half of the recorder range, a buzzer is automatically sounded as an alarm signal. When the purity drops to a

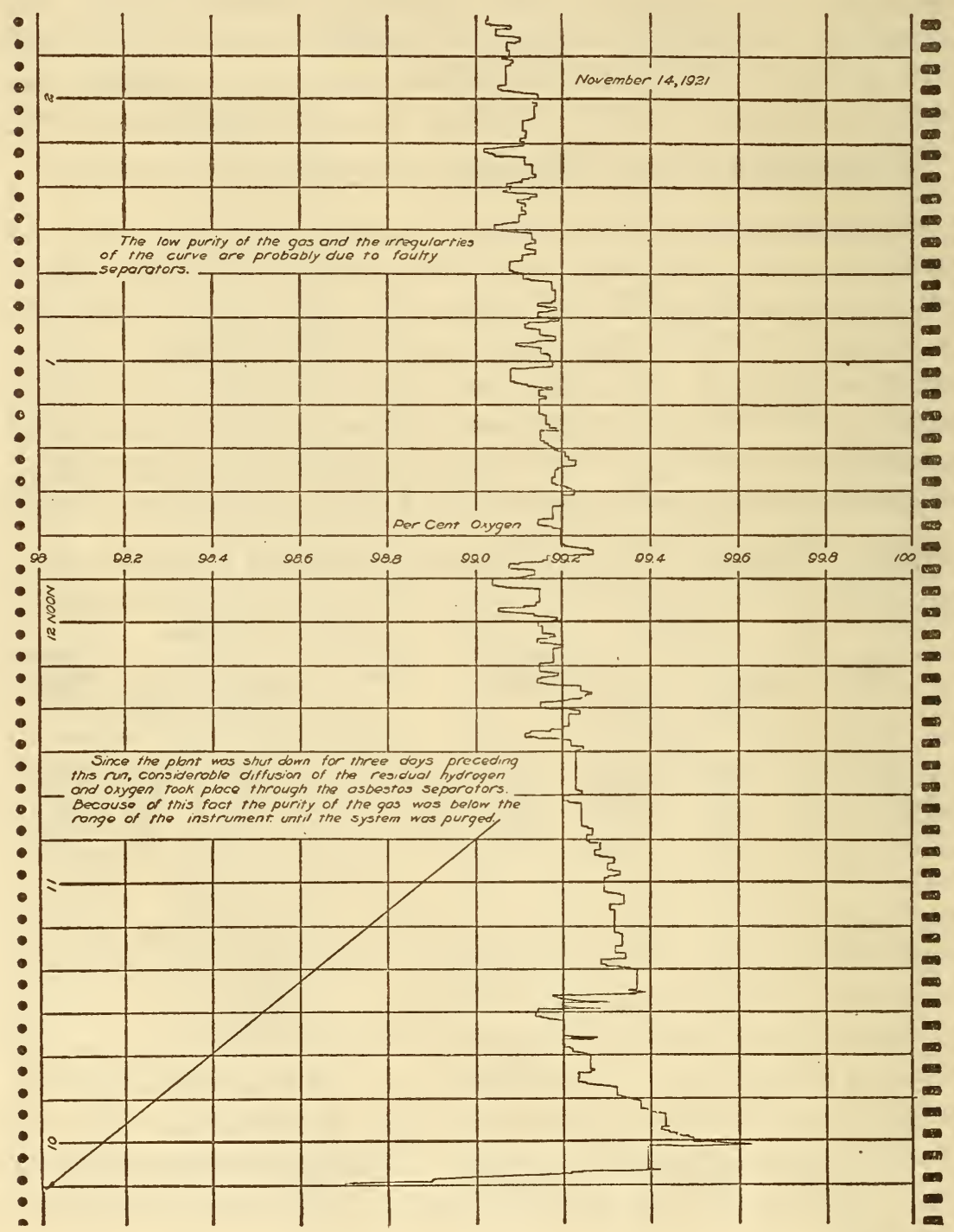

FIG. 9.-Portion of chart made by oxy'gen purity recorder.

little above 98 per cent, the lower limit of the recorder range, the generator supplying the hydrogen is cut off, allowing the purity to build up above 99 per cent before the gas is again contaminated and the cycle repeated. The alarm buzzer and second electrolytic 
generator are controlled by relays actuated by contacts on the recorder. This instrument has been in entirely successful operation intermittently for a period of over two years. In Figure ro a portion of the recorder chart is reproduced. When it is remembered that a great many factors govern the composition and the

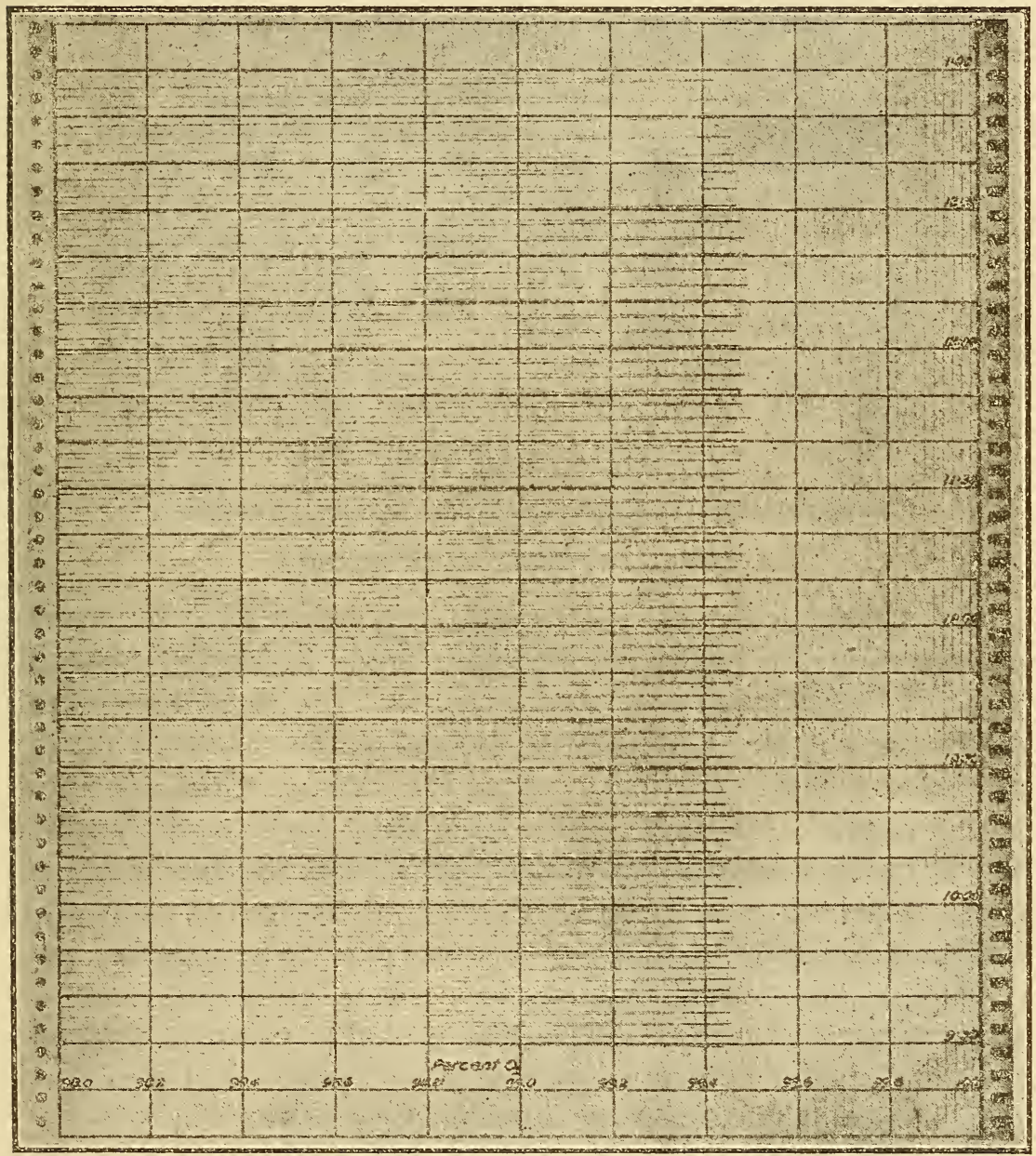

Fic. Io.-Portion of record of demonstration instrument.

accuracy of the analysis of the gas passing through the thermalconductivity cell, the consistency with which the instrument performs is remarkable. During the three and one-half hours' operation, in which 72 cycles are completed, the variation in the maximum purity of the oxygen indicated by the recorder is less than o.I per cent. 


\section{HYDROGEN IN HYD'ROGEN-NITROGEN MIXTURES.}

The data given in Table 5 were obtained with manually-operated equipment calibrated for use in a synthetic ammonia plant. The gas mixtures of variable composition passed through one thermalconductivity cell and pure hydrogen was used as the comparison gas.

TABLE 5.-Analyses of Hydrogen-Nitrogen Mixtures.

\begin{tabular}{|c|c|c|c|c|c|c|}
\hline \multirow{2}{*}{$\begin{array}{c}\text { Average of volu- } \\
\text { metric analysis, } \\
\text { per cent } \mathrm{H}_{2} \text {. }\end{array}$} & \multicolumn{6}{|c|}{ Analysis by thermal conductivity apparatus. ${ }^{1}$} \\
\hline & $\begin{array}{l}\text { Unit } \\
\text { No. } 1 .\end{array}$ & $\begin{array}{c}\text { Unit } \\
\text { No. } 2 .\end{array}$ & $\begin{array}{c}\text { Unit } \\
\text { No. } 3 .\end{array}$ & $\begin{array}{c}\text { Unit } \\
\text { No. } 4 .\end{array}$ & $\begin{array}{c}\text { Unit } \\
\text { No. } 5 .\end{array}$ & $\begin{array}{c}\text { Unit } \\
\text { No. } 6 .\end{array}$ \\
\hline 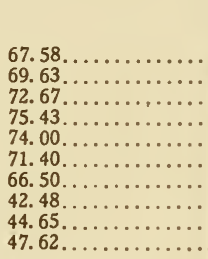 & $\begin{array}{c}\text { Per cent } \\
\mathrm{H}_{2 .} \\
67.58 \\
69.85 \\
72.67 \\
75.44 \\
\ldots \ldots \ldots \ldots \\
\ldots \ldots \ldots \ldots \\
\ldots \ldots \ldots \ldots \\
\ldots \ldots \ldots \ldots \\
\ldots \ldots \ldots\end{array}$ & $\begin{array}{c}\text { Per cent } \\
\mathrm{H}_{2 .} \\
67.58 \\
69.88 \\
72.67 \\
75.52 \\
\ldots \ldots \ldots \\
\ldots \ldots \ldots \\
\ldots \ldots \ldots \ldots\end{array}$ & 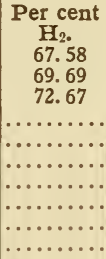 & 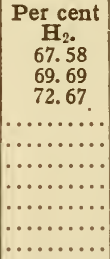 & 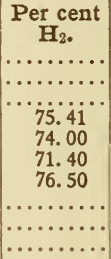 & 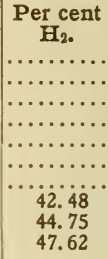 \\
\hline
\end{tabular}

1 Uncorrected reading of instrument with linear scale adjusted at two points.

\section{TOTAL IMPURITY IN HYDROGEN.}

The thermal-conductivity method was applied to the purpose of recording the purity of hydrogen made in an experimental plant by the thermal decomposition of oil. The percentage of each of the three principal impurities present in the gas was a rapidly changing function of time, and of the rate at which hydrogen was produced. It would have been quite impossible to follow the significant changes in the composition of the gas, and especially to determine accurately the effect of changes of plant operation by ordinary methods of gas analysis. The recorder indicated the direction of such changes within 20 seconds and the adjustment to a new condition was probably complete within a minute. Figure I I shows a typical record from one of the experimental runs replotted on an extended time scale.

The recorder was calibrated with analyzed mixtures of nitrogen and hydrogen. The conductivities of the principal impurities, nitrogen, carbon monoxide, and methane, are, in comparison with hydrogen, rather close together. The recorded purity of the hydrogen was, therefore, quite accurate regardless of the relative proportions of these impurities. Frequent analyses of the hydrogen produced in the plant were made by the combustion method in a good volumetric apparatus of the Orsat type. The results of a number of typical analyses are given in Table 6, 
together with the reading of the recorder at the time the sample was taken. In some cases the composition of the gas was changing rapidly, and some of the differences between the volumetric and conductivity analyses were probably caused in part by small differences in the time of sampling.

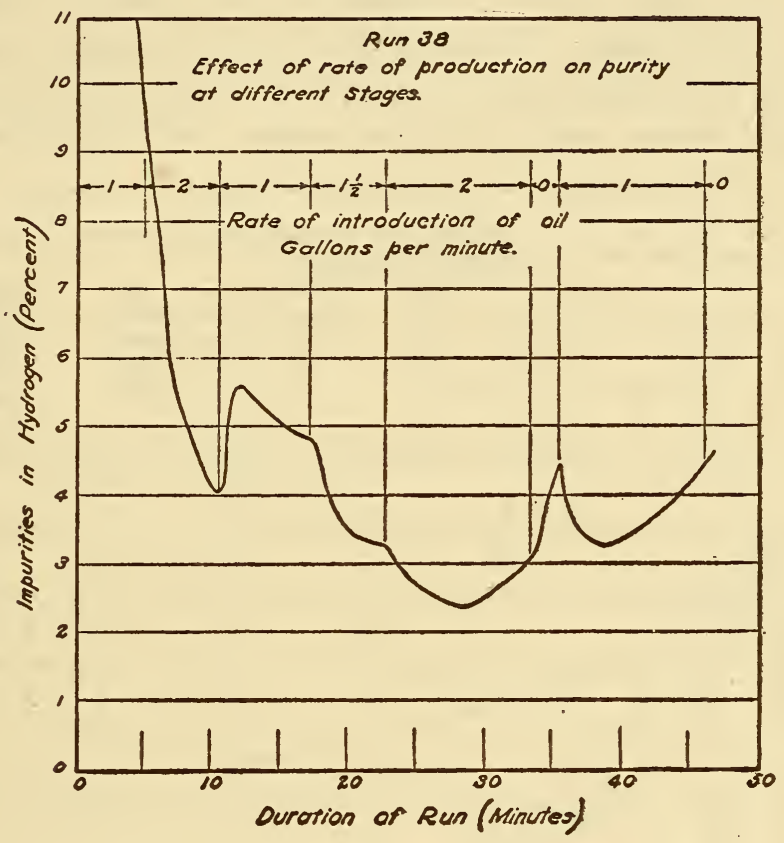

FIG. Ir.-Effect of rate of production on purity at different stages.

TABLE 6.-Typical Analyses of Hydrogen from Oil.

\begin{tabular}{|c|c|c|c|c|c|}
\hline \multirow{2}{*}{ Sample number. } & \multicolumn{4}{|c|}{ Volumetric analysis. } & \multirow{2}{*}{$\begin{array}{l}\text { Recorder } \\
\text { reading. }\end{array}$} \\
\hline & $\mathrm{N}_{2}$ & $\mathrm{CO}$ & $\mathrm{CH}_{4}$ & $\mathrm{H}_{2}$ & \\
\hline 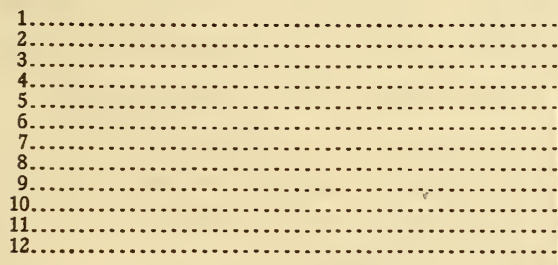 & $\begin{array}{r}0.5 \\
.0 \\
.8 \\
.9 \\
.7 \\
.2 \\
1.2 \\
.5 \\
.3 \\
.5 \\
.1 \\
.2\end{array}$ & $\begin{array}{l}3.2 \\
5.4 \\
2.5 \\
5.5 \\
5.6 \\
2.3 \\
5.2 \\
2.1 \\
2.9 \\
1.9 \\
1.8 \\
2.6\end{array}$ & $\begin{array}{l}0.0 \\
7.9 \\
.0 \\
2.3 \\
.0 \\
1.2 \\
3.7 \\
.6 \\
.0 \\
.3 \\
.6 \\
.4\end{array}$ & \begin{tabular}{l|}
96.3 \\
86.7 \\
96.7 \\
91.3 \\
93.7 \\
96.3 \\
89.4 \\
96.8 \\
96.8 \\
97.3 \\
97.5 \\
96.8
\end{tabular} & $\begin{array}{l}96.2 \\
86.8 \\
96.8 \\
92.0 \\
93.5 \\
96.0 \\
89.2 \\
97.4 \\
97.2 \\
97.3 \\
97.7 \\
96.8\end{array}$ \\
\hline
\end{tabular}

This recorder gave great satisfaction under plant conditions; indeed, it would have been almost impossible to carry out the investigation of this process of manufacturing hydrogen without the aid of the recorder. 


\section{HYDROGEN AND STEAM.}

The thermal-conductivity method was also used successfully in an experimental hydrogen plant to record the conversion of steam to hydrogen in the steam-iron process. For this purpose the analyzing unit was steam jacketed to keep the steam in the vapor phase. The three curves of Figure 12 are typical of the records obtained in this case. Precisely similar curves were obtained by computing the percentage of steam in the outgoing hydrogen from readings of steam and hydrogen meters, but the percentage of

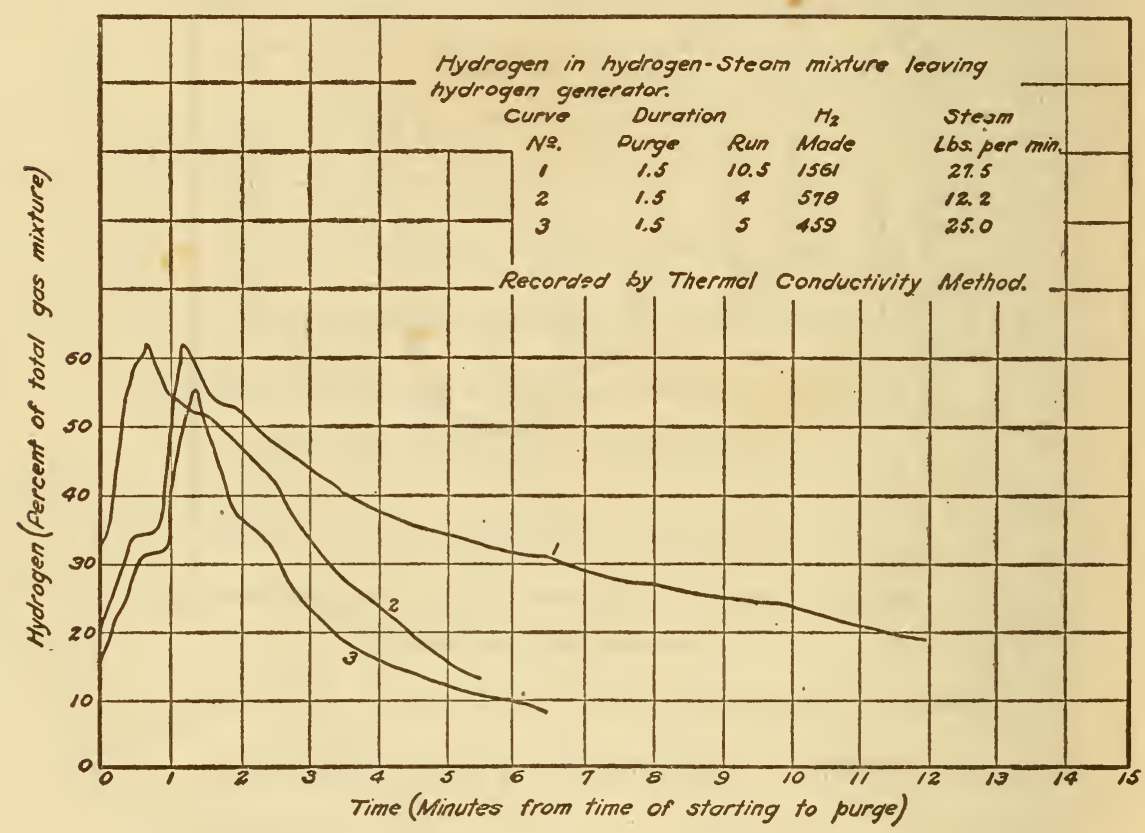

FIG. I2.-Hydrogen in hydrogen-steam mixture leaving hydrogen generator.

hydrogen shown by the recorder was always somewhat higher than that indicated by the meter readings. For certain reasons, which will not be discussed here, it is believed that the recorded composition was more accurate than the indications of the steam meter.

This application of the thermal-conductivity method is of especial interest because it is one of the very few cases in which steam, which is one of the two or three most important industrial gases, has been determined directly in the gas phase.

\section{HELIUM IN MIXTURES OF YELIUM AND NITROGEN.}

Helium in mixtures of helium and nitrogen is determined by passing the gas mixture through one thermal-conductivity cell while hydrogen is passed through the other cell as a comparison 
Technologic Papers of the Bureau of Standards, Vol. 18

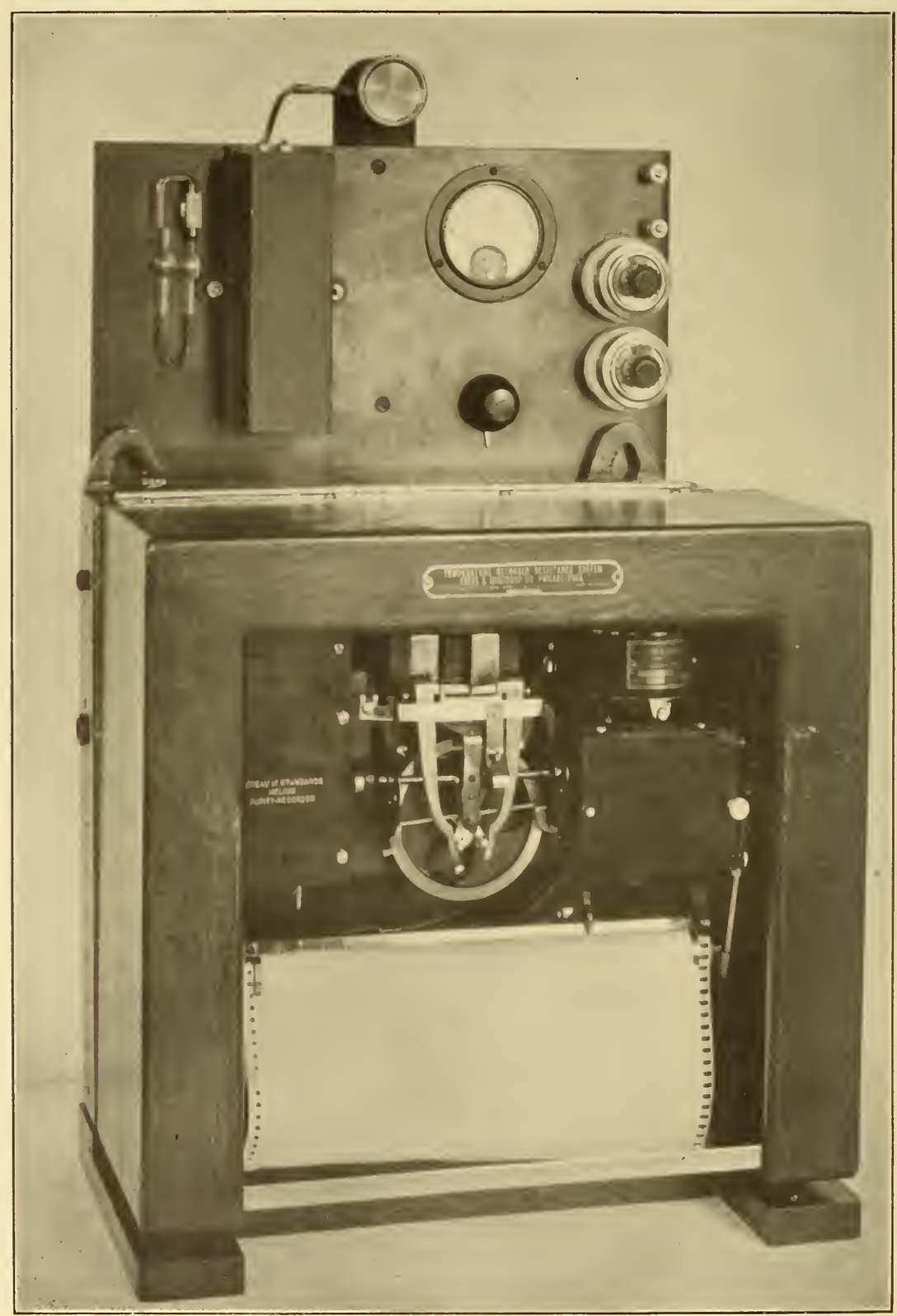

FIG. I3.-Bureau of Standards helium purity recorder. 
gas. In Table 7 are shown the uncorrected readings made by a recorder with a uniformly divided scale, when used in connection with two different thermal-conductivity units, together with the corresponding analyses made with a gas interferometer. Although the readings taken directly from the recorder chart deviate considerably from the corresponding interferometer analyses, the discrepancies disappear when the direct readings of the recorder are corrected by means of calibration curves.

TABLE 7.-Analyses of Helium-Nitrogen Mixtures. 0-100 PER CENT RANGE.

\begin{tabular}{|c|c|c|c|c|}
\hline \multirow[t]{2}{*}{ Gas interferometer ana!yses in per cent helium. } & \multicolumn{2}{|c|}{$\begin{array}{l}\text { Uncorrected recorder } \\
\text { readings from linear } \\
\text { scale adjusted at two } \\
\text { points. }\end{array}$} & \multicolumn{2}{|c|}{$\begin{array}{c}\text { Analyses from calibra- } \\
\text { tion curves. }\end{array}$} \\
\hline & Unit No. 1. & Unit No. 2. & Unit No. 1. & Unit No. 2. \\
\hline 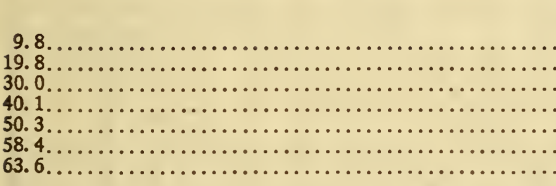 & \begin{tabular}{r|} 
Per cent Be. \\
7.1 \\
21.3 \\
34.3 \\
45.0 \\
54.7 \\
60.9 \\
64.7
\end{tabular} & $\begin{array}{r}\text { Per cent He. } \\
7.5 \\
22.5 \\
34.3 \\
45.7 \\
55.0 \\
61.4 \\
65.0\end{array}$ & $\begin{array}{r}\text { Percent He. } \\
9.8 \\
19.8 \\
30.0 \\
40.0 \\
50.3 \\
58.3 \\
63.6\end{array}$ & $\begin{array}{r}\text { Per cent He. } \\
10.0 \\
20.7 \\
29.9 \\
40.2 \\
50.3 \\
58.4 \\
63.3\end{array}$ \\
\hline 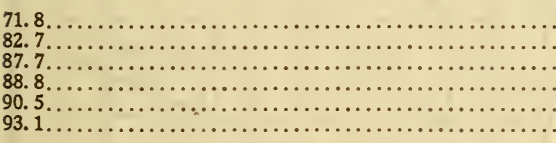 & $\begin{array}{l}70.7 \\
77.2 \\
80.2 \\
81.0 \\
82.0 \\
83.2\end{array}$ & $\begin{array}{l}71.2 \\
77.7 \\
80.7 \\
81.8 \\
82.4 \\
84.0\end{array}$ & $\begin{array}{l}72.4 \\
82.7 \\
87.6 \\
88.9 \\
90.8 \\
93.3\end{array}$ & $\begin{array}{l}72.3 \\
82.7 \\
87.6 \\
89.5 \\
90.5 \\
93.1\end{array}$ \\
\hline
\end{tabular}

80-100 PER CENT RANGE.

\begin{tabular}{|c|c|c|c|c|}
\hline 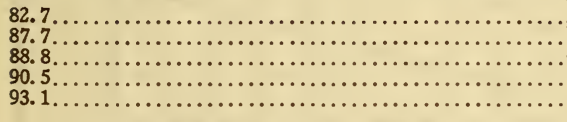 & $\begin{array}{l}81.7 \\
88.5 \\
90.0 \\
91.7 \\
95.5\end{array}$ & $\begin{array}{l}82.8 \\
89.8 \\
91.2 \\
92.7 \\
96.7\end{array}$ & $\begin{array}{l}82.7 \\
87.7 \\
88.9 \\
90.1 \\
93.1\end{array}$ & $\begin{array}{l}82.7 \\
87.9 \\
89.0 \\
90.1 \\
93.1\end{array}$ \\
\hline
\end{tabular}

Figure $\mathrm{I} 3$ is a reproduction of a photograph of one of the helium purity recorders constructed at the Bureau of Standards for installation in Government helium production and repurification plants.

\section{DETERMINATION OF CARBON DIOXIDE IN CARBON DIOXIDE-AIR MIXTURES.}

Figure I4 shows the relation between the composition of mixtures of carbon dioxide and air and the unbalanced potential measured across a thermal-conductivity bridge for various applied potentials. Each of the fixed arms had about ro ohms resistance. The unit was mounted vertically in a constant temperature oil bath maintained at $30^{\circ} \mathrm{C}$. These curves are given primarily for the purpose of indicating the approximate sensitivity or range required of a deflection instrument or potentiometer used with an unbalanced bridge in flue-gas analysis.

$57033^{\circ}-24-3$ 
The excellent agreement between analyses by a manually operated, balanced bridge, thermal-conductivity instrument and by careful volumetric analyses of several carbon dioxide air mixtures is shown in Table 8 .

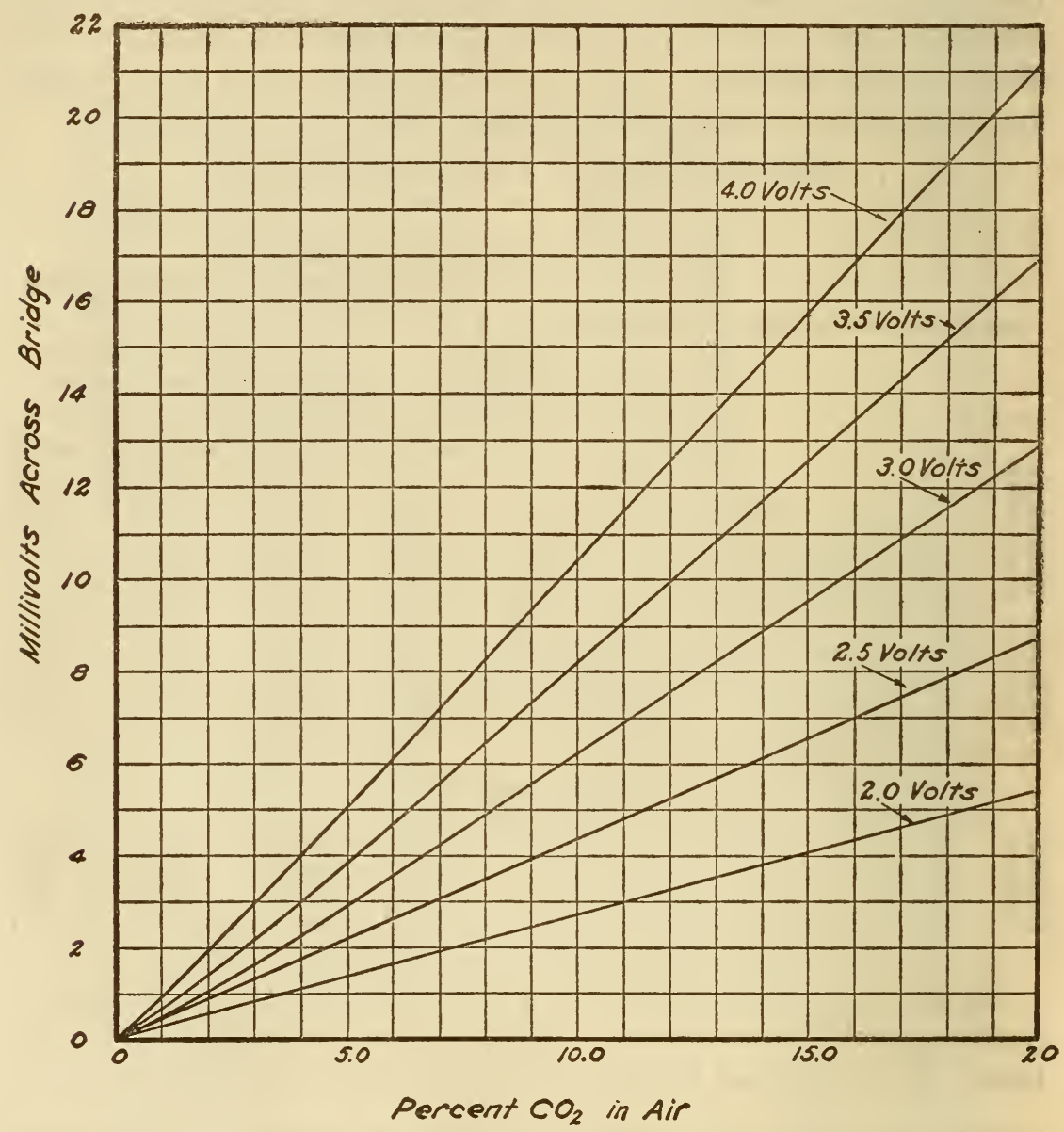

FIG. I4.-Relation between composition of $\mathrm{CO}_{2}$-air mixtures and unbalanced potential across a thermal-conductivity bridge.

TABLE 8.-Analyses of Carbon Dioxide Air Mixtures.

\begin{tabular}{|c|c|}
\hline $\begin{array}{c}\text { Averages of } \\
\text { volumetric } \\
\text { analyses. }\end{array}$ & $\begin{array}{c}\text { Analysis by } \\
\text { thermal } \\
\text { conductivity } \\
\text { apparatus. }\end{array}$ \\
\hline Per cent $\mathrm{CO}_{2 .}$ & Per cent $\mathrm{CO}_{2 .}$ \\
0.00 & 0.20 \\
2.65 & 2.68 \\
4.85 & 4.85 \\
7.12 & 7.14 \\
10.28 & 10.28 \\
\hline
\end{tabular}

1 Uncorrected reading of instrument with linear scale adjusted at two points. 
8. SULPHUR DIOXIDE IN MIXTURES OF SULPHUR DIOXIDE AND AIR.

Sulphur dioxide in mixtures of sulphur dioxide and air can be determined by comparing the conductivity of the mixture passing through one cell with that of air sealed in the other. The approximate unbalanced potential available for detection by a deflection instrument or a potentiometer is indicated by the data plotted in Figure 15 . The thermal-conductivity unit, fitted with platinum wires $0.05 \mathrm{~mm}$ in diameter and $100 \mathrm{~mm}$ in length, was mounted

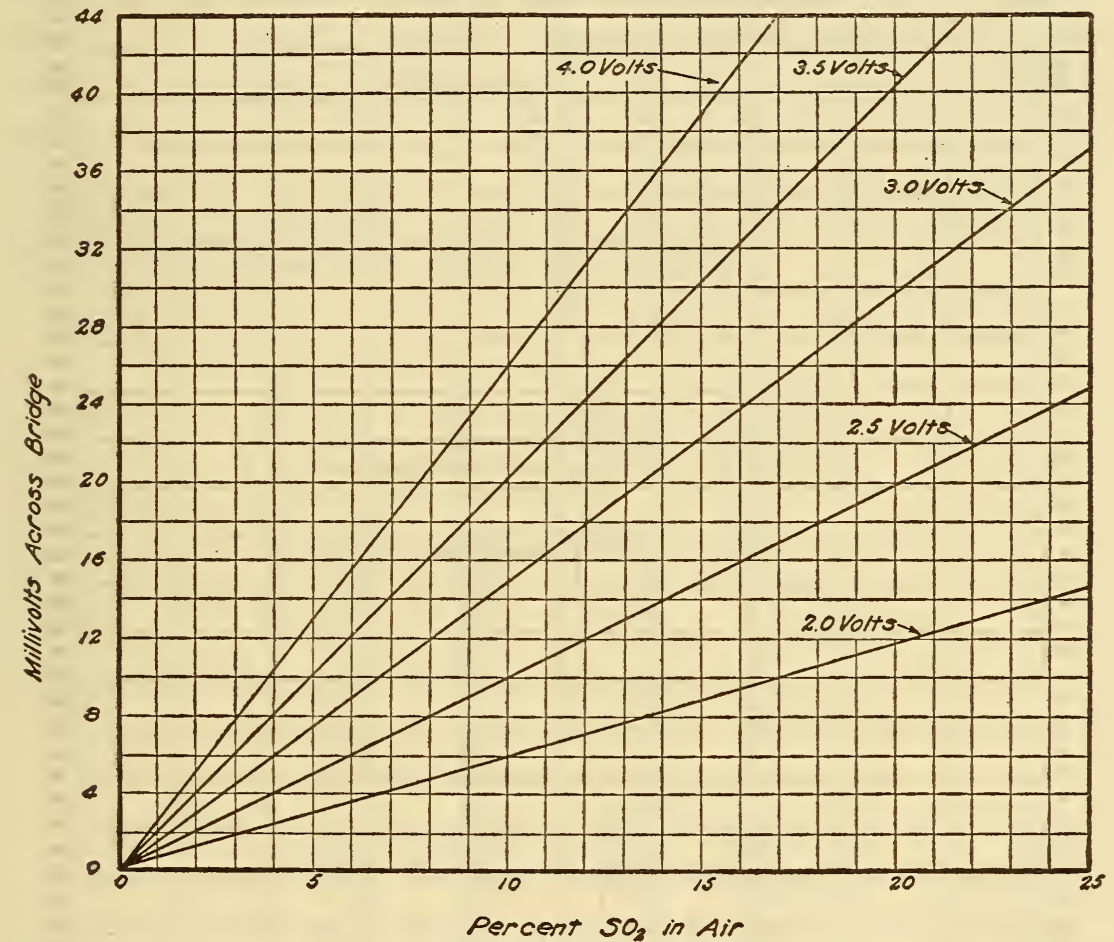

FIG. I5.-Relation between composition of mixtures of $\mathrm{SO}_{2}$ and air and unbalanced potential across a thermal-conductivity bridge.

vertically in a constant temperature oil bath maintained at $30^{\circ}$ C., and the fixed arms had each a resistance of about io ohms.

The accuracy with which records of the sulphur-dioxide content of the entrance gases supplied to the converter in contact sulphuric acid plants can be made is indicated by Figure 16 . This chart is the reproduction of a portion of a record traced during a night's operation of a sulphuric acid plant, during which time no adjustment was made of the thermal-conductivity instrument. The routine determinations of the sulphur-dioxide content of the entrance gas made hourly by the plant operators using the Reich 


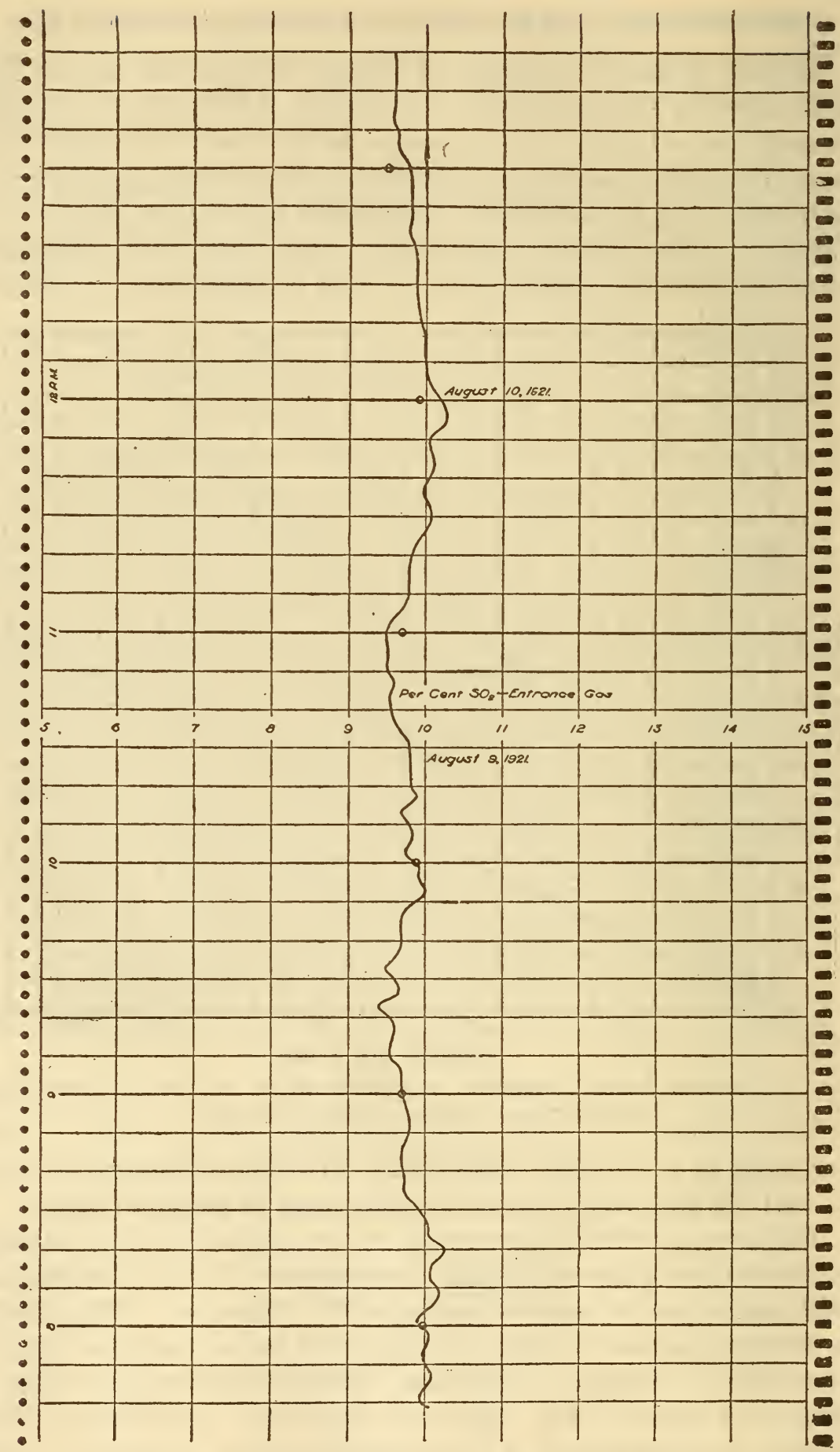

FIG. I6.-Portion of chart from a sulphur dioxide recorder. 
iodine titration are shown on the chart by the circles. Since the samples may not have been taken exactly on the hour, the agreement may have been even better than is indicated.

\section{DETERMINATION OF CARBON DIOXIDE IN MIXTURES OF HYDROGEN, NITROGEN, AND CARBON DIOXIDE.}

In the determination of carbon dioxide in mixtures of nitrogen and hydrogen, in which the ratio of nitrogen and hydrogen may vary somewhat, analysis is best made by a comparison of the thermal conductivity before and after the absorption of carbon dioxide in a suitable reagent. Results obtained with a manually operated apparatus calibrated for use in a synthetic ammonia plant are given in Table 9. It is to be noted that, although the hydrogen-nitrogen ratio in the mixtures has been varied considerably, the analyses of carbon dioxide by the thermal-conductivity instrument are almost unaffected.

TABLE 9.-Analyses of Carbon Dioxide, Hydrogen, and Nitrogen Mixtures.

\begin{tabular}{|c|c|c|c|}
\hline $\begin{array}{l}\text { Hydrogen in } \\
\text { residue. }\end{array}$ & $\begin{array}{l}\text { Nitrogen in } \\
\text { residue. }\end{array}$ & $\begin{array}{l}\text { Averages of } \\
\text { volumetric } \\
\text { analyses. }\end{array}$ & $\begin{array}{l}\text { Alalysis by } \\
\text { thermal } \\
\text { conductivity } \\
\text { apparatus. }\end{array}$ \\
\hline $\begin{array}{c}\text { Per cent } \\
\text { H. }_{2 .} \\
40.00 \\
40.00 \\
40.00 \\
40.00 \\
40.00\end{array}$ & $\begin{array}{c}\text { Per cent } \\
\mathrm{N}_{2 .} \\
60.00 \\
60.00 \\
60.00 \\
60.00 \\
60.00\end{array}$ & $\begin{array}{c}\text { Per cent } \\
\mathrm{CO}_{2 .} \\
2.42 \\
2.53 \\
2.79 \\
4.55 \\
5.30\end{array}$ & $\begin{array}{c}\text { Per cent } \\
\mathrm{CO}_{2 \circ} \\
2.45 \\
2.53 \\
2.73 \\
4.55 \\
5.20\end{array}$ \\
\hline $\begin{array}{l}40.00 \\
40.00 \\
40.00 \\
37.33 \\
37.33\end{array}$ & $\begin{array}{l}60.00 \\
60.00 \\
60.00 \\
62.67 \\
62.67\end{array}$ & $\begin{array}{r}6.90 \\
7.69 \\
10.05 \\
.00 \\
1.00\end{array}$ & $\begin{array}{r}6.90 \\
7.60 \\
10.05 \\
.00 \\
.90\end{array}$ \\
\hline $\begin{array}{l}37.33 \\
37.33 \\
37.33 \\
37.33 \\
29.36\end{array}$ & $\begin{array}{l}62.67 \\
62.67 \\
62.67 \\
62.67 \\
70.64\end{array}$ & $\begin{array}{r}3.29 \\
6.05 \\
8.10 \\
10.03 \\
.00\end{array}$ & $\begin{array}{r}3.29 \\
6.00 \\
8.27 \\
10.23 \\
.05\end{array}$ \\
\hline $\begin{array}{l}29.36 \\
29.36 \\
29.36 \\
29.36\end{array}$ & $\begin{array}{l}70.64 \\
70.64 \\
70.64 \\
70.64\end{array}$ & $\begin{array}{r}2.37 \\
3.67 \\
6.55 \\
10.82\end{array}$ & $\begin{array}{r}2.30 \\
3.64 \\
6.55 \\
11.07\end{array}$ \\
\hline
\end{tabular}

1 Uncorrected reading of instrument with linear scale adjusted at two points.

\section{DETERMINATION OF AMMONIA IN MIXTURES OF AMMONIA,} NITROGEN, AND HYDROGEN.

The determination of ammonia in mixtures of hydrogen and nitrogen, which have passed over the catalyst in the Haber synthetic ammonia process, is accomplished by passing the mixture first through one conductivity cell, then through an ammonia absorber, and finally through the second thermal conductivity cell. In Table Io analyses made by two units arranged with a manually operated balanced bridge are given. 
The residue after the removal of ammonia contained 75 per cent of hydrogen and 25 per cent of nitrogen.

TABLE 10.-Analyses of Ammonia, Nitrogen, and Hydrogen Mixtures.

\begin{tabular}{|c|c|c|}
\hline \multirow{2}{*}{$\begin{array}{l}\text { Averages of } \\
\text { volumetric } \\
\text { analyses. }\end{array}$} & \multicolumn{2}{|c|}{$\begin{array}{l}\text { Analysis by thermal conduc- } \\
\text { tivity apparatus. }{ }^{-}\end{array}$} \\
\hline & Unit No. 1. & Unit No. 2. \\
\hline $\begin{array}{c}\text { Per cent } \mathrm{NH}_{3} \text {. } \\
0.27 \\
2.55 \\
2.63 \\
5.26 \\
5.78 \\
8.03 \\
8.48\end{array}$ & $\begin{array}{c}\text { Per cent } \mathrm{NH}_{3} . \\
0.39 \\
2.52 \\
2.65 \\
5.20 \\
5.63 \\
7.96 \\
8.36\end{array}$ & \begin{tabular}{|c} 
Per cent NH $_{3}$. \\
0.30 \\
2.42 \\
2.62 \\
5.10 \\
5.55 \\
7.85 \\
8.28
\end{tabular} \\
\hline
\end{tabular}

${ }^{1}$ Uncorrected reading of instrument with linear scale adjusted at two points.

The curves in Figure 17 were plotted from data secured under plant conditions. The thermal-conductivity unit was arranged in an unbalanced bridge and a portable potentiometer was used as the measuring instrument. No correction was made for the effects of variations in room temperature, for the divergence of the potential-composition curve from a straight line, or for the fact that the potentiometer used was calibrated for temperature measurements. The figure illustrates the practicability of using for purposes of gas analysis whatever electrical measuring instruments may be at hand, even though they are designed and are in use for other purposes. A. T. Larson and F. A. Ernst, of the Fixed Nitrogen Research Laboratory, kindly furnished the writers with these data.

\section{DETERMINATION OF METHANE IN AIR.}

The determination of methane in air may be made by the comparison of the conductivity of the mixture before and after passing over hot copper oxide. Some results actually obtained by this method of analysis with a manually operated balanced bridge arrangement are given in Table II.

TABLE 11.-Determination of Methane in Air.

\begin{tabular}{|c|c|c|}
\hline & \multicolumn{2}{|c|}{$\begin{array}{c}\text { Analysis by thermal-conduc- } \\
\text { tivity method. }\end{array}$} \\
\cline { 2 - 3 } $\begin{array}{c}\text { Volumetric } \\
\text { analysis. }\end{array}$ & $\begin{array}{c}\text { Uncorrected } \\
\text { reading with } \\
\text { linear scale } \\
\text { adjusted at } \\
\end{array}$ & $\begin{array}{c}\text { Analysis from } \\
\text { calibration } \\
\text { curve. }\end{array}$ \\
\hline twoints. & \\
\hline Per cent $\mathrm{CH}_{4}$. & Per cent $\mathrm{CH}_{4} \cdot$ & Per cent $\mathrm{CH}_{4 .}$ \\
0.0 & -0.03 & -0.03 \\
2.5 & 2.20 & 2.5 \\
5.0 & 4.67 & 5.0 \\
7.65 & 7.69 & 7.7 \\
\hline
\end{tabular}




\section{DETERMINATION OF OXYGEN IN MIXTURES OF OXYGEN AND NITROGEN.}

Figure I 8 shows graphically the results obtained by a procedure in which hydrogen is mixed with the gas for the double purpose of effecting a reaction and serving as an indicator of the extent

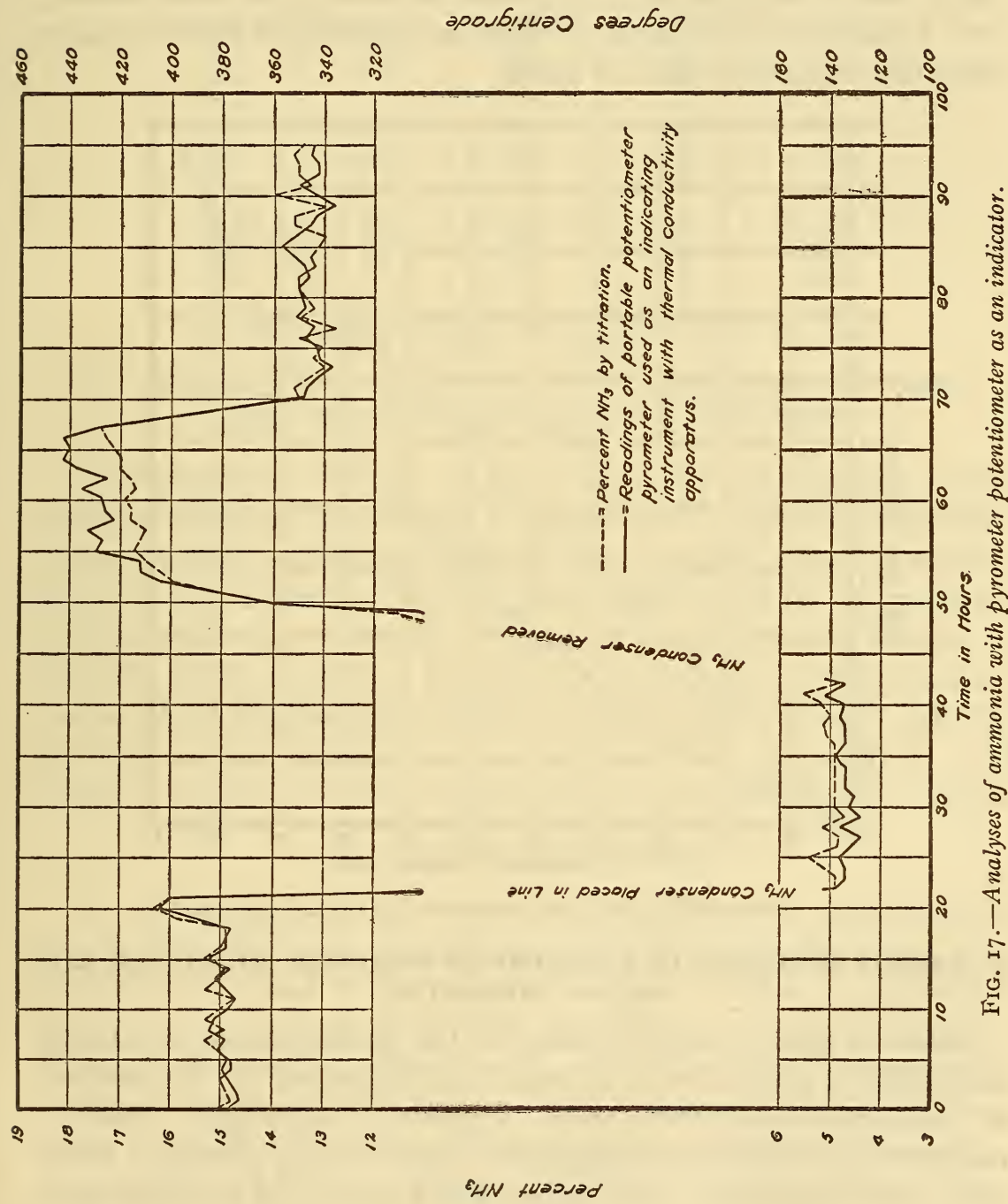

of the reaction by modifying the conductivity of the residual gas. Here oxygen in mixtures of oxygen and atmospheric nitrogen was determined by mixing the gas with an excess of hydrogen by means of the capillary mixing device, passing the mixture through a combustion tube, and comparing the conductivities of the mixture 
existing before and after the combustion. The readings depend upon the amount of hydrogen left in the nitrogen after the combustion, and since there is a change of two volumes of hydrogen for every one of oxygen, the method is extremely sensitive. It will be observed that all the points fall very close to a regular curve, which happens to have several times as great a curvature, over a range of 20 per cent, as does the calibration curve for any other determination thus far made.

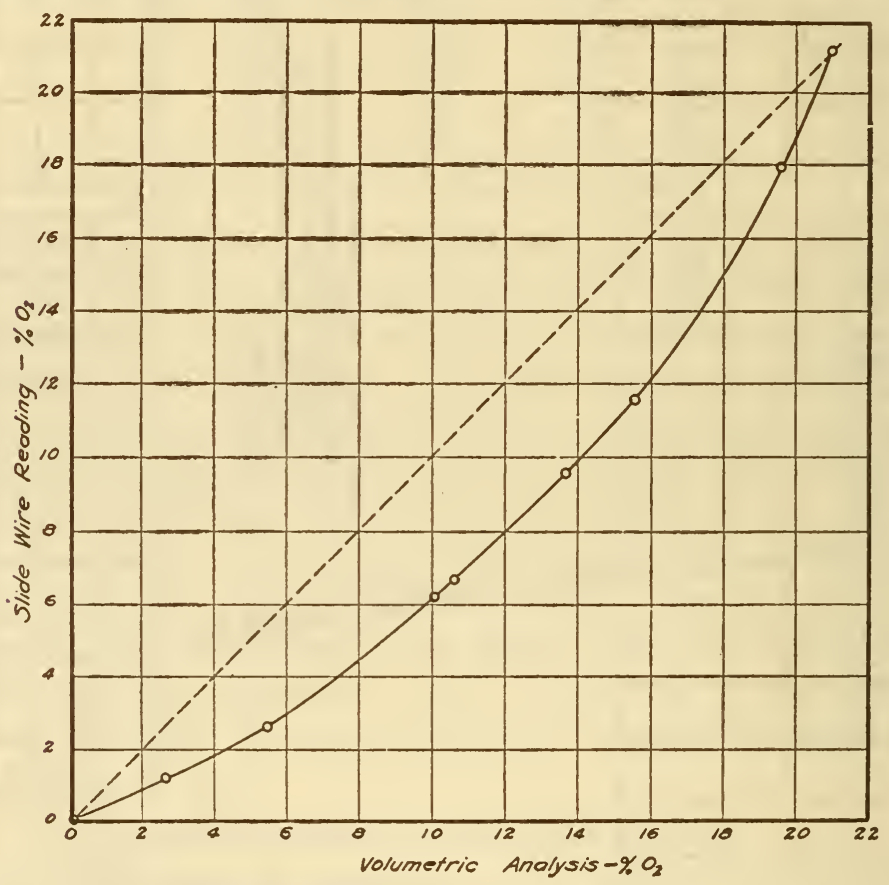

FIG. 18.-Determination of oxygen in mixtures of oxygen and nitrogen.

\section{CARBON MONOXIDE IN A MIXTURE OF NITROGEN, HYDROGEN, AND CARBON MONOXIDE.}

Table I 2 gives results obtained in the determination of carbon monoxide in a mixture of nitrogen and hydrogen by the method of successive combustion with oxygen and hydrogen. Unit A consisted of a thermal-conductivity unit, having platinum wires $0.025 \mathrm{~mm}$ in diameter and $150 \mathrm{~mm}$ in length, and a Kohlrausch slide-wire of approximately $30 \mathrm{ohms}$ resistance. Unit B consisted of a thermal-conductivity unit, having platinum wires 0.05 $\mathrm{mm}$ in diameter and $100 \mathrm{~mm}$ in length, and a 7 -ohm slide-wire from a Leeds and Northrup recording Wheatstone bridge. The extension resistances of the slide-wires had, of course, been adjusted prior to making the readings here given. 
TABLE 12.-Determination of Carbon Monoxide in a Mixture of Nitrogen, Hydrogen, and Carbon Monoxide.

\begin{tabular}{|c|c|c|c|c|}
\hline \multirow{2}{*}{\multicolumn{3}{|c|}{ Volumetric analysis. }} & \multicolumn{2}{|c|}{$\begin{array}{l}\text { Analysis by thermal } \\
\text { conductivity method. }\end{array}$} \\
\hline & & & Unit No. A. & Unit No. B. \\
\hline $\begin{array}{c}\text { Per cent } \mathbf{H}_{2 .} \\
66.1 \\
69.4 \\
70.5 \\
70.3\end{array}$ & $\begin{array}{c}\text { Per cent } \mathrm{N}_{2} \text {. } \\
33.7 \\
29.5 \\
27.4 \\
27.4\end{array}$ & $\begin{array}{c}\text { Per cent CO. } \\
0.21 \\
1.10 \\
2.13 \\
2.25\end{array}$ & $\begin{array}{c}\text { Per cent CO. } \\
0.21 \\
1.12 \\
2.13 \\
2.25\end{array}$ & $\begin{array}{c}\text { Per cent CO. } \\
\ldots \ldots \\
\ldots \ldots \\
\ldots \ldots\end{array}$ \\
\hline $\begin{array}{l}70.0 \\
68.8 \\
68.7 \\
51.8\end{array}$ & $\begin{array}{r}27.2 \\
26.6 \\
26.6 \\
5.8\end{array}$ & $\begin{array}{r}2.77 \\
4.62 \\
4.70 \\
42.43\end{array}$ & $\begin{array}{r}2.77 \\
4.63 \\
4.70 \\
42.43\end{array}$ & $\begin{array}{l}\ldots \ldots \\
\dddot{3} . .4\end{array}$ \\
\hline $\begin{array}{l}51.0 \\
50.2 \\
48.5 \\
47.4\end{array}$ & $\begin{array}{l}5.6 \\
5.6 \\
5.4 \\
5.2\end{array}$ & $\begin{array}{l}43.43 \\
44.15 \\
46.25 \\
47.40\end{array}$ & $\begin{array}{l}43.53 \\
44.24 \\
46.20 \\
47.40\end{array}$ & $\begin{array}{l}43.5 \\
44.5 \\
46.1 \\
47.4\end{array}$ \\
\hline
\end{tabular}

1 Uncofrected reading of instrument with linear scale adjusted at two points.

\section{DETAILS OF CONSTRUCTION, CALIBRATION, AND CARE OF THE APPARATUS EMPLOYED.}

In connection with the study of the many applications of the thermal-conductivity method to gas analysis, need has frequently arisen for the construction of auxiliary devices not readily obtainable on the market. Use has been freely made of suggestions coming from many sources. No claim is made of originality, or that the devices used are the best for the purpose. Nevertheless, inasmuch as helpful information on such subjects is not available to many, brief descriptions are included here of methods and apparatus which have proved successful at the Bureau of Standards.

\section{ELECTRICAL ARRANGEMENTS.}

In all applications of thermal conductivity to gas analysis herein described a comparison is made of the resistance of two electrically heated wires. Of the various possible methods for making such a comparison some form of the Wheatstone bridge is the most suitable. Figure 19 is a diagram of an arrangement using an unbalanced Wheatstone bridge with a deflection instrument. In this arrangement the two wires of the thermal-conductivity unit, $A$ and $B$, operating, respectively, in the gas for analysis and in a comparison gas, form two arms of the bridge, and two fixed resistances of manganin wire, $R$ and $R^{\prime}$, form the other two arms. A sensitive low-reading voltmeter may be used as the indicating instrument. Since the resistances of the wires $A$ and $B$ are very materially affected by the changes in the current strength, the current (or emf) must be carefully adjusted and 
maintained at a definite value. The resistances of $R$ and $R^{\prime}$ should be such that the bridge is balanced when the gas surrounding $A$ has the lowest concentration of the constituent to be determined. As the thermal conductivity of the gas changes with changes in its composition, the wires $A$ and $B$ will lose heat at different rates. This results in a difference in temperature and consequently in a difference in resistance, which, in turn, causes the bridge to be unbalanced. The indicator will show a deflection, the extent of which may be used to indicate directly the percentage of the variable constituent after an empirical calibration has been made. The range of the instrument, in terms of gas composition, may be adjusted by changing the resistance $S$ in

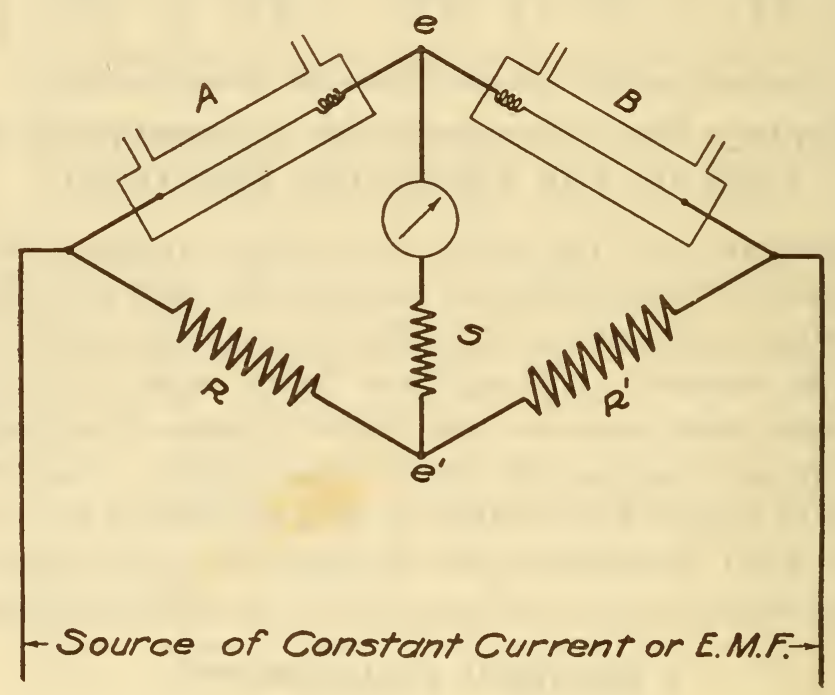

FIG. I9.-Unbalanced Wheatstone bridge with deflection instrument.

series with the voltmeter or galvanometer. A potentiometer may be used in place of the deflection instrument, as shown in Figure 20 , to determine the extent to which the bridge is unbalanced by the changes in resistance of the wires. Although a potentiometer is an expensive and rather intricate device for a measuring instrument, its wide use in pyrometry makes it especially useful in those applications of the thermal-conductivity method in which it may be desired to avoid a duplication of apparatus for gas analysis and temperature measurements.

Figure 2I $(a)$ is a diagram of an arrangement in which a calibrated slide-wire, together with extension resistances, is used with a thermal-conductivity unit as the ratio arms of the bridge. A 
galvanometer serves to indicate the balance point. The bridge is balanced by moving the contact on the slide-wire until the galvanometer gives a zero reading. After the apparatus has been calibrated the position of the contact on the slide-wire is an indication of the relative resistances of the two wires and of the amount of the constituent to be determined in the gas mixture. Thus a uniformly divided slide-wire of large range and wide open scale constitutes the measuring instrument.

If an alternating-current galvanometer is substituted for the galvanometer as the indicating instrument, the use of an alternating current with the balanced bridge is possible. Figure 2I (b) is a diagram of an arrangement in which the apparatus is connected

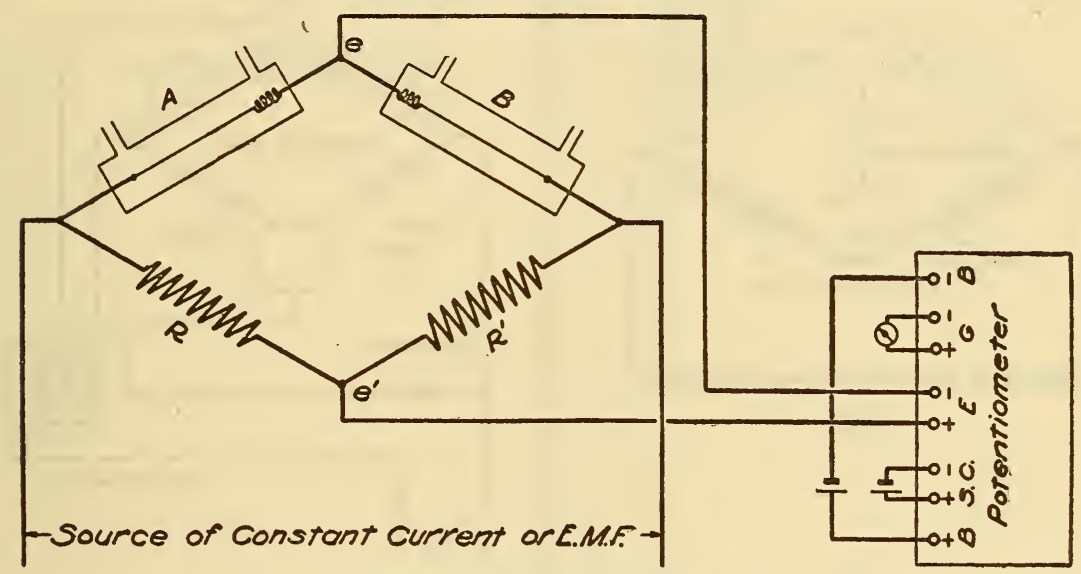

FIG. 20.-Unbalanced Wheatstone bridge with potentiometer.

with an alternating current lighting circuit. A detailed description of the ballast resistance is given further on.

Each of the three arrangements has advantages and limitations peculiar to itself. The first mentioned is perhaps the simplest, but the other two are, in general, more flexible. However, the choice of the electrical arrangement for any particular application is not a matter of great importance, since any one of the three can usually be made to give satisfactory service.

\section{CONSTRUCTION OF THE THERMAL-CONDUCTIVITY UNIT.}

In Figure 5 was shown the manner in which Shakespear's thermal-conductivity unit is constructed. The units developed by all the other investigators employ straight wires instead of helices. The designs adopted for the Bureau of Standards instruments have resulted from attempts to eliminate or avoid difficulties encoun- 
tered with earlier forms of construction. Ruggedness, freedom from secular changes, and ease of construction have been given primary consideration. Figure 22 shows a section through a cell of the form preferred for most purposes.

In order to secure high sensitivity with a small consumption of energy, the wires exposed to the gas mixture for analysis and to the comparison gas should preferably be of small diameter and made from metals having a high temperature coefficient of resistance. Wires of nickel, tungsten, and platinum of various diameters and lengths have been successfully employed. Platinum, however, on account of its freedom from reaction with most gases, low thermoelectric power against copper, permanence of physical

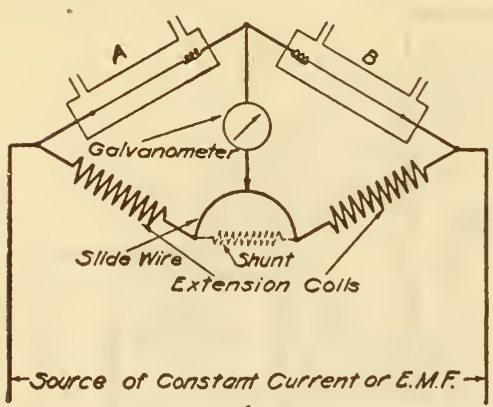

(a)

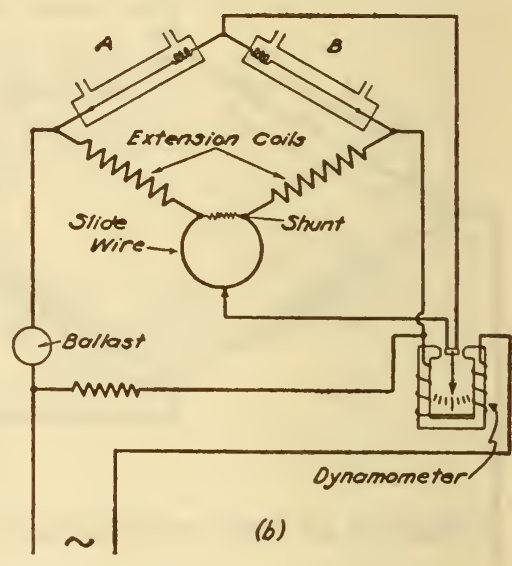

(b)

Fig. 21.-Balanced Wheatstone bridge.

properties, and the ease with which it can be fused or soldered to supporting and connecting terminals, has been selected as the metal most usually suitable. Care must be taken that the platinum is of good quality, for even slight impurities may greatly reduce the temperature coefficient of resistance. The best diameter and length to choose for the wires depends upon the current strength to be employed and the sensitivity desired. Wires having a diameter of $0.05 \mathrm{~mm}$ and a length of $100 \mathrm{~mm}$ have usually given ample sensitivity without the necessity of using excessive temperatures. To one end of each of the wires is fused a copper wire of No. 30 A. w. g., $5 \mathrm{~cm}$ in length, wound into a helical spring and joined by fusion to a copper wire of No. I6 A. w. g. The helical copper springs serve to keep the platinum wires stretched along the axes of the cells in which they are mounted, regardless of the elongation 

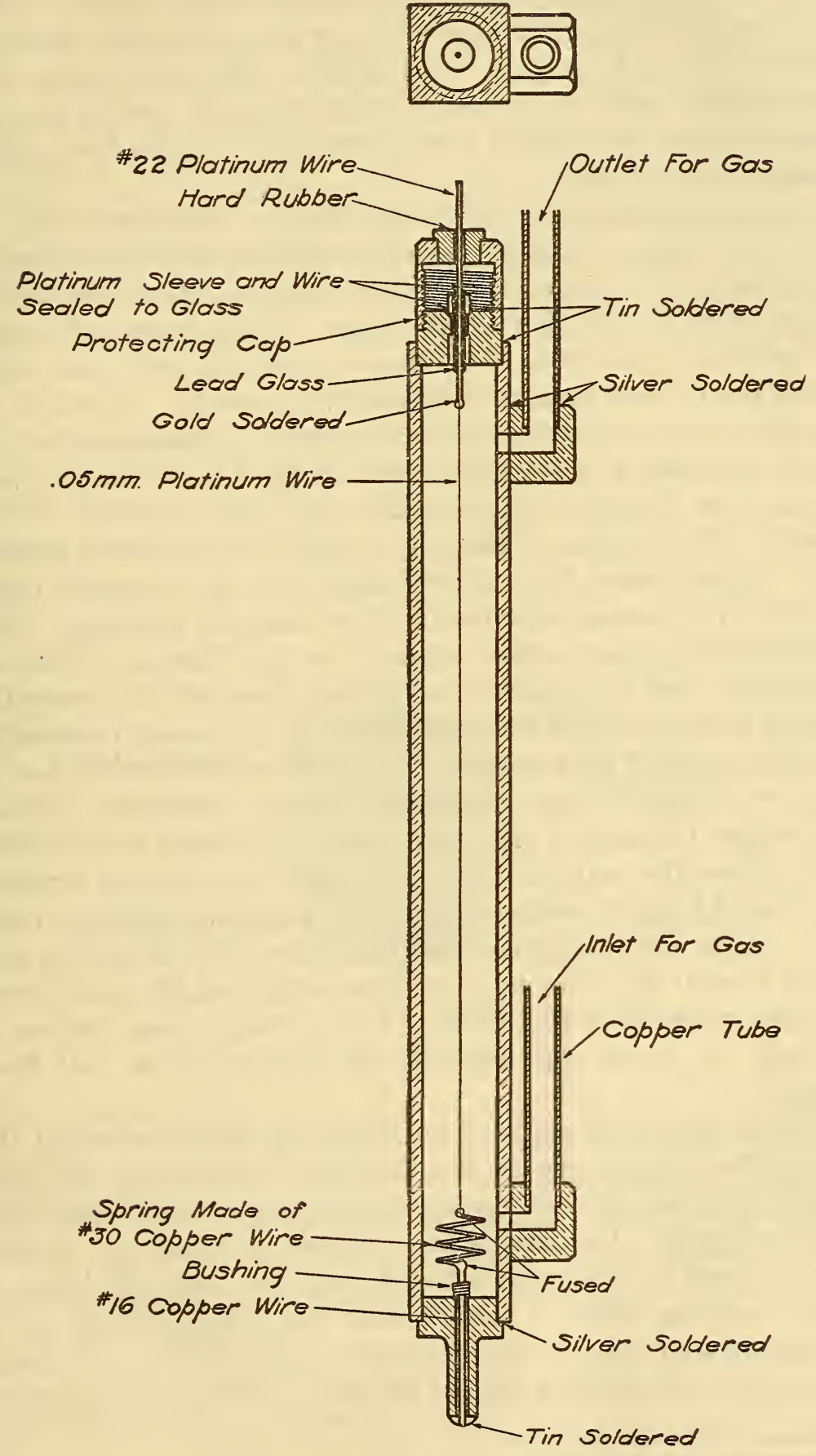

FIG. 22.-Section of thermal-conductivity cell. 
of the platinum wires when heated by electrical currents. The other ends of the fine platinum wires are gold soldered to platinum wires of No. 22 A. w. g., $3 \mathrm{~cm}$ in length. This construction concentrates the resistance in the platinum wires and renders the connections to the ends of the wires permanent and free from objectionable thermal emf.

The gas chambers in which these wires are stretched consist of cylindrical holes, Io $\mathrm{mm}$ in diameter, drilled lengthwise through a metal bar I $2.5 \mathrm{~mm}$ square and $\mathrm{I} 25 \mathrm{~mm}$ long. Inlets and outlets are provided for the circulation of gas. Rolled brass and copper are suitable metals when noncorrosive gases are used; cast metal should not be used because of its probable porosity. To minimize the effect on the calibration of any possible displacement of the active wires and to reduce the power required to produce a given temperature difference between the wire and the walls of the chamber, the diameter of the cells is made the maximum permissible. Experiments have shown that when the diameter much exceeds I cm, convection currents cause unsteady readings. This unsteadiness appears rather suddenly as the diameter of the cell is increased, and the value of the limiting diameter is in somewhat striking agreement with the thickness of the stationary conducting gas film assumed by Langmuir ${ }^{11}$ in his discussion of the loss of heat by conduction and convection from a cylindrical surface. The copper terminal of the active wires is soldered to a bushing which closes the bottom of the cell, while the platinum terminal is insulated from the walls of the cell by a small glass sleeve fused to it. Rigid and gas-tight connection to the cell is secured by first fusing a small platinum tube over the outside of the glass sleeve and then soldering it to a bushing hermetically closing the top of the cell. A metal cap protects the glass-platinum seal from injury.

Use has also been made of an insulating joint devised in the Geophysical Laboratory of the Carnegie Institution, ${ }^{12}$ and primarily intended for introducing thermocouple leads into highpressure bombs. Its construction is shown in Figure 23. A hole about $5 \mathrm{~mm}$ in diameter is bored part way into the brass or copper bushing, which is used to close the top of the cell, and a cylinder of soapstone or talc is turned to fit this hole. Through the soapstone is drilled a hole of the same diameter as the copper

11 Langmuir, Phys. Rev., 34, p. 40I; I9r 2.

12 Johnston and Adams, Am. J. Sci., 31, p. 506; I9II. 
terminal wire, which is then threaded through this hole. A small hard fiber sleeve is placed in the bushing to insulate the terminal wire where it emerges from the cell. The soapstone cylinder is inserted in the bushing and rammed firmly into position by applying a force of several tons; this force is communicated through a small hardened steel plunger of the same diameter as the stone cylinder. The plunger is drilled so as not to injure or interfere with the terminal wire. In order to insure a gas-tight joint around the wire, either one of two procedures can be followed. The soapstone cylinder may be made in two or more
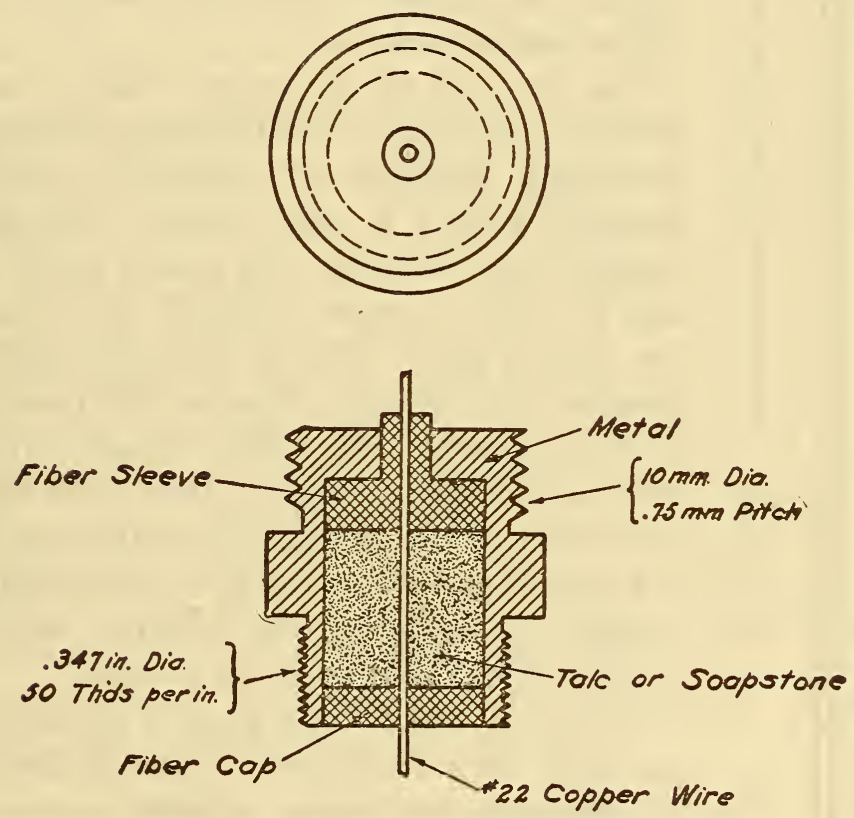

FIG. 23.-Talc insulating joint.

parts and the holes for the wires staggered slightly, or powdered talc may be pressed into place instead of the cylinder. Finally, a thin washer of fiber may be inserted under pressure to prevent particles of talc from becoming loosened and later dropping into the cell. If a suitable press is not available, an ordinary bench vise may be used for applying sufficient force to ram the soapstone or talc into a tight joint.

This type of insulating joint permits a form of construction illustrated in Figure 24 in which a separately mounted platinumwire system is inserted as a unit into the gas chamber. A No. $30 \mathrm{~A}$. w. g. copper wire, $5 \mathrm{~cm}$ long, is fused to one end of a plati- 
num wire of $0.05 \mathrm{~mm}$ diameter, and $100 \mathrm{~mm}$ in length and is then wound into a helical spring. To the other end of the platinum wire is attached, by fusion, a short length of No. $20 \mathrm{~A}$. w. g. copper wire. For fusing the copper leads to the small platinum wires a small gas-air flame from a laboratory blast lamp is ordinarily

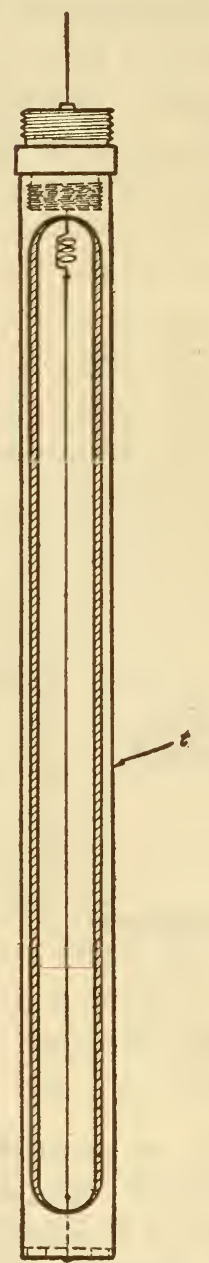

FIG. 24.-Separable mounting for conductivity cell. employed. A small bead of molten metal is formed on the copper wire, and the end of the platinum wire is inserted before the bead solidifies. Only the tip of the platinum wire is allowed to enter the flame, and the joint is removed as quickly as possible. The whole operation requires only a few seconds.

The free end of the copper helix is next soldered to the end of the insulated terminal wire previously prepared as described above. The encasing tube, $t$, is then screwed tightly to the bushing, the platinum wire placed under tension, and the lower copper terminal wire soldered to the bottom plug. The arrangement may now be inserted into the gas chamber, the open portion of the encasing tube being turned toward the inlet and outlet openings so that there will be no restriction to the passage of gas through the cell. A gas-tight seal at the top of the cell can be easily secured by soldering the bushing with a lowmelting alloy, such as Wood's metal.

A cell, in which only glass is exposed to the gas, has been developed for use in the analysis of mixtures containing a highly corrosive gas, such as chlorine. One form of this cell is shown in Figure 25. It consists essentially of a thin walled glass tube, $A$, of small diameter closed at one end and at the other expanded and sealed to a larger tube, $B$. This outer tube has an internal diameter of $\mathrm{ro} \mathrm{mm}$ and forms the chamber through which the gas for analysis is passed. $I$ and $O$ serve as inlet and outlet tubes, respectively. Two enameled copper wires are led through and cemented to a fiber bushing. One of these wires extends to the bottom of the inner glass tube, $A$, and has the fine platinum wire wound around, but insulated from it by the enamel coating except 
at the lower end where the wires are soldered together. The other end of the platinum spiral is soldered to the second copper terminal wire. A split metal tube, attached to the fiber bushing, slips over the outer glass tube, $B$, so as to keep the wires in place. The space between the wires and the inside of the glass tube is filled with oil and the cell is immersed in an oil bath maintained at a constant temperature. This particular cell has a lag of about one minute; about the same length of time is required to completely sweep out the cell with gas.

\section{INDICATING AND RECORDING INSTRUMENTS.}

In general, the types of indicating and recording millivoltmeters, potentiometers, and balanced Wheatstone bridges which have been developed for use in pyrometry can be easily adapted for use with the thermal-conductivity method for gas analysis. The choice of the instrument to be used in any particular case is governed by considerations of price and quality in addition to the suitability of the instrument with the electrical circuit used. A complete and detailed description of the instruments made by American manufac-

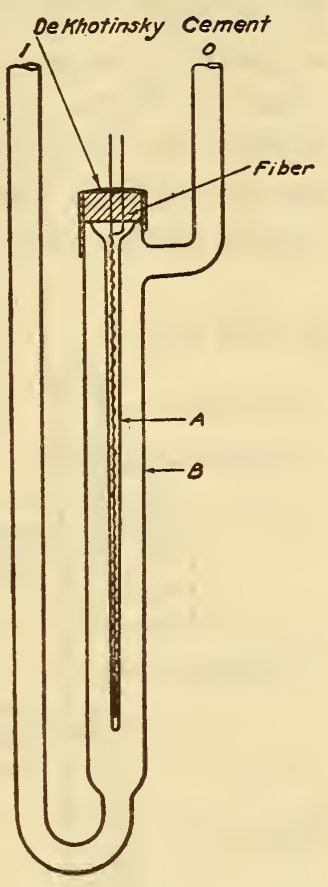

Fig. 25.-Glass cell for use with corrosive gases. turers in another publication of the Bureau of Standards ${ }^{13}$ renders further description here unnecessary.

\section{SOURCE AND ADJUSTMENT OF CURRENT.}

Since the wires in the two cells of a thermal-conductivity unit are usually surrounded by gases of different thermal conductivities, the ratio of their resistances will not remain constant with variations in current strength. It is, therefore, important that either the emf across the bridge or the strength of the current through the bridge be maintained at a certain definite value. To avoid the necessity for frequent adjustment, a storage battery should be used as the source of current. The use of a storage battery requires some provision for recharging or for always keeping it

${ }^{13}$ Foote, Fairchild, and Harrison, Pyrometric Practice, B. S. Tech. Paper No. 170; 1921. For sale by Superintendent of Documents, Government Printing Office, Washington, D. C. Price 60 cents. $57033^{\circ}-24-4$ 
in a fully charged condition. If the apparatus is of the recording type and is used continuously, it is advantageous, both with respect to the amount of attention required and the life of the battery, that the latter plan be adopted. When a source of direct current is available a lamp bank affords a simple and inexpensive means of regulating the charging current. The diagram in Figure 26 shows a suitable connection. The current through the lamps should be slightly in excess of that required by the gas-analysis apparatus, but not sufficient to cause frothing, violent gasing, or overheating. In case an alternating current is

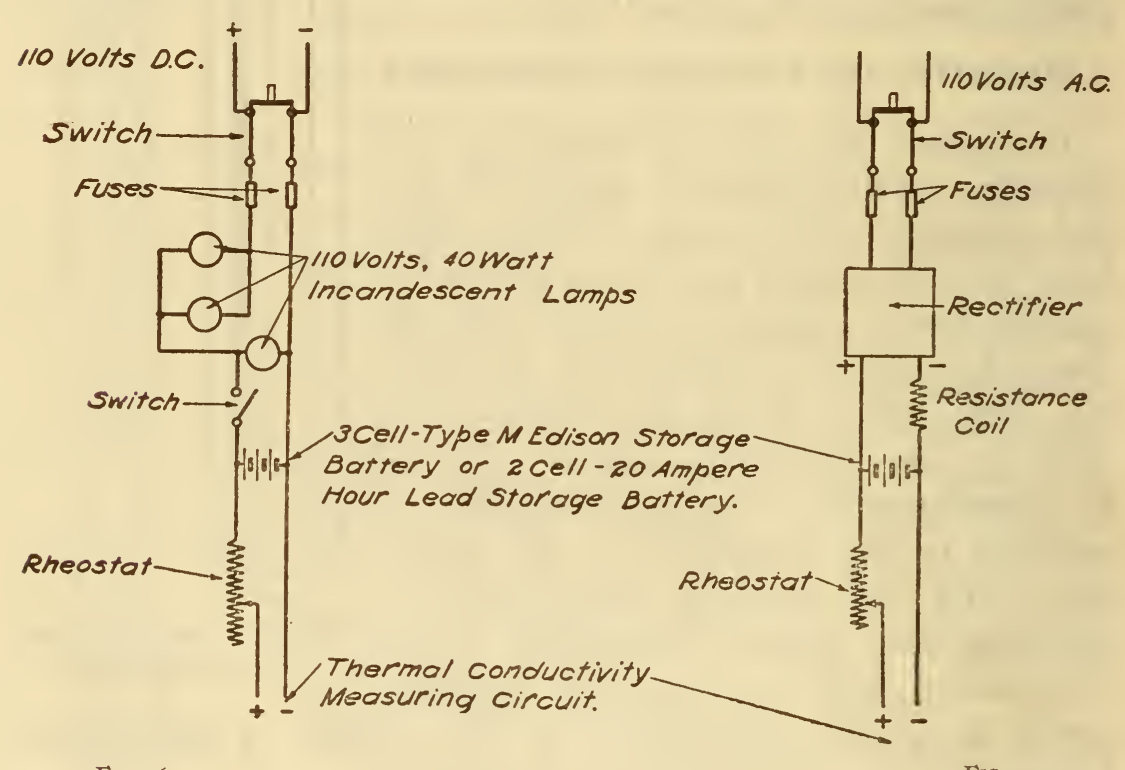

Fig. 26.

Fig. 27.

FIGs. 26 AND 27.-Connections for floating storage battery from direct and alternating current supply.

the only source of supply available, a thermionic rectifier, such as the "Tungar" or "Rectigon," or some form of vibrating rectifier can be used to convert the alternating to direct current. Figure 27 is a diagram of the connections that may be used. The charging current is limited to any desired value by means of the resistance unit connected in series between the battery and the output side of the rectifier. By floating the battery in either of the ways just described the emf of the battery will risr. until the battery is fully charged, after which it will remain very constant, even though the supply voltage fluctuates over a considerable range. The voltages actually supplied to a measuring circuit for 
gas analysis by a battery floated from a direct current and from an alternating-current lighting circuit with various line voltages are shown in Table $\mathrm{I} 3$.

TABLE 13.-Effect of Variations in Line Voltage on Voltage Supplied to Gas-Analysis Bridge.

\begin{tabular}{|c|c||c|c|}
\hline $\begin{array}{c}\text { Line } \\
\text { voltage. }\end{array}$ & $\begin{array}{c}\text { Voltage } \\
\text { supplied to } \\
\text { gas-analy- } \\
\text { sis bridge. }\end{array}$ & $\begin{array}{c}\text { Line } \\
\text { voltage. }\end{array}$ & $\begin{array}{c}\text { Voltage } \\
\text { supplied to } \\
\text { gas-analy- } \\
\text { sis bridge. }\end{array}$ \\
\cline { 1 - 2 } D. C. & & A. C. & \\
i11 & 2.80 & 123 & 2.80 \\
110 & 2.80 & 110 & 2.80 \\
100 & 2.80 & 100 & 2.80 \\
90 & 2.80 & 90 & 2.78 \\
85 & 2.80 & 85 & 2.77 \\
0 & 2.70 & 0 & 2.70 \\
\hline
\end{tabular}

The readings were taken in each case five minutes after the line voltage was varied. Rapid fluctuations in the line voltage, amounting to 30 per cent, produced no effect on the battery voltage that could be observed with the voltmeter.

The remarkable characteristics of iron-wire ballast resistances afford another convenient method for automatically controlling the current or emf supplied to the gas-analysis apparatus. In Figure 28 a typical potential-current curve of a ballast resistance of this type is plotted. The current is at first nearly proportional to the voltage, then increases more slowly, becoming practically constant for a considerable increase in potential; finally, as the wire begins to glow, the current again increases as the potential is raised. The sudden rise in the curve is especially interesting, since it indicates that for a certain value of the current the potential drop may have any value over a considerable range. This value of the current is the proper operating value for the ballast. Because of the lag of these ballasts they do not afford satisfactory control when the voltage fluctuates rapidly.

The best value of the constant emf (or current) to be used with the gas-analysis apparatus depends upon the gases of which the conductivities are to be compared. It was shown in Figure 2 that with gases of low conductivity the temperature of the wires will be much higher for a given emf (or current) than with gases of high conductivity. If the temperature rises too high, it may be expected that the wires will undergo secular changes, or, in certain cases, cause reactions to take place between constituents of the gas mixture. On the other hand, the curves show clearly that there is a marked increase in the sensitivity with the in- 
crease in temperature. For most work an emf of 2.5 or 3.0 volts across the bridge has been found to give sufficient sensitivity without heating the wires to excessive temperatures.

In order to determine whether the emf (or current) is correctly adjusted to the value for which the apparatus is calibrated, a voltmeter (or ammeter) may be used as an indicator. The introduc-

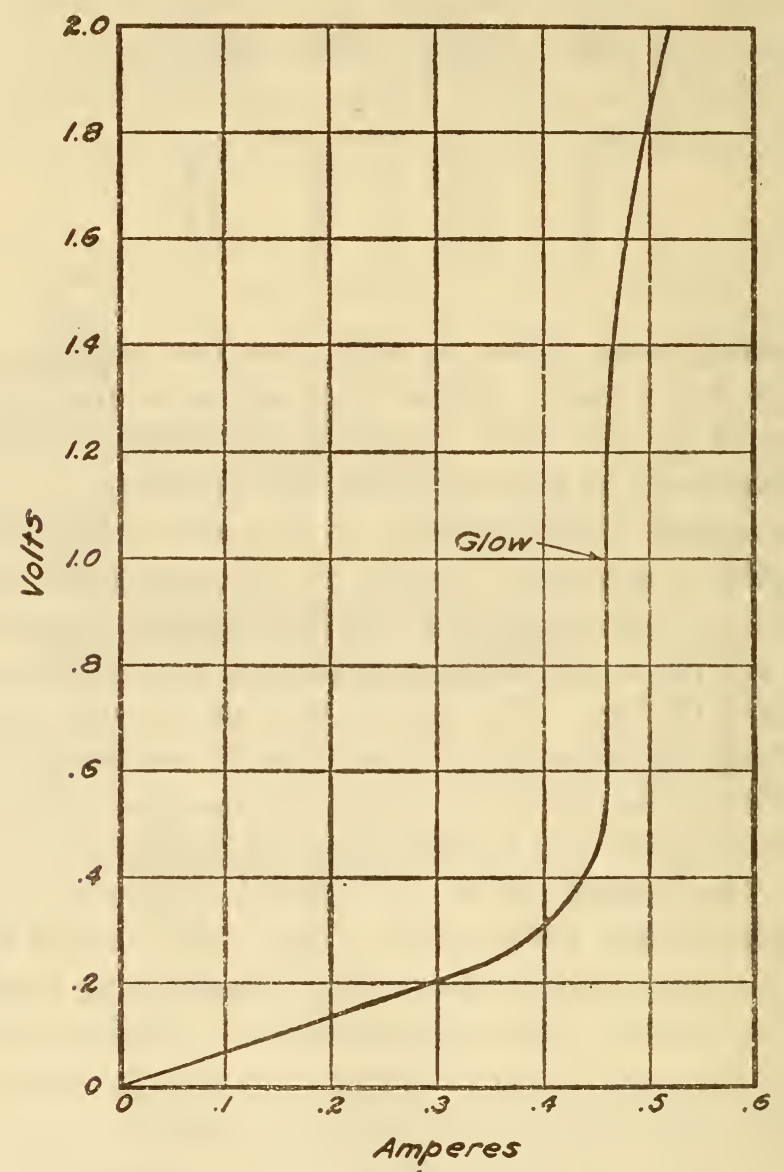

Fig. 28.-Potential-current curve of ballast resistance.

tion of an additional indicating instrument can, however, be avoided in each of the three electrical arrangements mentioned. In the case of an unbalanced Wheatstone bridge with a deflection instrument, the indicator may be switched, by means of a key, across a drop coil connected in series between the battery and the bridge, as shown in Figure $29(a)$, so as to determine the current strength, or across the terminals of the bridge in series with a resistance coil, as shown in Figure 29 (b), so as to determine the 
applied emf. Adjustment can then be made by varying the resistance of a rheostat in the battery circuit until the deflection of the pointer of the indicator reaches a certain mark on the scale.

Similarly, in the case of the unbalanced Wheatstone bridge with a potentiometer, the potentiometer can be switched as shown in Figure 30, and the rheostat adjusted until the potentiometer indicates a predetermined emf across the drop coil.
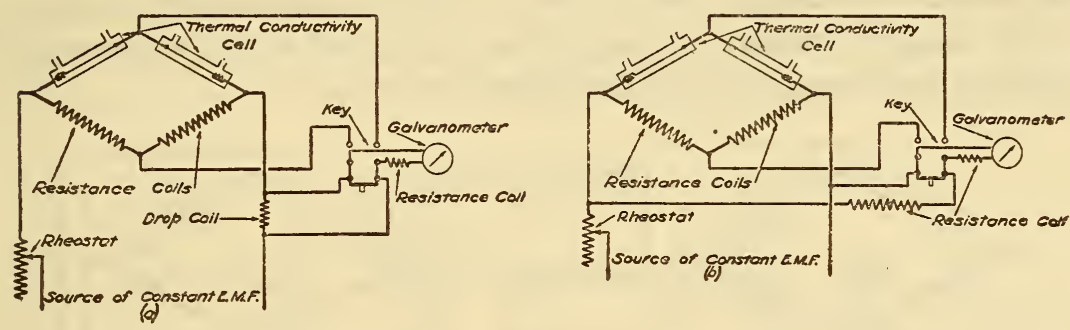

FIG. 29.-Unbalanced bridge with deflection instrument.

When the balanced Wheatstone bridge arrangement is used a somewhat different procedure is necessary. One method which has proved especially satisfactory for adjustment to constant emf makes use of the different current-resistance relations of untreated carbon and tungsten filament lamps. A bridge is arranged as shown in Figure 3I (a) in which two arms are manganinresistance coils and the other two are low-voltage carbon and tung-
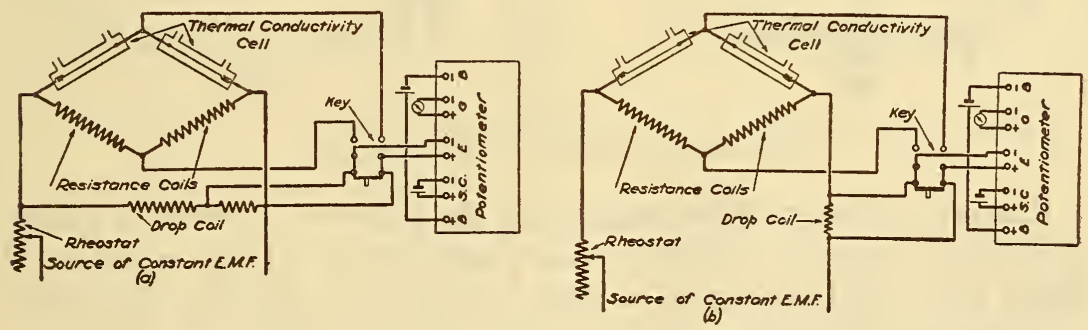

FIG. 30.-Unbalanced bridge with potentiometer.

sten filament lamps, respectively. The resistances of the manganin coils are of such value that the glavanometer gives no deflection when the desired voltage is applied to the terminals of the bridge. Any change in the voltage will then alter the current through the lamps and produce a deflection of the galvanometer. By means of the key shown in the diagram one galvanometer can be connected in turn with either the voltage-adjustment bridge or the gas-analysis bridge. If the lamp-bridge arrangement is placed 
in series with the battery as in Figure $3 \mathrm{I}(b)$, the current can be adjusted to a constant value in a similar manner. Because of the relatively large fall of potential across such an arrangement, the device is generally used for constant potential rather than constant current adjustment. Even very small changes in potential or current will produce a considerable deflection of the galvanometer when a suitable bridge and an ordinary portable galvanometer are used. Since the loss of heat from the filaments of the lamps is mainly by radiation, the device is not appreciably affected by changes in room temperature. ${ }^{14}$

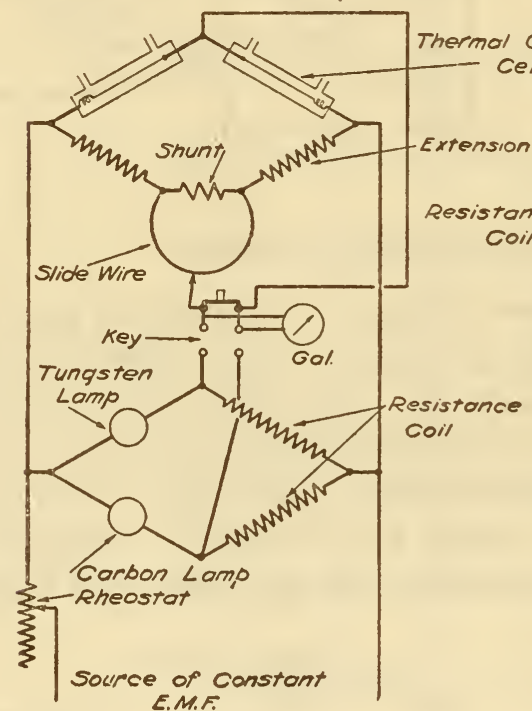

(a)

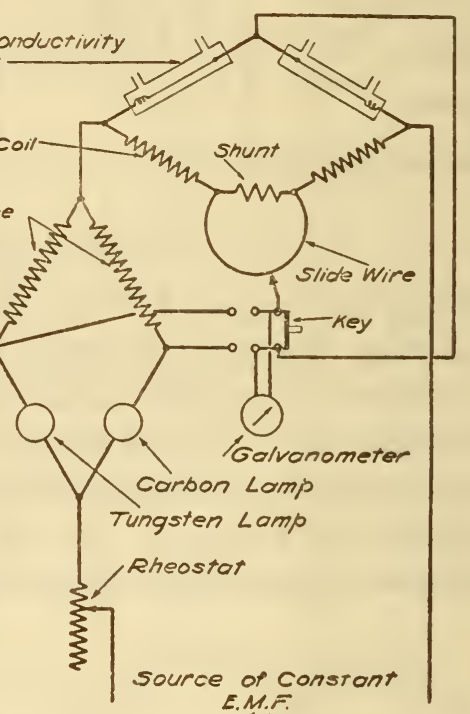

(b)

Fí. 3I.-Balanced bridge arrangement.

Rheostats designed for regulating the filament current of radioreceiving vacuum tubes are now available in a large number of forms and can be used very satisfactorily to vary the resistance of the battery circuit.

\section{MAINTENANCE OF CONSTANT TEMPERATURE.}

The rate at which heat is conducted through the gas in the cells of the thermal-conductivity unit depends not only on the conductivity of the gas, but also upon the difference in temperature between the wire and the walls of the cell. The fact

14 This device is essentially the same as the old Howell indicator. Other applications of a similar lamp bridge are mentioned by T. H. Amrine in his paper on "Incandescent lamps as resistances," Proc. A. I. E. E., 31, p. 1247; rgr2. 
that a comparison of the temperature of two similarly mounted wires is made in all applications of the thermal-conductivity method assures considerable compensation for the effects of changes in room temperature. If the cells are carefully constructed, no further compensation for changes in temperature is needed in many cases, especially when a high degree of accuracy is not essential. Frequently, however, an additional compensator is necessary or means must be provided for the maintenance of the thermal-conductivity units at a constant temperature. In the laboratory a constant temperature is easily secured by mounting
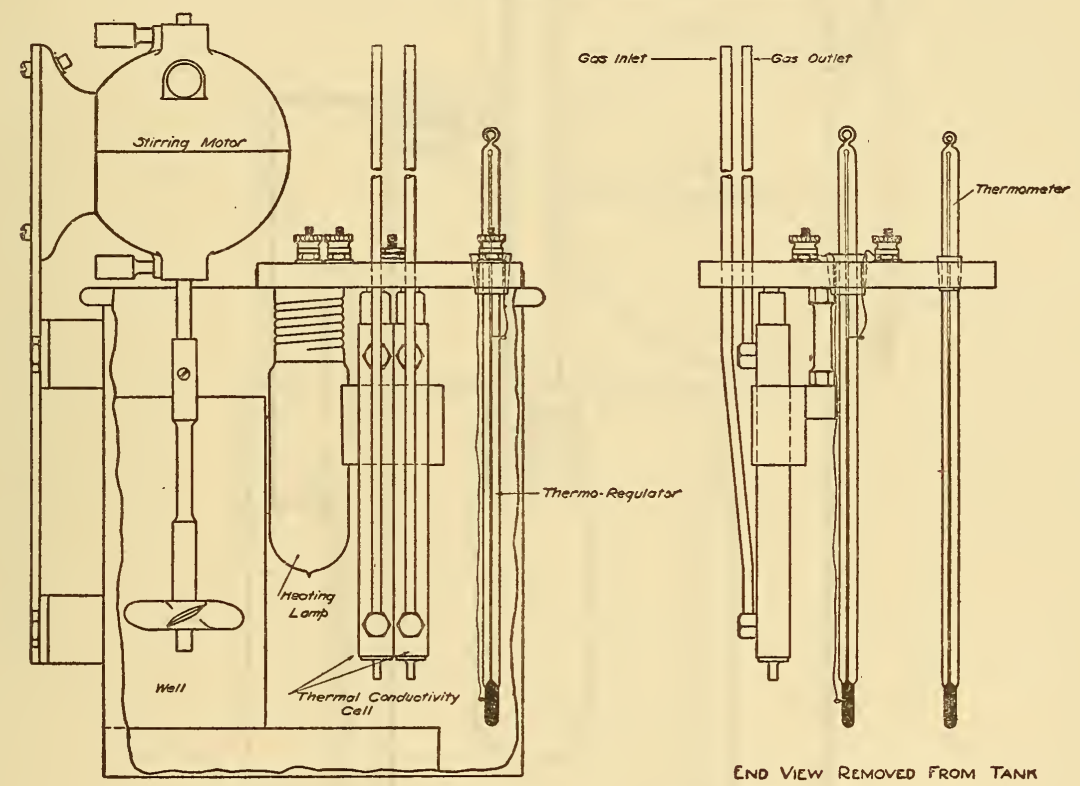

Side VIEW of TANK WITH SIDE Cut AMaV

FIG. 32.-Oil-bath thermosiat.

the units in an electrically-heated oil or air-bath thermostat. A simple thermostat of the former type, which was employed in obtaining the data given in Figures 2 and 3, is shown in Figure 32. The tank is made of sheet metal and is filled with transformer oil. Since the temperature of the room in which the apparatus is located may vary between wide limits during the course of the year, it is advisable to maintain the bath at a temperature which is always higher than that of the room, as it is usually easier to heat than to cool the bath. Temperature regulation may be automatically controlled by means of any one of a number of types of thermoregulator. A simple mercury thermometer 
type of thermo-regulator, with which it has been possible to hold a bath temperature constant to $0 . I^{\circ} \mathrm{C}$., is shown in Figure 33 , together with a diagram of the electrical connections of the thermostat.

When it is impractical to employ an oil-bath thermostat, a suitable bimetal thermoregulator may be used as a means for

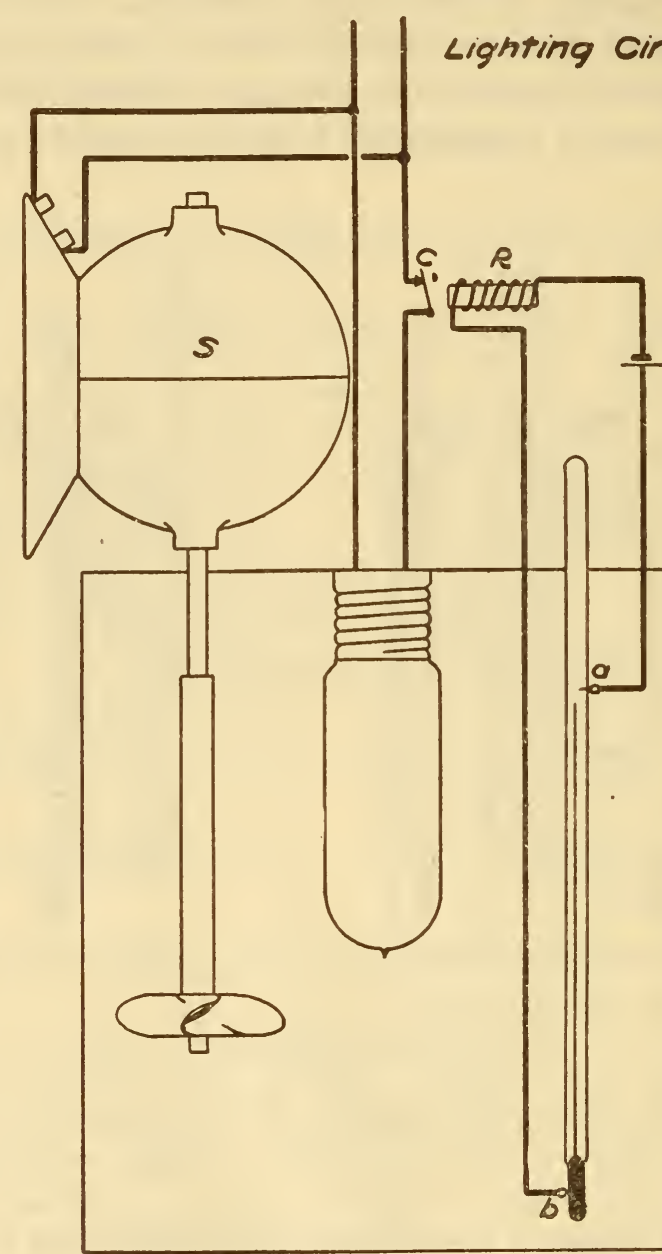

FIG. 33.-Diagram of thermostat connections.

controlling the temperature. Figure 34 illustrates one simple method by which this may be accomplished. Two bimetal strips (brass and steel), fitted with platinum contacts, are attached to a metal plate screwed to the casting that clamps the conductivity cells. The bimetal strips are insulated from the plate by mica and fiber. A heating coil is wound noninductively 

Technologic Papers of the Bureau of Standards, Vol. 18

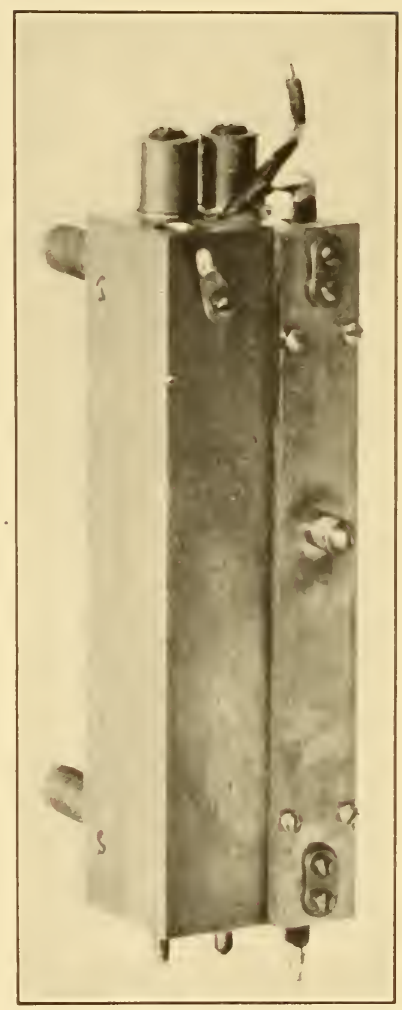

FIG. 34 (a).-Thermostuted unit. 
around a fiber core, inserted in a hole drilled in the clamp, and is surrounded with paraffin. The heating coil is connected in series with the bimetal strips to a source of current. When the strips are cold, the contact points are in electrical connection and current flows through the heating coil. As the heat from the coil raises the temperature of the clamp, the bimetal strips also rise in temperature and bend so as to break the connection between the contact points when the unit is heated to the desired temperature. When the clamp cools slightly, connection is again made and current again flows through the heating coil as before. In this manner the temperature of the unit is kept substantially constant. A small incandescent lamp is frequently connected in series with the heating coil to limit the heating current and to provide an indication of whether the thermoregulator is functioning. Adjustment of the regulator is effected by means of the screw which presses against one of the bimetal strips.

In some instances it has been found advantageous to use the thermalexpansion of the unit as a means of controlling its temperature. A bowed strip of invar is attached directly to the unit with a screw motion at one end for the adjustment of the bow. Platinum contact points, insulated with glass-platinum seals, are fastened to the invar strip and to a bracket attached to the

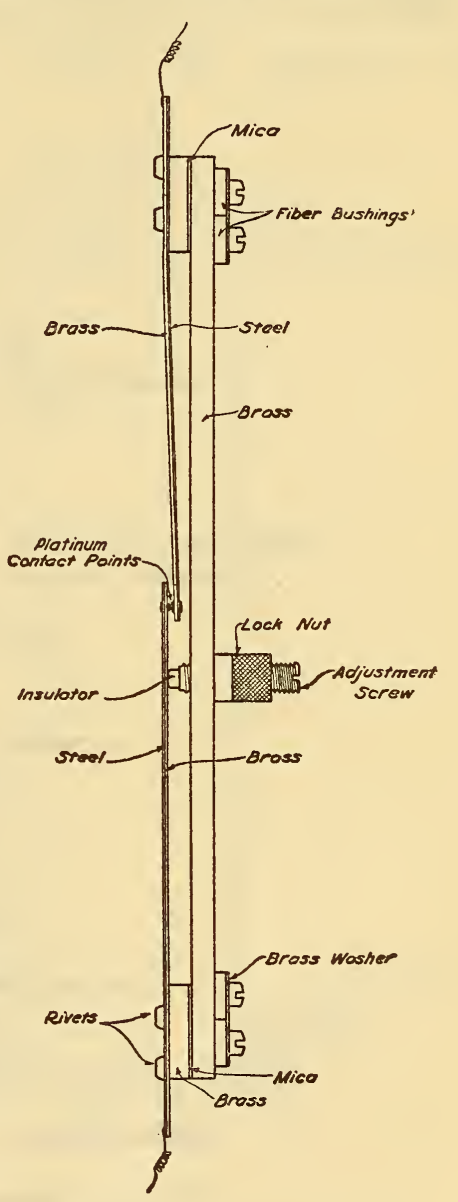

Fig. 34 (b).-Detail of thermoregulator.

unit. The heating coil is wound noninductively around the unit The construction may be seen in Figure 35. When the unit is cold the contact points touch one another and current flows through the heating coil. As the heat from the coil raises the temperature of the unit, the elongation of the metal bends the invar strip so as to open the circuit between the contact points. 
It is possible to control the temperature to about $\mathrm{I}^{\circ} \mathrm{C}$. by this regulator. Because of the possibility of changes in the thermal properties, some metals and alloys are unsuitable for an expansion type of regulator. Well-annealed copper, however, is quite satisfactory, though the adjustment of the regulator should be checked frequently with a thermometer.

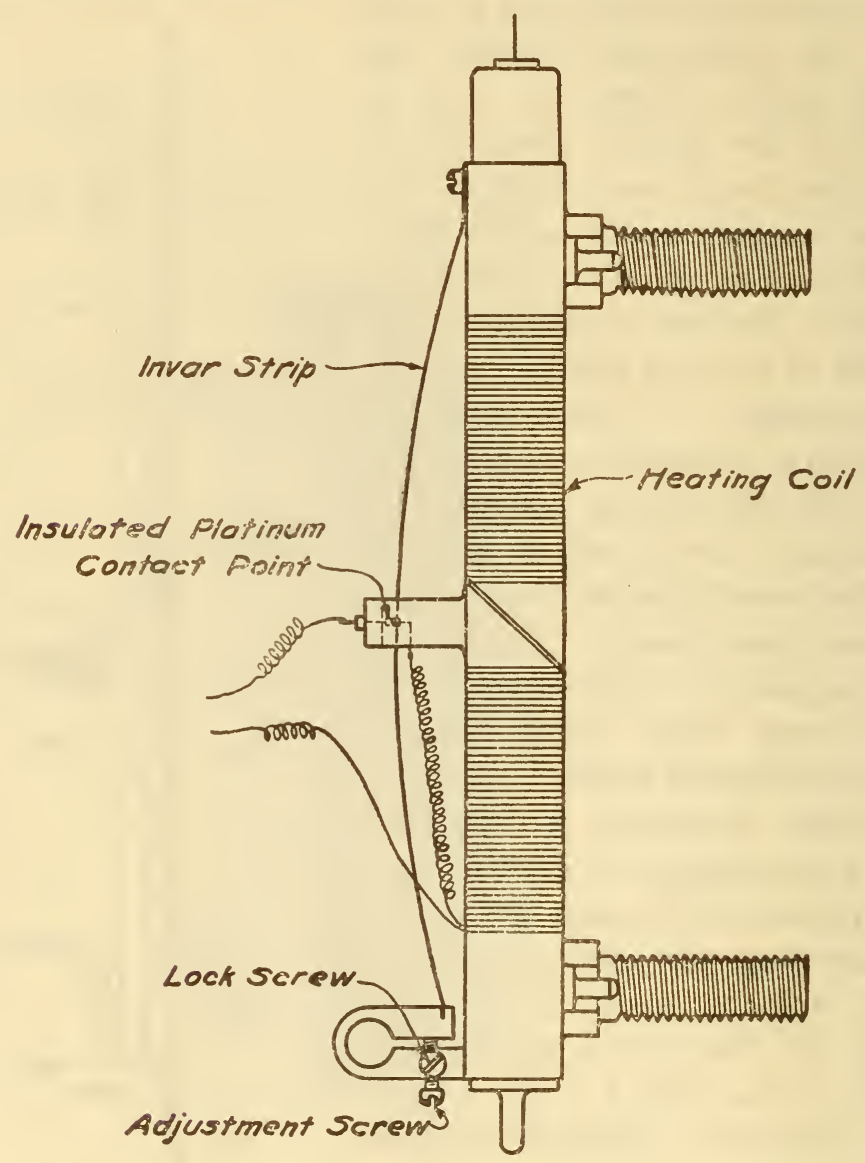

FIG. 35.-Thermostated unit with bow regulator.

It is sometimes convenient to maintain a thermal-conductivity unit at a constant temperature by surrounding the unit with a jacket through which wet steam is discharged at atmospheric pressure. An arrangement of this kind is especially desirable when water vapor is an important constituent of the gas mixture undergoing analysis and steam is readily available. Figure 36 shows a construction that was used with a recording instrument in an investigation extending over a period of several months. 
The thermoregulators which have been described here are all simple contrivances which have been found convenient for the rough adjustment required by this method.

\section{REGULATION OF FLOW OF GAS.}

It has been pointed out that some heat is carried away by the current of gas when there is a flow of gas past the wires of the thermal-conductivity units. However, unless the apparatus is

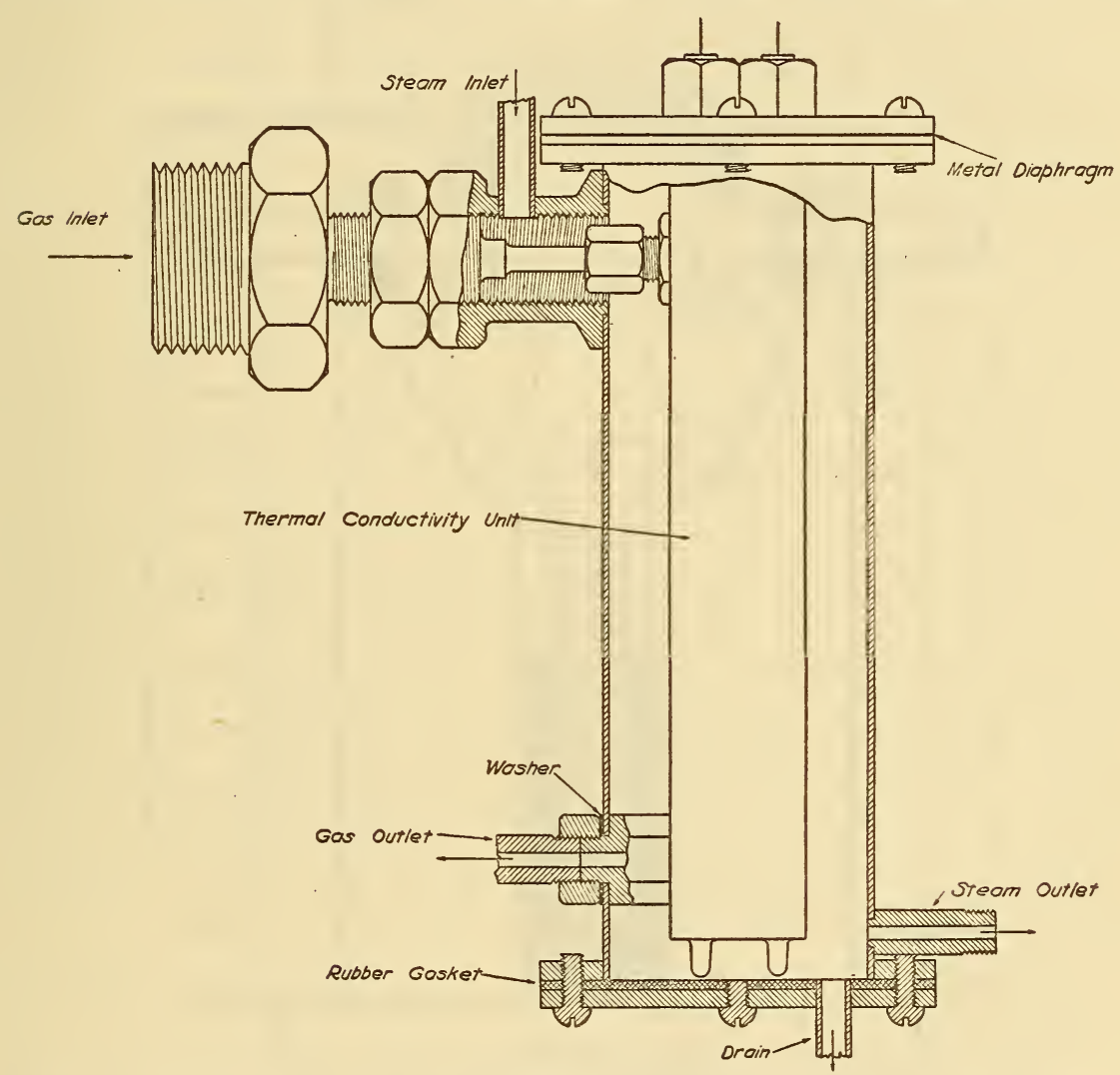

Fig. 36.-Steam jacket for unit.

especially designed for high sensitivity no appreciable cooling occurs with rates not exceeding $20 \mathrm{cc}$ per minute. To reduce the lag between a change in the composition of the gas undergoing analysis and the corresponding indication of the analytical apparatus, it is sometimes advantageous to sweep out the sampling line with a strong current of gas and to by-pass what is needed for analysis. By means of liquid seals the rate of flow can usually be kept sufficiently constant in spite of small fluctuations in the 
pressure. A differential manometer affords a ready means for observing the rate of flow. Figure 37 illustrates one convenient form in which the difference in the heights of the liquid indicates the rate at which gas is passing through the capillary. A. F. Benton ${ }^{15}$ has discussed the factors entering into the design of such flow meters for small rates of flow.

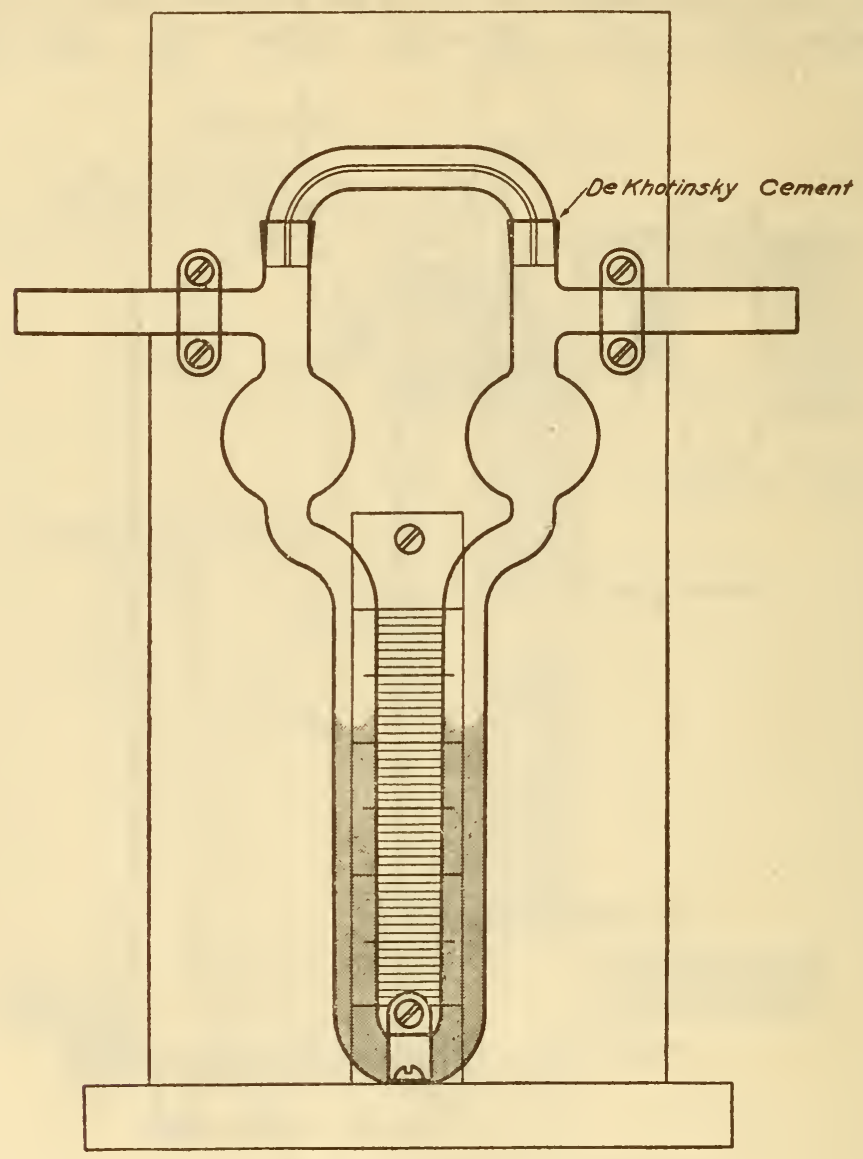

FIG. 37--Flow meter.

\section{EFFECT OF PRESSURE.}

Although the thermal conductivity of a gas is independent of its pressure over considerable ranges of variation, it does not follow that the resistance of a wire mounted in a thermal-conductivity cell will be unaffected by changes in the pressure of the surrounding gas. In fact, the data plotted in Figure 38 show that the dissipation of heat from an electrically heated wire surrounded by air

${ }^{15}$ Benton, Jour. Ind. and Eng. Chem., 11, p. 623; 1919. 
in a thermal-conductivity cell increases as the pressure is raised. The increase in the power expended in keeping the wire at a constant temperature is probably a result of the correspondingly greater thermal convection following a rise in the pressure of the gas. This is indicated by the unsteadiness of the readings at high pressures. Fortunately, however, the effects of variations in pressure amounting to several centimeters of mercury are not

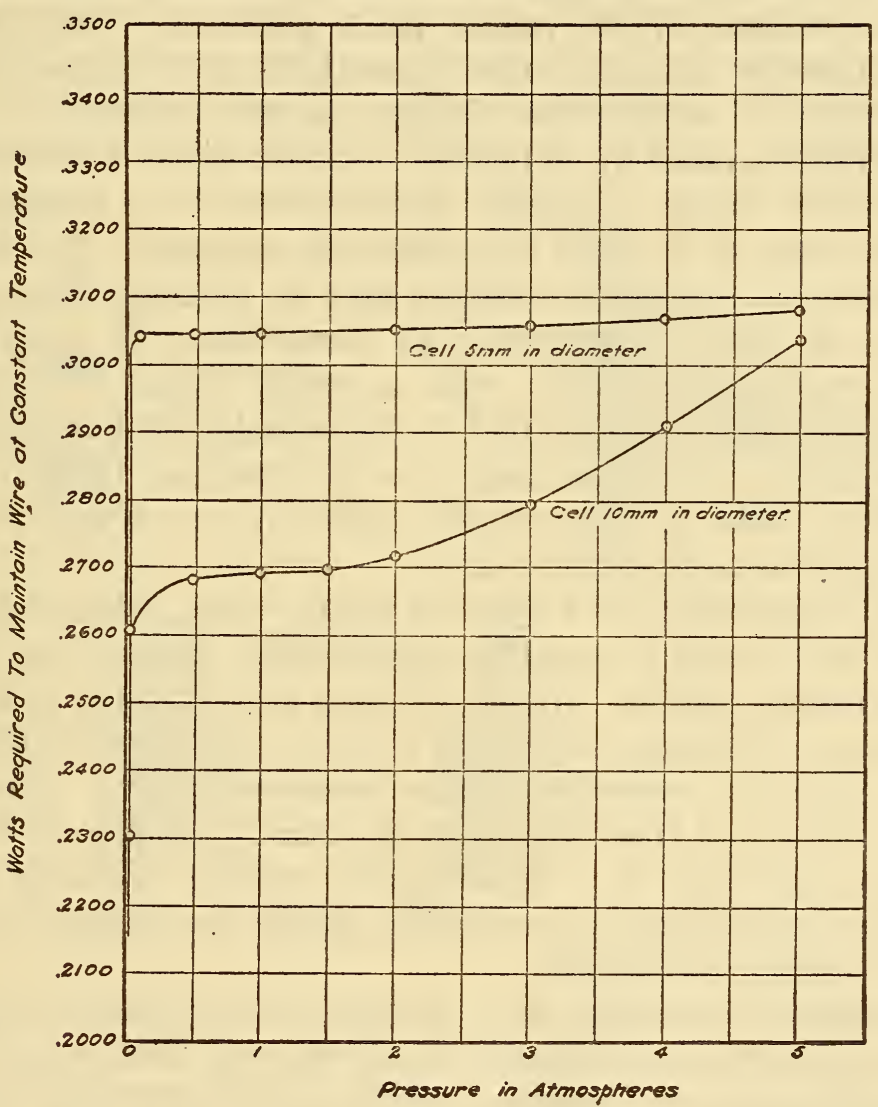

FIG. 38.-Relation between the power expended in maintaining a wire at a constant resistance and the pressure of the surrounding gas.

sufficiently great to materially affect the accuracy of the thermalconductivity method unless they are accompanied by great variations in the rate of flow of gas past the heated wires.

\section{CALIBRATION OF INDICATORS AND RECORDERS.}

Because one can not calculate the significance of the indications obtained by the thermal-conductivity apparatus, some method must be employed for making an empirical calibration 
which will hold under actual service conditions. This usually involves the preparation and careful analysis of gas mixtures having compositions similar to those with which the apparatus is to be used. Such mixtures can be prepared by forcing known quantities of the pure components into a suitable container. When a mercury-sealed gasometer is used to store the mixture, the heights of the drum afford a sufficiently accurate measure of the relative volumes of the various gases admitted. Care must be taken, however, that the holder is gas tight, for even small orifices may result in considerable changes in the percentages of the constituents caused by differences in their rates of effusion. A water-sealed holder is usually unsatisfactory as a container for gas mixtures to be used for calibration purposes. In case the equipment is available, a mixture may be prepared having very closely the desired composition by compressing the gases into a small steel cylinder fitted with a needle valve. The relative volumes of the gases admitted to the cylinder are best measured by means of a pressure gauge. In no case has it been found feasible to make up mixtures with sufficient accuracy as to render subsequent analysis unnecessary.

The construction of a type of needle valve, which has been found very useful in handling gases under pressure up to ${ }_{5} \mathrm{O}$ atmospheres, together with the fittings for attaching it to compressed gas cylinders, is shown in Figure 39. Some of the laboratory uses of a somewhat similar pressure-reducing valve have been pointed out elsewhere by S. W. Parr. ${ }^{16}$ In the use of a gas mixture made up to a considerable pressure, sufficient time ${ }^{17}$ for thoroughly mixing by diffusion should be allowed to elapse before making an analysis.

It happens frequently that the limit of variation of a desired constituent of a gas mixture is such that the indications of the thermal-conductivity apparatus are approximately linear functions of the volume percentages of the constituent. In such instances it is only necessary to locate experimentally two points on the scale and then make a uniform subdivision. If, as is frequently the case, a measuring instrument is employed which already has a uniformly divided scale, it is generally possible to make adjust-

\footnotetext{
${ }_{16}$ Parr, Jour. Ind. and Eng. Chem., 11, p. 768; rgig.

17 The diffusion of one gas into another takes place with considerable rapidity under ordinary conditions. The rate is inversely proportional to the total pressures of the two gases, and approximately proportional to the square root of the absolute temperature. The effect of increased pressure is very noticeable if a mixture of two gases, for example, nitrogen and hydrogen, be made by successive compression of the two gases into a cylinder, particularly if the cylinder be in a vertical position and the lighter gas be introduced. second. If, however, the cylinder be disposed in a horizontal position, diffusion is almost complete on standing I2 to 24 hours.-Greenwood, Industrial Gases, p. 9; I9I9. Van Nostrand.
} 
ments of electrical resistances which will make the existing scale indicate gas compositions directly. In other cases the displacement of the indicator on the scale is not a linear function of gas composition and several gas mixtures are required in order to determine the proper subdivision of the scale.

The calibration of apparatus for the determination of the purity of electrolytic oxygen will suffice to illustrate the methods that may be employed with the various forms of electrical arrangement.

Analysis at frequent definite intervals of oxygen manufactured by the electrolytic method is generally recognized as a necessity for the proper safeguarding of life and property against the

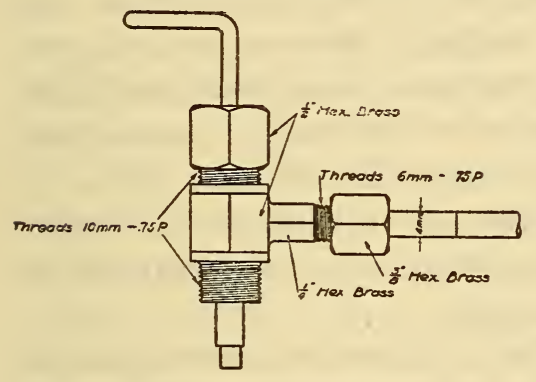

(a)
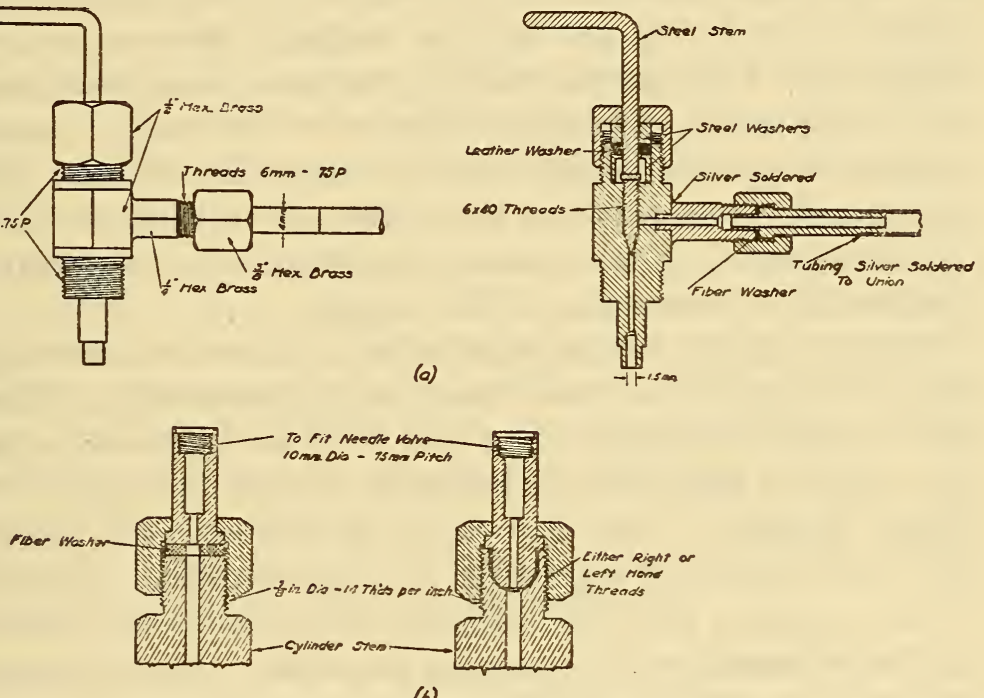

(6)

FIG. 39.-Needle valve and fittings for attaching it to compressed gas cylinders.

hazardous conditions that may arise in the production, collection, and storage of this gas, owing to possible contamination with hydrogen. The standard of purity specified by the Underwriters' Laboratories is: ${ }^{18}$ "For industrial purposes oxygen shall not contain more than I per cent by volume of impurities which form explosive mixtures with it, such as hydrogen." Although frequent chemical tests may be conducted to insure that the gas conforms to the above standard of purity, the desirability is obvious for automatic equipment, which not only provides a continuous record of gas purity, but which also can be arranged to sound an alarm and to shut down the plant by opening the circuit breaker in the electrolyzer circuit whenever the purity falls to a harardous

18 Underwriters' Laboratories, tentative standards. 
point. For these purposes the thermal-conductivity method can be readily adapted.

Since in this application we are dealing with mixtures containing only the two components oxygen and hydrogen, measurements of changes in composition are most simply made by a comparison of the conductivity of the mixture to be analyzed with that of a standard reference gas. Inasmuch as air has very nearly the same thermal conductivity as oxygen, it is convenient to use it as the comparison gas. Compensation for variations in watervapor content is easily secured by keeping the gases in both cells of the unit saturated. The range of the instrument scale need not cover more than o to 2 per cent of hydrogen in oxygen or a purity of 98 to roo per cent of oxygen. As a source of pure oxygen, gas from an electrolytic generator, freed from hydrogen by passage over a glowing platinum wire or through a combustion furnace containing copper oxide or hopcalite may be used. A mixture of 2 or slightly less than 2 per cent of hydrogen in oxygen is also required. This mixture should be carefully analyzed by combustion or absorption of the oxygen.

The unbalanced bridge with deflection instrument arrangement may be connected as was shown diagrammatically in Figure I 9. $R$ is a coil of manganin wire and $R^{\prime}$ is an adjustable resistance. The cell $B$ is filled with air saturated with water vapor at atmospheric pressure. Pure oxygen is allowed to flow through the cell $A$ at a rate not exceeding $20 \mathrm{cc}$ per minute. The rheostat is then adjusted until the voltmeter indicates the emf value which has been chosen for the operating potential. While this potential should not be high enough to result in combustion ${ }^{19}$ of hydrogen at the surface of the platinum wire, it should not be so low as to require the use of an exceptionally sersitive or expensive deflection instrument. The curves of Figure 2 indicate that with 2.50 volts applied to the bridge terminals (with a consequent drop in potential across the wire of each conductivity cell of about I.25 volts) the wires will be heated to a temperature not greater than $150^{\circ} \mathrm{C}$. when surrounded by oxygen. The temperature will be somewhat lower when the gas contains hydrogen. As this temperature is not excessive, 2.50 volts may be tentatively selected as the value for the emf to be supplied to the bridge. The resistance of $R^{\prime}$ should now be varied until on closing the circuit through

\footnotetext{
${ }^{19} \mathrm{By}$ coating the platinum wire with a thin film of gold deposited electrolytically, the possibility of combustion at the surface of the wire is rendered very remote. Disappearance of the protective coating by volatilization or alloying does not occur at the low temperatures employed. The coating can be made so thin that no appreciable change is made in the resistance of the wire.
} 
the detecting instrument there is no deflection of the needle. A manganin coil adjusted to have the same resistance as the value of $R^{\prime}$ just found may be substituted for the variable resistance. An adjustable resistance, $S$, is next connected in series (or parallel) with the indicator and the mixture of oxygen and hydrogen previously prepared and analyzed is passed in a slow stream through the thermal-conductivity cell $A$. When the system has been thoroughly swept out with the gas mixture, the resistance of $S$ is varied until the deflection of the pointer of the instrument indicates a scale reading corresponding to the purity of the oxygen. A manganin coil of the proper resistance may now be substituted for the adjustable resistance in $S$. No further adjustment of the apparatus is necessary, since over the range of gas variation a uniformly divided scale gives sufficient accuracy. Intermediate calibration points can be easily determined, however, if it is thought desirable. The sensitivity required of the indicating or recording instrument depends upon the change in emf between $e$ and $e^{\prime}$ following the maximum variation in gas composition for which analysis is to be made. Table 14 shows that this change in emf varies somewhat with the resistance of the measuring instrument. Consequently an instrument must be selected which will give a full-scale deflection on the unbalanced voltage available at the particular value of the resistance between $e$ and $e^{\prime}$. An increase in the operating potential increases the change in emf across the indicator terminals with alterations of gas composition, and permits the use of a less sensitive indicator.

TABLE 14.-Effect of Resistance of Indicator on Unbalanced Potential. 2.5 VOLTS SUPPLIED TO BRIDGE.

\begin{tabular}{|c|c|c|}
\hline Gas. & $\begin{array}{c}\text { Resistance } \\
\text { of } \\
\text { indicator. }\end{array}$ & $\begin{array}{l}\text { Millivolts } \\
\text { across } \\
\text { indicator } \\
\text { terminals. }\end{array}$ \\
\hline 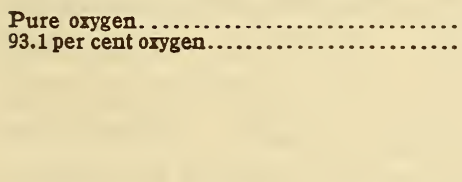 & $\begin{array}{r}\infty \\
\infty \\
500 \\
400 \\
300 \\
200 \\
100 \\
50\end{array}$ & $\begin{array}{l}0.0 \\
7.1 \\
7.0 \\
7.0 \\
7.0 \\
6.9 \\
6.6 \\
6.0\end{array}$ \\
\hline
\end{tabular}

3.0 VOLTS SUPPLIED TO BRIDGE.

\begin{tabular}{|c|c|c|}
\hline 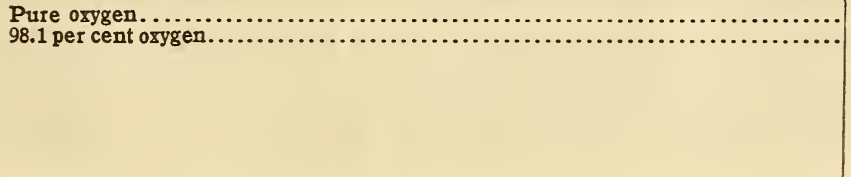 & $\begin{array}{r}\infty \\
\infty \\
500 \\
400 \\
300 \\
200 \\
100 \\
50\end{array}$ & $\begin{array}{r}0.3 \\
11: 1 \\
11.0 \\
10.9 \\
10.8 \\
10.7 \\
10.2 \\
9.5\end{array}$ \\
\hline
\end{tabular}

$57033^{\circ}-24-5$ 
When the unbalanced bridge is used with a potentiometer as the measuring instrument, the connections may be made as was shown schematically in Figure 20. $R$ is a manganin coil and $R^{\prime}$ is an adjustable resistance, the cell $B$ is filled with air saturated with water vapor at atmospheric pressure, and the gas for analysis flows through cell $A$. Just as, in the case of the unbalanced bridge with a deflection instrument, cell $A$ is first filled with pure oxygen, the bridge is supplied with current at the proper operating potential, and $R^{\prime}$ is adjusted so that the potentiometer indicates no difference in potential between $e$ and $e^{\prime}$. A manganin coil accurately adjusted to the same resistance is then substituted for the variable resistance in $R^{\prime}$. Further calibration consists only in noting the potentiometer readings when $A$ is filled with mixtures of oxygen and hydrogen and marking the potentiometer scale in terms of purity of the oxygen.

The use of a balanced bridge arrangement possessing the direct reading feature involves a somewhat different procedure in calibration. The arrangement of the apparatus is that shown in Figure 40. By making the extension coils of the slide-wire of the proper resistances, the position of the sliding contact with respect to a uniformly divided scale indicates directly, and with considerable accuracy, the percentage of the desired constituent of the gas mixture being analyzed when the bridge is adjusted to give no deflection of the galvanometer needle. Consequently the process of calibration consists mainly in determining the proper resistance values for the two extension coils. The calibration of recording apparatus for the determination of the purity of electrolytic oxygen will suffice to illustrate the method employed for finding the value of the end resistances.

$R$ and $R^{\prime}$ are resistance boxes. $R^{\prime}$ should be adjustable to o.I ohm, or better still to o.or ohm. Cell $B$ is filled with air saturated with water vapor at atmospheric pressure, and the gas for analysis flows through cell $A$ as in the other cases. With the contact set at the end of the slide-wire marked Ioo, pure oxygen is allowed to flow through cell $A$ at a rate of $20 \mathrm{cc}$ per minute. When the cell has been thoroughly swept out the battery circuit is closed, the setting of the rheostat is varied until the voltmeter indicates the proper operating potential across the bridge terminals, and with one resistance box, for example, $R$, set at a definite value, the other resistance, $R^{\prime}$, is adjusted until the galvanometer gives no deflection. Care must be taken that the emf across the bridge 
is correct when the final adjustment is made. The settings of the two resistance boxes are noted, and by increasing the resistance in $R$ by regular steps and obtaining the corresponding values of $R^{\prime}$ for a zero reading of the galvanometer, a series of values of correct end resistances is secured for the upper limit of the purity of the oxygen.

A mixture of approximately 2 per cent of hydrogen in oxygen, previously prepared and carefully analyzed, is next allowed to flow through $A$. With the contact of the slide-wire set at the scale division corresponding to the oxygen content of the mixture

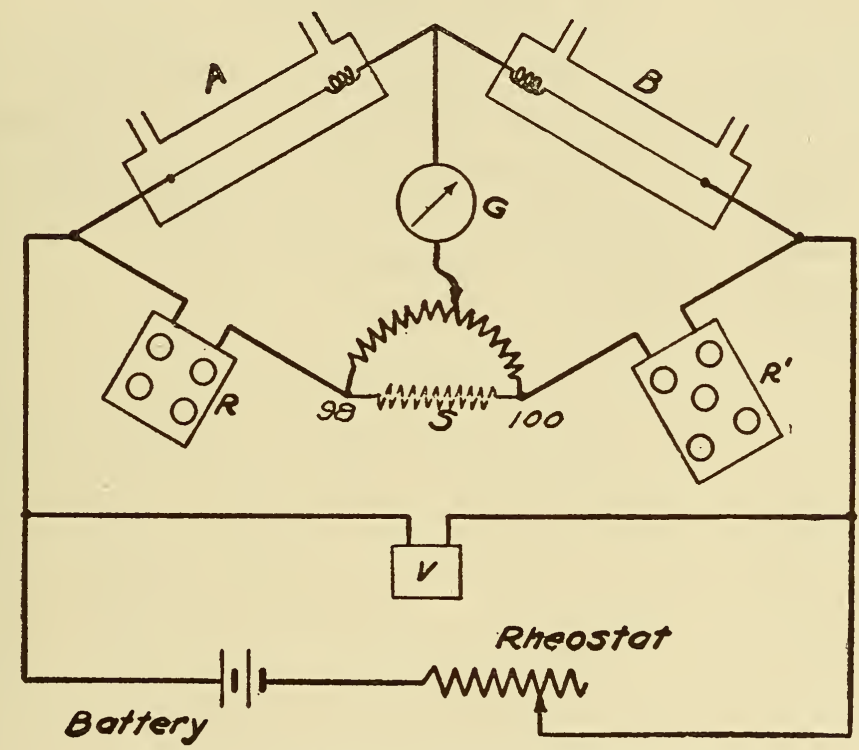

FIG. 40.-Calibration of balanced bridge arrangement.

as found by the analysis, another series of correct end resistance values for the lower limit of the purity of the oxygen is secured.

Choosing the resistances of one box as ordinates and of the other as abscissas, end resistance curves corresponding to the upper and lower limits of variation of oxygen are plotted. The intersection of these curves gives the values of the end resistances to be used for this range of variation in the purity of oxygen when contaminated with hydrogen, and manganin coils of these resistances may be substituted for the resistance boxes.

It is advantageous both for the purpose of securing high sensitivity and for the sake of uniformity of electrical characteristics to have the resistances of the extension coils of the same order of 
magnitude as the resistances of the thermal-conductivity cells. Since, for two slide-wires having the same number of divisions, the same readings correspond to the ratios

$$
\frac{R_{1}^{\prime}}{R_{2}^{\prime}}=\frac{R_{1}}{R_{2}}=\frac{S_{1}}{S_{2}}
$$

in which $R$ and $R^{\prime}$ are the resistances of the extension coils and $S$ the resistance of the slide-wire, it is only necessary to shunt the slide-wire to some suitable value in order to bring the extension coils to any desired magnitude.

\section{MULTIPLE OPERATIONS.}

By the use of a suitable switch the same deflection instrument, potentiometer, or slide-wire, and galvanometer may be employed in connection with any desired number of thermal-conductivity units. Multiple-point recorders are also available for each of the three types of electrical arrangements.

WASHINGTON, October 30, 1923. 
